\title{
VIABILIDADE ECONÔMICA EM SISTEMAS AGROFLORESTAIS NOS ECOSSISTEMAS DE TERRA FIRME E VÁRZEA NO ESTADO DO AMAZONAS: UM ESTUDO DE CASOS
}

\section{mário Jorge Campos dos Santos}

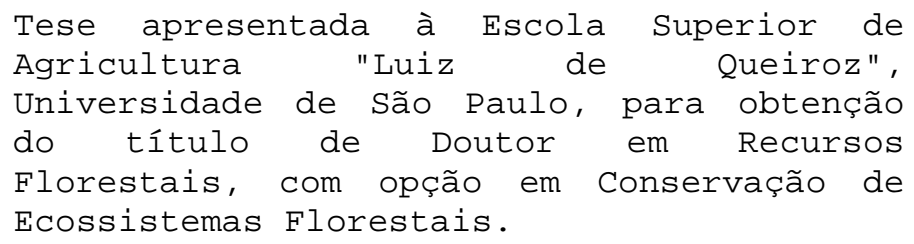

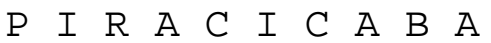

Estado de São Paulo - Brasil

Novembro - 2004 


\title{
VIABILIDADE ECONÔMICA EM SISTEMAS AGROFLORESTAIS NOS ECOSSITEMAS DE TERRA FIRME E VÁRZEA NO ESTADO DO AMAZONAS: UM ESTUDO DE CASOS
}

\author{
Mário Jorge Campos dos Santos \\ Engenheiro Florestal \\ Orientador: Prof. Dr. RICARDO SHIROTA
}

Tese apresentada à Escola Superior de
Agricultura "Luiz de
Universidade de são Paulo, para
obtenção do título de Doutor em
Recursos Florestais, com opção em
Conservação de Ecossistemas Florestais.

\author{
$\begin{array}{lllllllllllllll}P & I & R & A & C & I & C & A & B & A\end{array}$ \\ Estado de São Paulo - Brasil \\ Novembro - 2004
}


Dados Internacionais de Catalogação na Publicação (CIP)
DIVISÃO DE BIBLIOTECA E DOCUMENTAÇÃO - ESALQ/USP

Santos, Mário Jorge Campos dos

Viabilidade econômica em sistemas agroflorestais nos ecossistemas de terra firme e várzea no Estado do Amazonas: um estudo de casos / Mário Jorge Campos dos Santos. - - Piracicaba, 2004

$142 \mathrm{p}$.

Tese (Doutorado) - - Escola Superior de Agricultura Luiz de Queiroz, 2004. Bibliografia.

1. Agricultura familiar 2. Ecossistemas 3. Sistemas agroflorestais 4. Várzeas 5. Viabilidade econômica I. Título

CDD 634.94 
Dedico

$\grave{A}$ Deus,

Por ter sempre me dado perseverança

À minha esposa Beatriz

Ao meu filho Gabriel 


\section{AGRADECIMENTOS}

Ao professor Dr. Ricardo Shirota, pela orientação, dedicação, paciência e por acreditar no meu trabalho.

Ao Departamento de Ciências Florestais, a Escola Superior de Agricultura "Luiz de Queiroz" - Universidade de São Paulo - ESALQ/USP, que possibilitou a minha freqüência no curso de Pós-Graduação.

Ao Prof. Dr. Luiz Carlos Estraviz Rodriguez, pessoa fundamental e incentivador de minha carreira científica desde o tempo de mestrado.

Ao Prof. Dr. Rodolfo Hoffmann, pelo auxílio seguro e eficiente das análises hamônica para conclusão desta pesquisa.

Aos professores e funcionários do Departamento de Ciências Florestais e aos pesquisadores e colegas que compartilharam esta jornada.

Aos pesquisadores Johannes Van Leeuwen, Dr. Charles Roland Clement do Instituto Nacional de Pesquisas da Amazônia (INPA), Núcleo Agroflorestal da Coordenação de Pesquisas em Ciências Agronômicas (CPCA), pelo convite em participar do projeto PPG7 e o pesquisador João Batista Gomes, pelo apoio logistico das visitações e aos agricultores que disponibilizaram seu tempo para receber a equipe de campo gerando informações que deu suporte a esta tese.

À Coordenação de Aperfeiçoamento de Pessoal de Nível Superior (CAPES), pela concessão da bolsa de estudos. 


\section{SUMÁRIO}

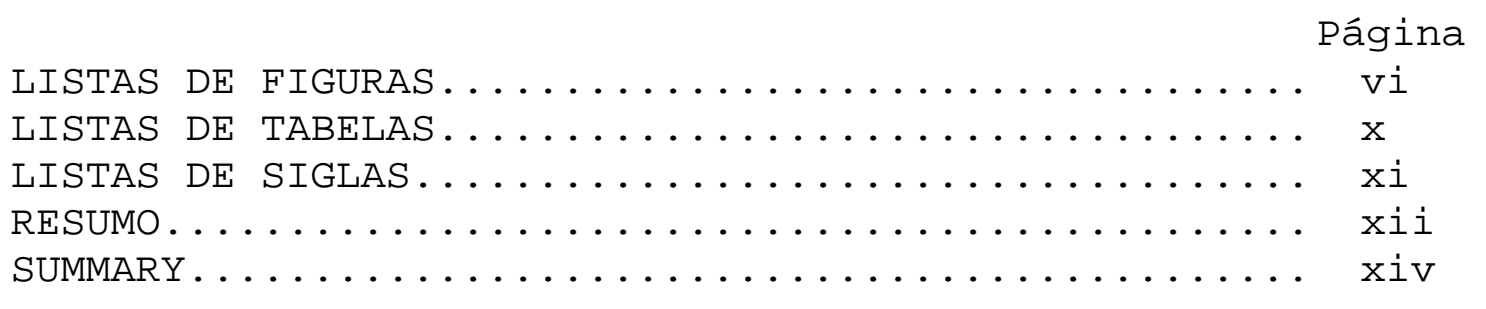

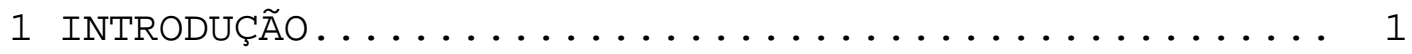

1.1 Antecedentes, Justificativas e Objetivos........ 4

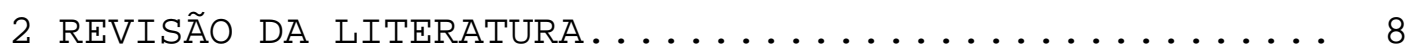

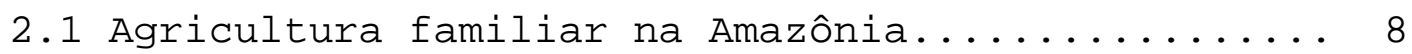

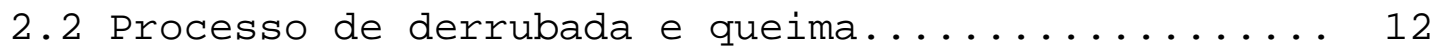

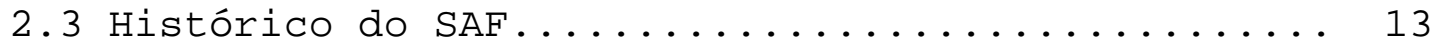

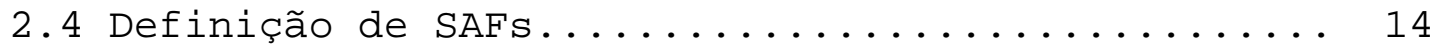

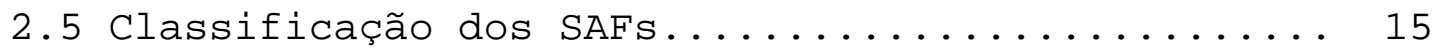

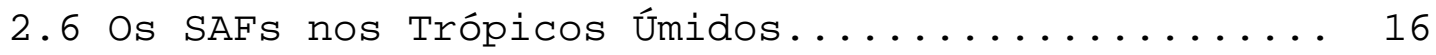

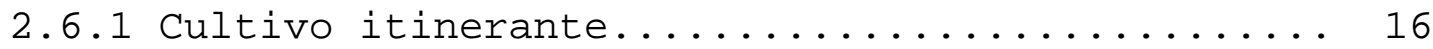

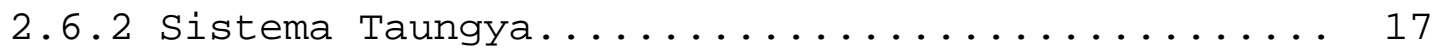

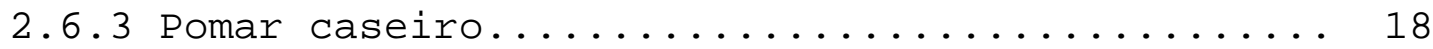

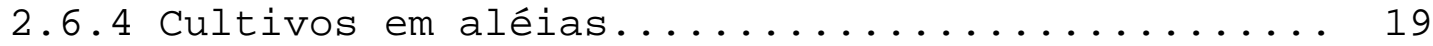

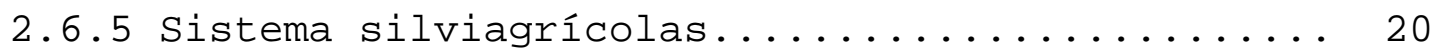

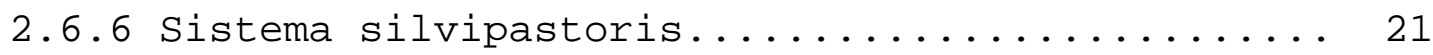

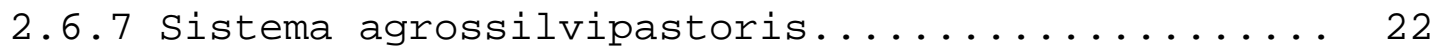

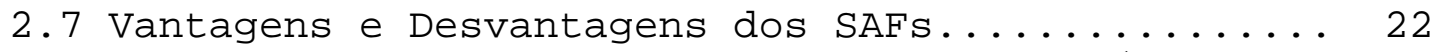

2.8 Estudos econômicos em SAFs nos Trópicos Úmidos... 24

2.9 Importância dos SAFs para Amazônia........... 25

2.10 Ecossistemas e agricultura de terra firme na

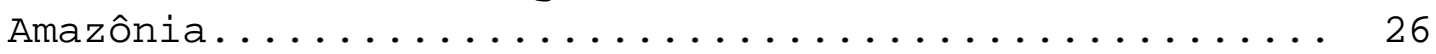

2.11 Ecossistemas e agricultura de várzea......... 27 


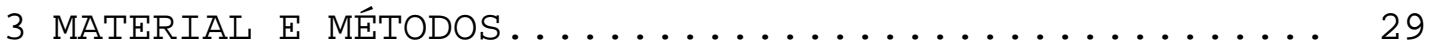

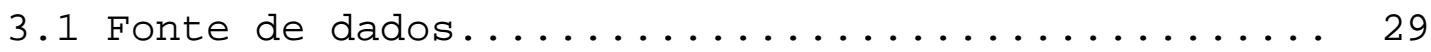

3.2 Caracterização geral da área de estudo......... 32

3.3 Geomorfologia do solos de terra firme........... 35

3.4 Geomorfologia dos solos da várzea............. 37

3.5 Determinação do padrão de variação estacional.... 37

3.6 Cálculo econômicos dos produtos florestais...... 39

4 RESULTADO E DISCUSSÃO..................... 43

4.1 Resultados das pesquisas de campo............. 43

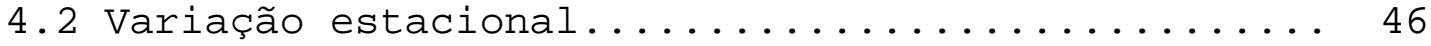

4.3 Análise de tendência...................... 50

4.4 Analises de rentabilidade das culturas perenes... 64

4.5 Analises econômicas dos produtores da várzea..... 66

4.6 Aspectos sócio econômicos dos agricultores

da terra firme.......................... 70

4.7 Aspecto sócio econômico dos agricultores da

várzea............................. 73

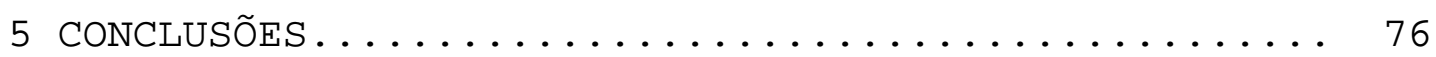

Anexos.................................. 80

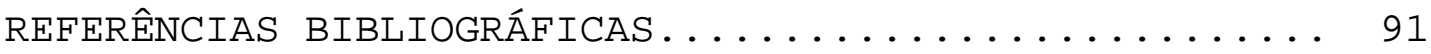

Apêndices............................. 108 
IISTA DE FIGURAS

Página

1 Mapa geral das áreas estudadas............. 34

2 Precipitação e evaporação (mm), médias mensais da Região de Manacapuru, 1990 a 2002..... 35

3 Temperaturas médias máximas e mínimas mensais $\left({ }^{0} \mathrm{C}\right)$ da Região de Manacapuru-AM, 1990 a $2002 \ldots \ldots . \ldots . .36$

4 Evolução da cota média do Rio Negro, medida no porto de Manaus, janeiro de 1980 a dezembro - 2003,

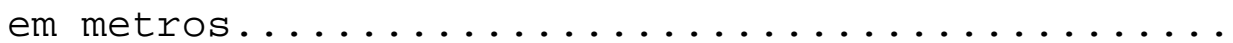

5 Precipitação média da região de estudo, janeiro de 1980 a dezembro de 2003, em milímetros........

6 Variação estacional da flutuação do rio em relação à precipitação obtida pelo método da média geométrica móvel centralizada no período

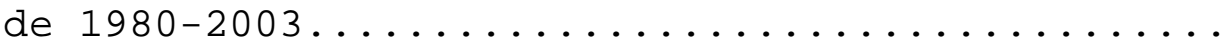

7 Calendário agrícola das populações da área de várzea em relação ao fluxo do rio............

8 Variação do preço da alface recebido pelos produtores nas feiras livres de Manaus de julho de 1998 a junho de 2003, de acordo com o método da média geométrica móvel centralizada..........

9 Índices sazonais e seus limites superiores e inferiores do preço da alface recebido pelos produtores. Obtido pelo método da média geométrica móvel centralizada utilizando preços correntes

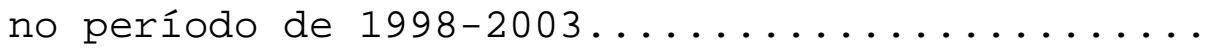

10 Variação do preço da alface em relação à variação da cota do Rio, de acordo com o método da média geométrica móvel centralizada ............... 
11 Variação do preço da batata doce recebido pelos produtores nas feiras livres de Manaus de julho de 1998 a junho de 2003, de acordo com o método da média geométrica

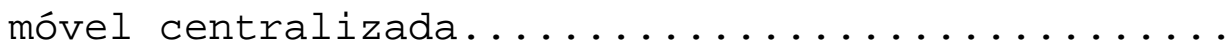

12 Índices sazonais e seu limites superiores e inferior do preço da batata doce recebido pelos produtores. Obtido pelo método da média geométrica móvel centralizada utilizando preços correntes no período de 1998-2003........... 56

13 Variação do preço da batata doce em relação à variação da cota do rio, de acordo com o método da média geométrica móvel centralizada......... 57

14 Variação do preço do maxixe recebido pelos produtores nas feiras livres de Manaus de julho de 1998 a junho de 2003, de acordo com o método da média geométrica móvel centralizada... 58

15 Índices sazonais e seu limite superior e inferior do preço do maxixe recebido pelos produtores. Obtido pelo método da média geométrica móvel centralizada utilizando preços correntes no

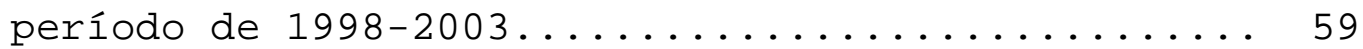

16 Variação do preço do maxixe em relação à variação da cota do rio, de acordo com o método da média geométrica móvel centralizada.......... 60

17 Variação do preço do pepino recebido pelos produtores nas feiras livres de Manaus de julho de 1998 a junho de 2003, de acordo com o método da média geométrica móvel centralizada..........

18 Índices sazonais e seu limite superior e inferior do preço do pepino recebido pelos produtores. Obtido pelo método da média geométrica móvel centralizada utilizando preços correntes no

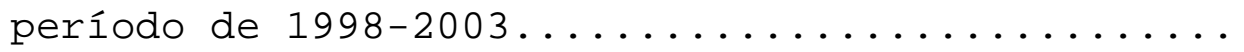


19 Variação do preço do pepino em relação a variação da cota do rio, de acordo com o método da média geométrica móvel centralizada......... 63

20 Composição da fôrça de trabalho nas áreas

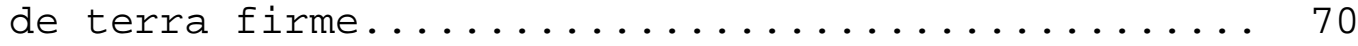

21 Evasão de membros das familias das zonas rurais de terra firme para os centros urbanos.............

22 Composição familiar média das propriedades

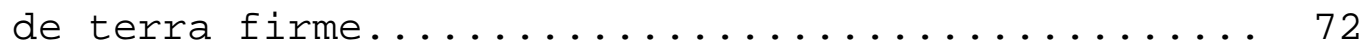

23 Composição da fôrça de trabalho nas áreas

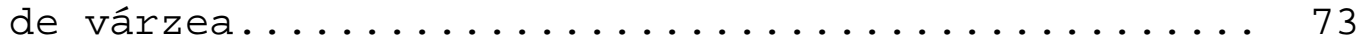

24 Evasão de membros das familias das zonas rurais

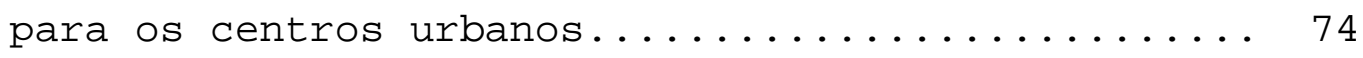

25 Composição familiar média das propriedades

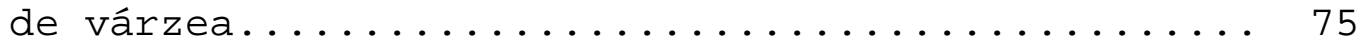




\section{IISTA DE TABELAS}

Página

1 Relação dos agricultores por localização, Ecossistema e percentual de ocupação da área...... 44

2 Produtos cultivados pelos agricultores da amostra e comercializados nas feiras livres.......... 45

3 Comparação econômica geral dos agricultores

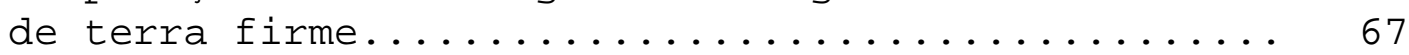

4 Diversidade e riqueza das espécies utilizadas nos arranjos de cultivos mais freqüentes encontrados nas propriedades estudadas................ 68

5 Comparação econômica geral dos agricultores

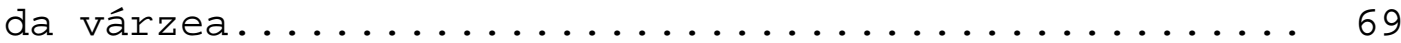




\section{LISTA DE SIGLAS}

\begin{tabular}{|c|c|}
\hline $\mathrm{A} S-\mathrm{PTA}$ & Assessoria e Serviços a Projetos em Agricultura \\
\hline & Alternativa \\
\hline CATIE & Centro Agronómico Tropical de Investigación \\
\hline & Enseñanza \\
\hline $\mathrm{CPCA}$ & Coordenação de Pesquisas em Ciências Agronômicas \\
\hline FAO & Food and Agriculture Organization \\
\hline FNO & Fundo Constitucional do Norte \\
\hline IDAM & Instituto de Desenvolvimento da Amazônia \\
\hline IGRAF & Council for Research \\
\hline & Agroforestry \\
\hline INCRA & Instituto Nacional de Reforma Agrária \\
\hline INPA & Instituto Nacional de Pesquisas da Amazônia \\
\hline INMET & Instituto Nacional de Meteorologia \\
\hline INPE & Instituto Nacional de Pesquisa Espacial \\
\hline $\mathrm{LRR}$ & Levantamento Rápido Rural \\
\hline $\mathrm{NRC}$ & National Research Council \\
\hline OTS & Organization Tropical Studies \\
\hline REBRAF & Rede Brasileira Agroflorestal \\
\hline SEAD & Secretaria Estadual de Administração \\
\hline SEMAF & $\begin{array}{l}\text { Secretaria Municipal de Abastecimento, Mercados e } \\
\text { Feiras }\end{array}$ \\
\hline SEOMA & Seção de Observação Meteorológica Aplicada \\
\hline SEPROR & $\begin{array}{l}\text { Secretaria Municipal de Abastecimento e Produção } \\
\text { Rural }\end{array}$ \\
\hline $\mathrm{F}$ & Unidade de $\mathrm{P}$ \\
\hline
\end{tabular}




\title{
VIABILIDADE ECONÔMICA EM SISTEMAS AGROFLORESTAIS NOS ECOSSITEMAS DE TERRA FIRME E VÁRZEA NO ESTADO DO AMAZONAS: UM ESTUDO DE CASOS
}

\author{
Autor: MÁRIO JORGE CAMPOS DOS SANTOS \\ Orientador: Prof.Dr. RICARDO SHIROTA
}

\section{RESUMO}

O objetivo do presente trabalho foi de analisar a viabilidade econômica de sistemas agroflorestais (SAFs) em dois ecossistemas amazônicos (terra firme e várzea) próximo a Manaus/AM. A amostra utilizada foi constituída por 21 módulos agroflorestais: 13 localizados em áreas de terra firme, no município de Manacapuru/AM; e, 08 localizados na margem direita do rio Solimões, em áreas de várzea. Os dados foram coletados via uso de questionários apropriados, visando a caracterização da amostra e para o estudo econômico proposto. Os preços dos produtos agrícolas cobrem um período de 23 anos (1980-2002) e foram fornecidos pela Secretaria Municipal de Abastecimento Mercados e Feiras (SEMAF) e Secretaria Municipal de Abastecimento e Produção Rural (SEPROR). Os padrões de variação estacional dos preços foram estimados pelo método da média geométrica móvel centralizada. A avaliação econômica das culturas 
perenes e semiperenes foi feita utilizando os seguintes indicadores: Valor Presente Líquido (VPL); Taxa Interna de Retorno (TIR); Relação Benefício Custo (RB/C); e, Valor Esperado da Terra (VET). Os resultados obtidos mostraram que os SAFs estudados apresentaram viabilidade econômica para a pratica nos dois ecossistemas, sendo que as áreas de terra firme são mais estáveis que as áreas de várzea. 


\section{ECONOMIC VIABILITY OF AGROFORESTRY SYSTEMS IN "TERRA FIRME" AND "VARZEA" ECOSYSTEMS IN THE STATE OF AMAZONIA: A CASE STUDY}

Author: MÁRIO JORGE CAMPOS DOS SANTOS Adviser: Prof. Dr. RICARDO SHIROTA

\section{SUMMARY}

The objective of this study was the estimation of the economic viability of Agroforestry Systems (SAFs) in two Amazon ecosystems ("terra firme" and "varzeas") near Manaus/AM. The sample used had 21 observations of farmers adopting SAFs: 13 located in areas of "Terra Firme" in the Manacapuru/AM municipality; and, 8 located on the right margin of "Solimões" River, in "varzea" area. The data was collected using a properly developed questionnaire, to determine the profile of the sample and to do the economic evaluation. Selected agricultural prices, covering a period of 23 years (1980 - 2002) were collected from the Secretaria Municipal de abastecimento Mercados e Feiras (SEMAF) and Secretaria Municipal de Abastecimento e Produção Rural (SEPROR). The patterns of seasonal price variation were estimated using the centralized geometrical moving average method. The economic evaluation of SAFs was 
estimated using the following indicators: Net Present Value; Internal Rate of Return; Benefit-Cost Ratio; and, Expected Land Value. The results obtained indicate that the SAFs in the sample studied were economic viable on both ecosystems, and they are more profitable in "Terra Firme" than in the "Varzeas". 


\section{INTRODUÇÃO}

Os modelos de agricultura extensiva hoje em uso no Brasil, como o monocultivo, exigem a aplicação de grande quantidade de produtos químicos, tais como adubos e defensivos agrícolas. Os usos excessivos desses produtos podem afetar várias espécies de microorganismos benéficos que vivem no solo (Fearnside \& Barbosa, 1998; Hodnett \& Pimentel, 1995).

Na Amazônia, atualmente, além da agricultura convencional, a expansão da pecuária extensiva vêm causando modificações em grandes extensões de florestas nativas (Fernandes et al., 1994). Em razão do manejo inadequado, muitos solos da região tornam-se improdutivos ${ }^{1}$. Os resultados refletem na degradação dos solos, assoreamento de rios, igarapés e destruição de áreas de floresta nativa com uma riqueza de recursos potencialmente úteis para o homem, que podem não ter sido sequer conhecidos e identificados (Fernandes et al., 1994; Serrão et al.,1998).

\footnotetext{
${ }^{1}$ Especialmente em áreas de solos pobres e sujeitos à erosão.
} 
Para esses problemas, os Sistemas Agroflorestais ${ }^{2}$ (SAFs), vêm proporcionando alternativas de restauração desses ambientes antropizados (Fernandes et al., 1994; szott et al., 1991).

Desde a década de 80, os SAFs têm sido apresentados como uma alternativa de uso da terra para a agropecuária nas regiões tropicais. Estes sistemas são formas de cultivos em que se associam, numa mesma área, árvores e arbustos com cultivos agrícolas ou com animais, de maneira simultânea ou escalonada no tempo (Montagnini, 1992; Nair, 1993) .

A presença do componente madeireiro nos SAFs tem o objetivo de gerar uma série de benefícios ao solo e ao meio ambiente, tais como: proteção contra a erosão; deposição de folhas e aumento da matéria orgânica; conservação da água no lençol freático; aumento de organismos benéficos; menor proliferação de pragas e doenças; menor ocorrência de invasoras; conservação da biodiversidade (fauna e flora); microclima favorável ao crescimento de plantas e animais; proteção da área contra as queimadas; e, manutenção das condições climáticas da região. Entretanto, alguns agricultores resistem à adoção do componente madeireiro devido ao seu retorno econômico demorado (Vilas-Boas, 1991; Castro, 1999; Santos, 2000).

Os SAFs são quase sempre manejados sem aplicação de agrotóxicos (ou requerem quantidades mínimas) diminuindo os efeitos negativos da atividade agrícola ao meio ambiente (Vilas-Boas, 1991; Dubois, 1996; Santos, 2000).

\footnotetext{
2 Sistemas Agroflorestais são combinações de culturas (anuais, semiperenes e perenes) com estrutura vertical e horizontal que procuram reproduzir uma floresta nativa (ver item 2.5).
} 
Diversos estudos mostram que a ocupação da Amazônia tem provocado desmatamento e queimadas de maneira descontrolada, ocasionando graves conseqüências ao meio ambiente. Redução da capacidade nutricional do solo e perda da biodiversidade são apenas dois exemplos desses problemas (Sioli, 1991; Fearnside \& Barbosa, 1997; Fearnside, 1989, 1990, 1998; Serrão et al.,1998).

A partir da década de 70, a região mostra uma grande expansão da atividade agropecuária utilizando-se de práticas como "derrubada e queima". Sem tecnologia, estas áreas são utilizadas até o esgotamento da fertilidade natural do solo por um período de 3 a 5 anos, e posteriormente, são abandonadas passando por um período de pousio (capoeira) de 8 a 15 anos (Homma, 1989).

Durante 0 pousio ocorre uma recuperação da fertilidade dos solos, pela atuação de espécies fixadoras de nitrogênio e pela reciclagem e absorção de nutrientes (Morokawa, 1991; Almeida 1992; Homma et al., 1998; Carvalho, 1999).

Até 1997, estima-se que a área de desmatamento na região já atingia 53 milhões de hectares, dos quais, aproximadamente 50 milhões (95\%) foi transformada em pastagem. Das pastagens, metade está em total degradação e atualmente encontra-se abandonada (Skole \& Tucker, 1993, Fearnside \& Barbosa, 1997; INPE, 1998; Gerwing, 2002).

Tradicionalmente, a exploração agrícola predominante na Amazônia e nos países da América Latina, não tem adotado - recurso arbóreo em larga escala. Em parte, isto é devido ao longo período que demora para sua maturação (árvore adulta). Em função disto, as árvores não são incluídas 
dentro das funções produtivas e geradoras de serviços nos sistemas produtivos agropecuários. Esta ótica, promovida, em muitas ocasiões, por políticas inadequadas de colonização, tem dado lugar à vegetação arbustiva (Brown \& Lugo, 1990) .

1.1 Antecedentes, Justificativas e Objetivos.

A agricultura tradicional, conhecida como "agricultura migratória", é ainda, provavelmente, o sistema de uso da terra mais importante na Amazônia. Este sistema é responsável por pelo menos, 80\% da produção de alimento da região e também por quantidade considerável de pessoas que dela dependem direta ou indiretamente (Kitamura, 1994a).

Esta modalidade de agricultura é desenvolvida e praticada em quase toda a região por pelo menos, 600.000 pequenos agricultores, produzindo principalmente, feijão, mandioca, arroz, milho, malva, juta, frutas e algodão (Homma, 1993; Macedo 1992).

Devido à crescente demanada de terras para cultivos, têm-se observado que o período de pousio utilizado pelos agricultures da região tem sido insuficiente para a total reabilitação da fertilidade do solo. Isso tem causado redução da produtividade (das culturas agrícolas e da vegetação secundária), perda de biodiversidade e a degradação do ambiente (Macedo, 1992).

Esses problemas têm incentivado os pesquisadores da região a desenvolver, divulgar e transferir para os produtores, sistemas alternativos de produção agropecuários. Idealmente, busca-se tecnologias de produção adequadas às características ambientais, com a finalidade 
de utilizar os recursos naturais de maneira produtiva e sustentada (Macedo e Zimmer, 1993).

Nesse sentido, a melhoria do desempenho da agricultura itinerante com sistemas florestais e agroflorestais alternativos é uma demanda prioritária para a região tropical (Macedo, 1995).

Ainda que os SAFs sejam preconizados como uma alternativa capaz de promover mudanças ambientais e sociais nas regiões tropicais, na Amazônia, fatores econômicos, sociais, culturais e políticos, não têm criado um cenário favorável para que essa modalidade de uso da terra seja uma atividade economicamente atrativa e incorporada aos interesses dos diferentes segmentos da sociedade (Brienza Junior et al.,1993; Franco, 1991; Macedo, 1993).

A viabilidade econômica e a longevidade produtiva são duas características importantes para sistemas de uso da terra na Amazônia (Franke, et. al., 1998; Santana \& Tourinho, 1998).

Para tanto, algumas medidas devem ser tomadas conduzindo esforços no sentido de conscientização dos benefícios dos SAFs no que se refere ao monitoramento, organização e execução, para que se possa justificar ao agricultor que este tipo de atividade é fundamental para o desenvolvimento sustentável das famílias rurais na região amazônica (Ávila, 1992, Rodrigues et al., 2000, Santos, $2000)$. 
O objetivo principal deste estudo foi analisar a viabilidade econômica dos SAFs implantados em dois ecossistemas amazônicos na região de Manacapuru-AM.

Os objetivos específicos contaram com visitas as áreas das amostras dos dois ecossistemas, aplicação de questionário participativo, levantamento dos preços dos produtos gerados pelos SAFs e comercializados nas feiras locais, e da precipitação e da cota de flutuação do rio da região.

O presente trabalho está organizado em seis partes. A primeira parte, resume o problema, a relevância da pesquisa e os seus objetivos.

Em seguida, o capitulo 2 apresenta a revisão da literatura sobre a dimensão da degradação da Amazônia causada pela atividade pecuária e agrícola na região. No mesmo capitulo, é feita a definição dos diferentes tipos de SAFs. Adicionalmente, as características potenciais para o re-estabelecimento das áreas antropizadas e como sistemas potencialmente viáveis para o sustento de famílias rurais na região.

No capitulo 3, descreve-se o processo de levantamento de dados a nível sócio-econômico, avaliando a composição familiar através da aplicação dos questionários, em seguida, aplicou-se os critérios de avaliação econômica dos SAFs (propriedades). 
O capitulo 4, "Resultados e Discussão", apresenta os resultados da composição sócio-econômico dos agricultores, correlação da cota e precipitação em relação a variação do preço dos produtos agrícolas adotados nas amostras, seguido das análises econômicas de cada amostra.

$\mathrm{Na}$ última seção são apresentadas as conclusões, das amostras que foram viáveis economicamente. São apresentadas sugestões e recomendações para a continuidade e adoção dos SAFs em outras áreas da Amazônia. 


\section{REVISÃO DA LITERATURA}

\subsection{Agricultura familiar na Amazônia}

Muito se fala em agricultura familiar nos tempos de hoje. Do seu crescimento, da sua importância para o Brasil e como esta pode servir de resposta para muitos dos problemas do campo. Problemas estes que vão desde a necessidade de desconcentração de terras/renda, ocupação e geração de empregos. E que não se minimizaram com a entrada de governos supostamente mais democráticos a partir de 1990 (Schineider, 2000).

A agricultura familiar que atualmente simboliza a geração de empregos no meio rural, sempre esteve presente no Brasil, talvez como a principal forma de atividade econômica de muitas famílias (Schineider, 2000).

A realização do trabalho em família se mostrou necessário desde épocas muito remotas, quando o ser humano aprendia a lidar com a lavoura e vivia em sociedades agrícolas cujos meios de produção pertenciam à comunidade, sendo que cada família administrava um espaço dentro das terras utilizadas pelo grupo (Silva, 2003).

Essa prática milenar de trabalho em família acompanhou a história da humanidade em seus diversos aspectos e setores de atividades econômicas. Ganhou força teóricopolítico ao longo das transformações vividas pelas 
sociedades e sofreu grande influência dos sistemas de organização da vida social (Silva, 2003).

O que denominamos hoje como agricultura familiar, já apresentou formas de produção, de relações de trabalho, de geração de renda e de sobrevivência diferenciadas. Nem sempre definimos as propriedades de produção com base no trabalho familiar como agricultura familiar, e, esta raramente foi incentivada pelo governo nacional, que aliás, raramente depositou algum nível de interesse nesse tipo de propriedade agrícola que são caracterizadas por minifúndios (Wanderley, 1994; Silva, 2003).

Famílias organizadas em pequenas propriedades, se politizadas, representavam uma ameaça política para o governo nacional, se não politizada mas com interesse em aumentar a produção era considerado atraso econômico e estímulo à improdutividade, já que a prioridade sempre foram as grandes propriedades agrícolas. Ao pequeno produtor e sua família cabia o papel de assalariar-se no campo - nas grandes lavouras de café, cana-de-açúcar etc ou na cidade - ocupando a função de construtor civil, entre outras funções (Prado Jr., 1977).

A produção familiar possui um aspecto histórico muito intenso e bastante significativo para explicar as problemáticas de hoje. É bem verdade que a transformação da natureza do trabalho, com a implementação de técnicas mais avançadas de produção, a conseqüente especialização da divisão social do trabalho e a própria abertura das economias nacionais com a intensificação do sistema capitalista em várias partes do mundo acarretaram em uma grande diferenciação das formas de trabalho e sobrevivência 
da produção familiar existente ao longo do século XX (Abramovay, 1992).

Contudo, a sua principal característica, que é o trabalho realizado em família no abastecimento de alimentos, sobretudo para o mercado interno, persistiu se adequando aos diferentes interesses do sistema capitalista e (re)criando estratégias de sobrevivência e aumento de renda familiar (Abramovay, 1992).

Nos últimos dois séculos, aproximadamente, várias inovações tecnológicas, produzidas principalmente em sociedades capitalistas, têm modificado profundamente as relações do ser humano com a atividade no campo. A intensificação da atividade industrial e o próprio soerguimento da indústria como principal atividade econômica do sistema capitalista trouxe alguns desdobramentos para a agricultura que resultaram em muitos estudos que inclusive sugeriram 0 fim das formas de produção familiar no campo (Silva, 2003).

A agricultura familiar é caracterizada pela atividade não explicita e monetariamente remunerada de sua força-detrabalho, onde a unidade produtiva é administrada pela família. Nessa forma de organização, o trabalho é distribuído entre os membros da família, com homens, mulheres e crianças participando do processo produtivo. O nível de exploração da unidade familiar depende do tamanho da família, determinando assim a super ou a sub-utilização da força-de-trabalho. O objetivo do trabalho nas unidades de produção familiar (UPF) é atender às necessidades de subsistência da família, sendo o excedente comercializado 
no mercado (Fearnside, 1989; Junior \& Yared, 1991; Maydell, 1991) .

Silva (1990) e Blum (1999) caracterizam a produção familiar como aquela que utiliza a mão-de-obra familiar no processo produtivo; a produção destina-se primeiramente ao consumo da família e secundariamente ao mercado; 0 gerenciamento da unidade de produção é feito pelo chefe da família; e, pela pequena extensão de terras (Vicente, $1995)$.

O conjunto familiar pode ser subdividido em familiares puros (que não contratam nenhum tipo de trabalho externo à família do produtor, sejam permanentes, temporários, parceiros ou de empreitada), familiares complementados por empregados temporários (têm algum tipo temporário) e empresas familiares (têm trabalhadores permanentes, podendo ou não usar temporários) (Carvalho, 1996).

Com isso, vê-se que a produção familiar não enquadrase na forma de exploração puramente capitalista dos recursos, pois não baseia-se no trabalho assalariado e o executor das tarefas é também o dono dos meios de produção, ou seja, não há alienação do trabalho. Além disso, o objetivo da exploração dos recursos na propriedade familiar é a satisfação de suprir as necessidades da família (Carvalho, 1996). 
2.2 Processo de derrubada e queima

Pequenos produtores rurais da Amazônia, dificilmente irão deixar de praticar de derrubada e queima na agricultura se não dispuserem de alternativas técnicas, financeiras e mercadológicas que possam lhes assegurar melhores condições de produção (Sanchez \& Houten, 1994).

O processo de derrubada e queima faz parte da ação de conquista do território, principalmente, a partir da década de 70. Isto se deve ao fato de que, tradicionalmente a posse da terra era garantida com o desmatamento. Apesar de mudanças legais recentes, a garantia da posse da propriedade - independentemente do título - continua a induzir ao desmatamento. Isto porque, apenas a terra trabalhada é aceita como produtiva (Sanchez \& Houten, $1994)$.

A partir dos anos 70, a compra de terras passa a ter um caráter fortemente especulativo: buscando crédito, incentivos e valorização da terra através dos projetos de pecuária. Vários estudos na década de 90 mostraram articulação entre estes processos na ocupação da Amazônia (Almeida, 1992).

Pequenos e grandes investidores, todos buscam coletar da forma mais lucrativa possível o que se apresenta como a riqueza mais imediata da floresta. Em período mais recente a extração da madeira tem se ampliado significativamente, principalmente, aquelas de maior potencial de mercado. Isso decorre não apenas da crise mais geral que atinge a produção agrícola e pecuária, mas também, por causa de mudanças no comércio internacional de madeiras (Macedo, $1995)$. 
Esse mercado tem ressentido a diminuição das florestas tropicais dos países asiáticos com a redução da oferta e na elevação dos preços internacionais de madeiras nobres. Empresas madeireiras asiáticas vêm se deslocando para a Amazônia brasileira, provocando a expansão da fronteira de extração madeireira na região e a formação de dois centros produtores no estado do Pará e um no estado do Amazonas (Vidal et al., 2002).

Infelizmente essa expansão tem ocasionado de maneira aparentemente predatória e parte considerável da extração de madeira na Amazônia brasileira tem sido feita de modo ilegal (Gerwing, 2002).

2.3 Histórico do SAF

Nair (1985) e Bryant (1994), citam que os sistemas agroflorestais - SAFs já eram praticados desde a Idade Média.

$\mathrm{Na}$ Índia por volta de 1806, Nair (1987) e Bryant (1994), comentam que foi estabelecido um plantio florestal de teca (Tectona grandis) juntamente com culturas anuais e foi denominado de método de TAUNGYA (taung = montes ou morro e ya = cultivo). Este método se tornou muito atrativo a partir do programa de reflorestamento com o uso da teça, onde o governo fomentava e permitia que os agricultores plantassem cultivos de subsistência entre as árvores. 0 sistema funcionava em parceria, na qual cabia aos agricultores a responsabilidade de manter a limpeza das linhas de plantio. O acordo com o governo garantia aos agricultores um período de 2-3 anos de cultivo agrícolas nestas áreas de plantio, a produção era direcionada ao 
consumo familiar ou comercializavam seus produtos no mercado local (Nair, 1987; Bryant, 1994).

$\mathrm{Na}$ África do Sul por volta de 1989, foram introduzidos pequenos módulos agroflorestais como forma de diversificação da atividade agrícola tradicional praticada. Esta modalidade de agricultura chegou a Finlândia por volta de 1920 (Bryant, 1994).

\subsection{Definição de SAFs}

Os sistemas agroflorestais ou SAFs são formas de uso e manejo da terra, nas quais árvores ou arbustos são utilizados em associação com cultivos agrícolas ou com animais, numa mesma área, de maneira simultânea ou em seqüência temporal. Aplicam-se práticas de manejo compatíveis com os padrões culturais da população local, dando um melhor aproveitamento do fator mão-de-obra e ajudando na fixação do homem no campo (Huxley, 1983; Young 1991; Nair, 1993; Benavides, 1994; Kitamura, 1994b; Engel, 1999) .

Nos SAFs as espécies florestais, além de fornecer produtos úteis para o agricultor, preenchem também um papel importante na manutenção da fertilidade do solo. Com esses atributos, os SAFs podem beneficiar interações ecológicas e econômicas que acontecem nesses processos (Hect, 1982; Huxley, 1983; Nair,1993; Lopes Cavalcante, 1995, Reeves, $1998)$.

Vale ressaltar que a incorporação de árvores em sistemas de produção de alimentos é uma prática com longa história. Isto é especialmente verdadeiro em regiões tropicais e subtropicais do planeta, nas quais os 
produtores manejam árvores e animais simultaneamente com a atividade agrícola, para atender as suas necessidades básicas de alimento, madeira, lenha, forragem e para ajudar na conservação dos recursos naturais disponíveis na propriedade (solo, água, biodiversidade, entre outros) (Young, 1991).

Os SAFs procuram otimizar os efeitos benéficos das interações que ocorrem entre componentes arbóreos, cultivos agrícolas e criação de animais, para obter a maior diversidade de produtos, diminuindo a necessidade de insumos externos e reduzindo os impactos ambientais negativos da agricultura convencional (Young, 1991; Nair, 1993).

2.5 Classificação dos SAFs

Existem muitas classificações dos SAFs, mas atualmente adota-se a que é utilizada pelo ICRAF (International Council for Research in Agroforestry), pelo Centro Agronômico Tropical de Investigación y Enseñanza (CATIE) (OTS/CATIE, 1986) e pela Rede Brasileira Agroflorestal (REBRAF), que baseia-se nos tipos de componentes incluídos e na associação entre eles. Essa classificação é descritiva e a denominação indica os principais componentes empregados. O sistema apresenta a idéia de sua fisionomia e suas principais funções e objetivos. Todas têm suas vantagens e desvantagens. Será apresentada uma classificação mais simplificada, abrangendo os principais SAFs utilizados na América Latina. 
2. 6 Os SAFs nos Trópicos Úmidos

Os principais SAFs praticados nas áreas tropicais úmidas brasileiras (principalmente nos Estados Amazônicos) são os seguintes:

\subsubsection{Cultivo itinerante}

Conhecido também como agricultura migratória ou agricultura de derrubada e queima. Trata-se de um sistema de uso do solo no qual a cobertura vegetal é derrubada e queimada. O cultivo com espécies alimentícias é feita durante alguns anos e então, a área é abandonada para regeneração (pousio) da vegetação natural em média de 10 a 14 anos (Huxley, 1983; Nair \& Fernandes, 1984).

O sistema varia de acordo com as condições ecológicas locais. Em muitas áreas, a prática da derruba da floresta acontece no período seco, a queima é realizada antes das primeiras chuvas. O plantio de espécies como milho, feijão, mandioca, inhame e banana é realizado aproveitando as cinzas da queimada e o material em decomposição (Nair \& Fernandes, 1984).

Este sistema tradicional de cultivo de solo é talvez - mais importante de todos os SAFs utilizados no mundo tropical. Estimativas da FAO (1982) mostram que aproximadamente 360 milhões de ha (ou cerca de 30\% dos solos aráveis do globo) estão sendo explorados com o cultivo itinerante e envolvendo o sustento de cerca de 250 milhões de pessoas.

Estes autores esclarecem que o sucesso do cultivo itinerante está baseado no ciclo de nutrientes e na 
eliminação das pragas durante o período de pousio. A estratégia em alguns casos tem sido a de enriquecer o pousio com o plantio de algumas leguminosas herbáceas, tais como Pueraria phaseoloides, Centrosema pubescens, Calopogonium muconoides e até com leguminosas arbustivas como o Cajanus cajan (Webster e Wilson, 1980).

No pousio com árvores, o sistema é rotacional com espécies de árvores selecionadas (ou preferidas) em seqüência com espécies alimentícias, como no cultivo tradicional. Neste caso, as árvores selecionadas servem como produto econômico do sistema de pousio e ainda prestam serviço como melhoradoras do solo. Um exemplo deste sistema é o pousio de 5 anos com Inga edulis interplantado com bananas e leguminosas forrageiras, seguido de um período de 2 anos com cultivos alimentícios. Este último sistema é praticado no Equador (Okigbo, 1985; Nair, 1993).

\subsubsection{Sistema taungya}

É um dos sistemas agroflorestais de maior importância, porque envolve grande variedade de combinações de espécies, modalidades e adaptações às condições regionais (Nair, 1993; Beer et al., 1994).

O método consiste em cultivar espécies alimentícias anuais conjuntamente com espécies florestais durante os primeiros anos de estabelecimento. Nestas áreas, o sistema pode ser empregado na formação de florestas plantadas com espécies de alto valor comercial (Nair, 1993; Beer et al., $1994)$.

O sistema de parceria utilizado em Costa Rica no plantio de Cordia alliodora, Eucalyptus deglupta (Budowski, 
1983), a consorciação de Bertholletia excelsa com vários cultivos alimentícios e horti-granjeiros no sul da Bahia e - consórcio de Eucalyptus sp., são apenas alguns exemplos da utilização desta modalidade de SAF em várias localidades do país (Sena-Gomes, 1991).

Muitos plantios de espécies lenhosas perenes, tanto em grande como em pequenas propriedades do sul da Bahia e de vários Estados amazônicos, tiveram início através de um sistema semelhante ao taungya. Mas, a modalidade de exploração das culturas alimentares não foi o da parceria e sim na base de contratação de mão-de-obra pelo proprietário. Desta forma, o sistema não seguiu um dos objetivos do processo que é o de prover melhorias sociais para os parceiros (Broonkird et al., 1984).

\subsubsection{Pomar caseiro}

É um sistema tradicional existente em quase todos os países tropicais. Consistem no conjunto de plantas, incluindo árvores, arbustos, trepadeiras e herbáceas, cultivadas próximas ou nos arredores das moradias nas fazendas ou nas vilas rurais. Dependendo da região, esta modalidade de sistema recebe outras denominações. Na Amazônia, é conhecido como pomar caseiro, quintal, jirau3, terreiro ou horta familiar (OTS-Catie, 1986; Prance, 1989; Van-Leeuwen \& Gomes, 2001).

Em geral, os pomares são estabelecidos pela família e os produtos obtidos são usados pelos seus membros. Os pomares podem ser ornamentais e podem fornecer sombra e

3 Armação feita de varas e troncos para cultivo de hortaliças e dependendo do ecossistema (várzea ou terra firme). Este jirau fica suspenso devido a flutuação do nível das águas (Ferreira, 1975. p 802). 
abrigo para os animais. Outra característica deste sistema é a grande presença de árvores frutíferas e outras espécies de características regionais (Nair, 1987; Van-Leeuwen et al., 1994; Van-Leeuwen \& Gomes, 2001).

Os pomares têm muitas peculiaridades, tais como: cultivo misto de espécies alimentícias diversificadas e de árvores de uso múltiplo, que satisfazem as necessidades básicas familiares. A configuração multi-estratificada e alta diversidade de espécies destes pomares ajudam a reduzir a degradação ambiental comumente associada aos sistemas monoculturais. A alta diversidade de espécies, nestas áreas, representa preservação "in situ" de germoplasma das principais espécies alimentícias. E em certas localidades, de espécies florestais. O número de espécies de plantas encontradas neste tipo de atividade é muito variável (NRC, 1993).

Além disso, os pomares agroflorestais permitem que as populações locais obtenham uma complementação importante de alimentos e fármacos dentre outros recursos para sua subsistência (Fernandes \& Nair 1986; Van Leeuwen \& Gomes, $2001)$.

2.6.4 Cultivos em aléias

Os cultivos em aléias foram desenvolvidos na Nigéria. Este sistema de cultivo é praticado em áreas com problemas de fertilidade ou terrenos declivosos. As culturas anuais como milho, feijão, mandioca, soja e cereais são arranjadas entre fileiras únicas ou multiestratificadas de árvores (leguminosas) fixadoras de nitrogênio e são interplantadas entre faixas largas de 6 a 8 metros (OTS/CATIE, 1986). 
Nesta modalidade estão inclusos os cultivos do cacaueiro, seringueira, dendezeiro, coqueiro, cafeeiro, cajueiro, chá mate e pimenta-do-reino (Elevitch \& Wilkinson, 2002).

Jong (1996) ressalvam que este tipo de sistema oferece algumas vantagens como: as fases de cultivo e de pousio podem ser realizadas de forma simultânea; o período de pousio é bem maior, proporcionando o aumento na intensidade do uso da terra e produção efetiva da fertilidade do solo.

As distribuições no espaço e no tempo dos componentes (plantas e animais) de um sistema agroflorestal são classificadas como silviagrícola, silvipastoris e agrissilvipastoris (Combe \& Budowski, 1979; Mac. Dicken \& Vergara, 1990).

\subsubsection{Sistemas silviagrícolas}

Estes sistemas são caracterizados pela combinação de árvores ou arbustos com espécies agrícolas. Exemplos: consórcios agroflorestais simples do tipo café/freijó e mais complexas, como pupunha consorciada com cupuaçu, castanheira-do-brasil e mogno (Daniel, et al.,1999).

\subsubsection{Sistemas silvipastoris}

Caracterizados pela combinação de árvores ou arbustos com plantas forrageiras herbáces e animais em áreas de pastagem (Nair \& Fernades, 1984; Macedo, 1993).

As comunidades nativas e caboclas da Amazônia nunca tiveram tradição de pecuária ou de sistemas silvipastoris. Elas se alimentavam de proteína animal obtida da caça e pesca e eventualmente, da coleta de determinadas larvas comestíveis. Isto explica porque os conhecimentos sobre 
espécies amazônicas forrageiras arbóreas ou arbustivas são praticamente inexistentes e o pouco que se conhece decorre de observações relativamente recentes, feitas por fazendeiros, peões e colonos (Macedo \& Zimmer, 1993).

A pecuária praticada hoje na Amazônia é, com pouquíssimas exceções, uma pecuária extensiva, requerendo grandes áreas de pasto (Zimmer et.al., 1994; Macedo, 1995).

De maneira geral, os grandes proprietários de terras formam seus pastos utilizando sistemas tradicionais, com o uso do corte e queima das florestas nativas, muitas vezes sem tirar grande proveito dos recursos madeireiros existentes. Nesse sistema, o gado fica sem abrigo durante as horas mais quentes do dia (Meirelles, 1993; Macedo, 1995).

Estas pastagens artificiais abrigam aproximadamente 80\% do rebanho existente na região e são formadas mediante plantio de gramíneas forrageiras, como $\circ$ quicuio da amazônia, o braquiarão e o andropógon (Noda \& Noda, 1994; Sanchez, 1999; Daniel et al., 1999).

Geralmente, esses pastos não são bem manejados e degradam-se rapidamente. A produtividade das pastagens nos cinco primeiros anos é considerada muito boa, no decorrer do tempo observa-se uma queda gradual da produtividade devido à baixa fertilidade natural dos solos, ao manejo deficiente e à invasão da pastagem por ervas e arbustos daninhos, resultando em um pasto sujo de baixíssimo rendimento (Meirelles, 1993; Noda \& Noda, 1994). 
A tendência do agricultor é de abandonar os pastos sujos e abrir novas extensões de floresta para implantar novas pastagens. Dessa forma, a pecuária extensiva mal manejada se torna a causa principal do desmatamento na Amazônia (Macedo, 1993).

2.6.7 Sistemas agrissilvipastoris

Caracterizados pela criação ou manejo de animais em consórcios silvi-agrícolas, tem papel significativo na economia familiar dos agricultores no que se refere a produção de lenha, forragem e sombreamento para o conforto térmico dos animais. Este tipo de sistema pode evoluir economicamente com o passar do tempo em decorrência da inclusão de espécies em função do interesse do agricultor (OTS/CATIE, 1986; Hernadez \& Benavides, 1995; Somarriba, 1995) .

2.7 Vantagens e desvantagens dos SAFs

Os SAFs, em sua grande maioria apresentam vantagens e desvantagens. Os casos de sucessos e insucessos provem da falta de uma tecnologia que garanta ao agricultor uma melhor adoção desta atividade. A seguir serão descritas algumas vantagens e desvantagens nos SAFs (Wilson, 1990; Dicken \& Vergara, 1990; Young, 1991). 
Vantagens:

a) Os custos de implantação e manutenção dos SAFs podem ser mantidos entre limites aceitáveis para o pequeno produtor (Swinkels \& Scherr, 1991);

b) Ajudam a manter ou a melhorar a capacidade produtiva da terra (Vilas-Boas, 1991);

c) Possibilitam melhor distribuição da mão-de-obra ao longo do ano (Dicken \& Vergara, 1990);

d) Podem contribuir para a proteção do meio ambiente;

e) Os vários componentes ou produtos dos SAFs podem ser utilizados como materiais para a produção de outros produtos tanto na forma de substrato, como na forma de sombreamento para espécies menos tolerantes (Swinkels \& Scherr, 1991);

f) Os produtos arbóreos geralmente podem ser obtidos durante todo o ano, gerando maior oportunidade de emprego (Swinkels \& Scherr, 1991) e

g) A alta diversidade de espécies presente nos SAFs pode contribuir na redução dos ataques de pragas e, também, para a utilização mais eficiente de nutrientes do solo (Vilas-Boas, 1991; Smith et al., 1996).

Desvantagens:

a) Os conhecimentos dos agricultores e de técnicos sobre os SAFs são, ainda, muito limitados (Vilas-Boas, $1991)$; 
b) O manejo dos SAFs é mais complicado que o cultivo de espécies anuais ou de ciclo curto (Allegretti, 1990);

c) o custo de implantação e do monitoramento é bem mais elevado em comparação ao monocultivo (Fernandes \& Serrão, 1992);

d) $O$ uso do componente florestal pode diminuir 0 rendimento dos cultivos agrícolas e das pastagens dentro dos sistemas agroflorestais (Price, 1995);

e) O processo do uso de mecanização torna-se mais difícil devido ao espaçamento adensado proveniente da consorciação (Serrão \& Toledo, 1990);

f) Muitos produtos gerados pelo sistema têm mercados limitados (Serrão \& Toledo, 1990);

g) Existe uma limitação de vários produtos gerados pelo sistema que estão correlacionados com as características individuais de cada espécies (Fearnside, 1990) e,

h) Faltam estudos econômicos comprovando a viabilidade de tais sistemas (Santos, 2000).

2.8 Estudos econômicos em SAFs nos Trópicos Úmidos

Os sistemas agroflorestais praticados na Amazônia vêm sendo vistos pelos agricultores como uma fonte de renda de médio a longo prazos, dependendo da qualidade da cultura que está sendo empregada. Os SAFs preenchem, portanto, um papel importante na luta contra a pobreza nos meios rurais (Fearnside, 1989). 
Atualmente, os agricultores estão dando prioridade para culturas que possuem maior procura no mercado local. Essas culturas podem passar por um processo de beneficiamento na propriedade ou ser comercializadas in natura nos mercados e feiras. A vantagem de se trabalhar com produtos beneficiados está associada a maior ganho no momento da comercialização (Vilas-Boas, 1991).

\subsection{Importância dos SAFs para Amazônia}

Os trópicos úmidos, com cerca de 25 milhões de $\mathrm{km}^{2}$, estão na faixa do globo terrestre onde as atividades biológicas são muito intensas e a produtividade primária alcança valores elevados (Alvim, 1977).

Estas características, comuns em áreas dos trópicos apresentam produtividade econômica baixa, ocasionada pela baixa fertilidade natural do solo, alta erosão e perdas de nutrientes, via lixiviação, devido à excessiva precipitação, alta incidência de plantas invasoras, pragas e doenças, bem como a deficiência de infra-estrutura e carência de investimentos (Silva, 2000).

Outro importante motivo de insucessos da agricultura nos trópicos é a utilização de sistemas de cultivos e de tecnologias inadequadas. Na grande maioria das vezes, elas foram adaptadas da agricultura dos países temperados. Sobre o assunto, Alvim et al., (1989) comentam que o fato de o exuberante crescimento e desenvolvimento dos ecossistemas naturais não se traduzir em produtividade semelhante após a conversão ao uso agrícola é explicado pela fragilidade do ecossistema. 
De fato, os solos de grande parte dos trópicos úmidos são de baixa fertilidade e facilmente degradadas pelas altas taxas de erosão e lixiviação a que são submetidos após a remoção de sua cobertura vegetal. Por esses motivos, pode-se entender a importância de se explorar os solos dessas regiões com os sistemas agroflorestais, que são reconhecidamente os que mais se aproximam da floresta natural. Eles são considerados como uma alternativa de uso sustentado do ecossistema tropical úmido, no que se refere aos aspectos ecológicos, agronômicos, econômico e sociais (Nair, 1985; Alvim, 1990; Serão \& Homma, 1991).

2.10 Ecossistemas e agricultura de terra firme na Amazônia

O ecossistema de terra firme cobre cerca de 90\% da Amazônia. Na mesma área pode ser encontrada uma grande variedade de espécies vegetais, sem a predominância de uma sobre a outra. A floresta de terra firme pode apresentar diferentes tipos fisionômicos: Mata de cipós; Campinarana; Floresta seca; e, Campos (Pires, 1973; Prance, 1978).

Na terra firme, pratica-se a agricultura itinerante método tradicional de rotação do cultivo, utilizado por índios e caboclos. As culturas anuais são feitas por pequenos agricultores pioneiros que migraram de outras regiões. Eles exploram também a pecuária bovina, algumas culturas perenes e anuais mecanizadas e horticultura (Serrão et al., 1998). 
O sistema de produção tradicionalmente desenvolvido por pequenos produtores na Amazônia envolve atividades agrícolas, extrativistas, domésticas que produzem combinações significativas para a sua economia de subsistência (Serrão et al., 1998; Cayres, 1999).

A agricultura convencional aplicada neste ecossistema baseia-se em práticas como o cultivo intensivo do solo, monocultura, irrigação, aplicação de fertilizantes inorgânicos e controle químico de pragas, entre outras (Kitamura, 1994a; Flebes, 2002).

Os produtos resultantes dessas atividades, em geral, destinam-se ao consumo familiar e à venda do excedente (Kitamura, 1982; Homma, 1993; Porto \& Siqueira, 1994).

\subsection{Ecossistemas e agricultura de várzea}

Várzea é a denominação ao terreno novo, formado pela deposição de sedimentos organo-minerais carreados pelos rios de águas brancas. São áreas inundáveis que representam de 5 a $10 \%$ da bacia amazônica. Estão geralmente situadas nas áreas ao longo dos grandes rios, em faixas cuja largura varia consideravelmente. Essas áreas inundáveis podem ter até $100 \mathrm{~km}$ de largura (Junk et al., 1989; Sioli, 1991; Ferreira et. al., 1999).

$\mathrm{Na}$ Amazônia, as florestas inundáveis apresentam variação da topografia da periferia para o centro, existem variações na altura das restingas ao longo do rio, o que resulta em diferenças significativas entre as propriedades de uma mesma comunidade com relação à freqüência e a duração da cheia, com importantes implicações para o potencial agrícola (Prance, 1979; Kubitzki, 1989; Sioli, 
1991; Junk, 1997; Winklerprins, 1999; Winklerprins \& McGrath, 2000).

$\mathrm{Na}$ várzea, são desenvolvidas as culturas anuais ou temporárias praticadas pelas populações ribeirinhas, e as culturas de fibras e a criação de bovinos e bubalinos (Kitamura, 1994; Homma, 1998; Winklerprins 1999).

o período de plantio começa quando a cheia termina e as restingas são descobertas. Todavia, o período de seca normalmente divide a época de plantio em dois períodos: o primeiro inicia-se com a exposição das restingas, estendendo-se até outubro, e o outro começa com o início das chuvas e termina quando as águas do rio alcançam as restingas novamente. Tanto a época da cheia quanto a época da seca são muito variáveis, e não é raro o produtor perder a primeira safra para a seca e a segunda para a cheia (Winklerprins, 1999). 


\section{MATERIAL E MÉTODOS}

\subsection{Fonte de Dados}

o presente estudo foi desenvolvido tomando como referência dois ecossistemas amazônicos (terra firme e várzea). As áreas principais de estudos foram dois assentamentos localizados nos ramais Laranjal e Nova Esperança (terra firme) próxima ao município de ManacapuruAM, e agricultores que habitam as margens do Rio solimões nessa mesma região (várzea).

O estudo analisa a viabilidade econômica dos SAFs, procurando atender aos objetivos específicos do presente estudo.

Objetivando aprofundar as análises desenvolvidas a partir dos dados iniciais fornecidos pelo Núcleo agroflorestal CPCA/INPA, foram realizadas visitas técnicas, durante os meses de maio e junho/2002 e setembro e outubro/2003.

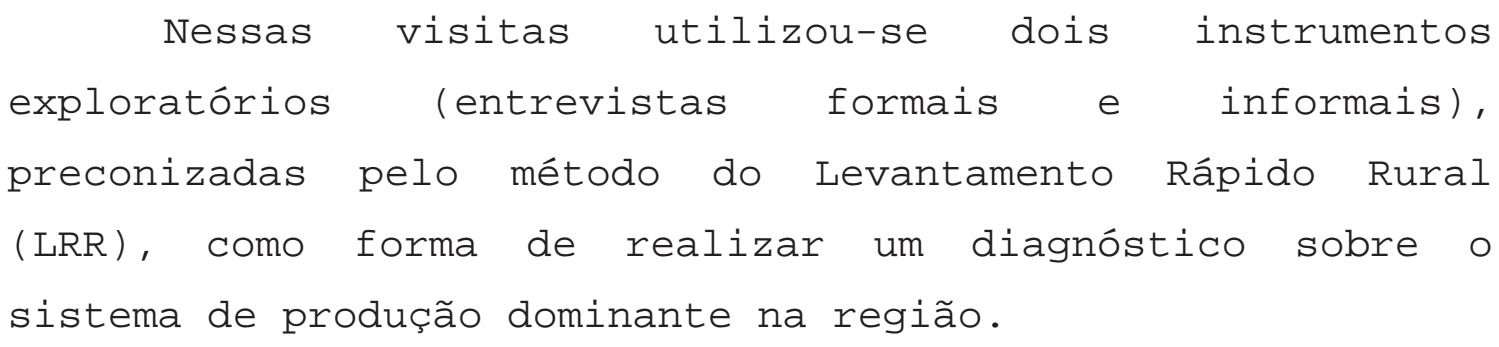


Esta metodologia permitiu avaliar a realidade rural e gerar informações importantes sobre os processos dos SAFs (Santana et al., 1996).

O LRR baseia-se, em um conjunto de técnicas que envolvem abordagens exploratórias, interativas, interdisciplinares e multidisciplinares (Hartmann, 1991 \& Mitlewski, 1994).

As informações (tanto da parte econômica como da parte de produção, variação e periodicidade das culturas), foram coletadas durante a aplicação de questionários (anexos) previamente elaborados para a realidade local de cada ecossistema.

Para os agricultores da várzea, além da aplicação do questionário, foram levantadas informações paralelas sobre a forma e elaboração do planejamento agrícola ao longo do ano, e estudo sócio econômico da composição familiar em relação a produção e mão-de-obra. A coleta dessas informações tem o objetivo de detectar a visão de cada agricultor e qual o momento ótimo do preparo do solo para o cultivo em relação à flutuação do rio e a disponibilidade da fôrça de trabalho.

Os dados climáticos foram fornecidos pelo Instituto Nacional de Meteorologia (INMET), Seção de Observação Meteorológica Aplicada (SEOMA) do $1^{\circ}$. Distrito de Meteorologia (DISME) de Manaus e os dados da cota do nível do rio pela administração do porto de Manaus (PORTOBRAS) em parceria com a Capitania dos Portos, para o período de 1980 a 2003 . 
Os dados referem-se às precipitações mensais de Manaus, durante 23 anos (1980-2003), tomados em milímetros e ajustados para meses de 30 dias. O procedimento é o mesmo adotado por Panofsky (1968), e consiste na multiplicação da precipitação mensal pelo fator de $30 / 31$ nos meses de 31 dias, e por $30 / 29$ no mês de fevereiro dos anos bissextos e $30 / 28$ no mês de fevereiro dos anos não bissextos.

Os dados da cota do Rio Negro, referentes às leituras (cota) diárias, foram fornecidos pela administração do Porto de Manaus que, juntamente com a Marinha do Brasil, são encarregados de gerarem as informações.

Para padronização dos dados utilizou-se a média mensal no período de 23 anos (1980-2003), tomada em milímetros sendo que a variação do rio (pulsos) é lida em centímetros.

A tomada de preço dos produtos praticados pelos agricultores nas feiras livres foram levantados junto à Secretaria Municipal de Abastecimento, Mercados e Feiras (SEMAF) e Secretaria Municipal de Abastecimento e Produção Rural (SEPROR) de Manaus no período de 1983 a 2003. Estas informações foram coletadas semanalmente às quintas e sexta feiras.

Os preços foram deflacionados utilizando-se o índice Geral de Preços (disponibilidade interna) - IGP(DI), da FGV Fundação Getulio Vargas - FGV. A utilização deste índice deve-se ao fato de que ele absorve a alta de preços da economia como um todo e, portanto, pode-se ter uma base para predizer como está se comportando o poder real de compra e venda do agricultor. 
Como o modelo utilizado na análise exige uniformidade nas unidades de tempo, os dados referentes aos preços foram calculados em termos médios mensais.

3.2 Caracterização geral das áreas de estudo

O estudo foi realizado em dois ecossistemas: em áreas de terra firme localizadas entre o Rio Negro e o Rio Solimões; e, nas áreas de várzea localizadas na margem direita do Rio solimões, em frente ao município de Manacapuru-AM (Figura 1).

$\mathrm{Na}$ área de terra firme, existem dois ramais onde foram assentados vários agricultores desde 1986. Os ramais do Laranjal e ramal Nova Esperança estão localizados na rodovia AM-070 entre os Kms 62 e 64 que liga Manaus a Manacapuru.

Na área de várzea, as famílias já estão estabelecidas há mais de 30 anos e estão localizadas ao longo do Rio Solimões.

As atividades agroflorestais tiveram início em 1993 com a iniciativa do Núcleo Agroflorestal da Coordenação de Pesquisas em Ciências Agronômicas (CPCA), e do Instituto Nacional de Pesquisas da Amazônia (INPA) •

O grupo de pesquisa do (CPCA) apresentou aos agricultores os objetivos do projeto e salientou a importância da participação ativa dos agricultores. 
O Núcleo Agroflorestal selecionou os agricultores com base em alguns critérios, tais como: possuir título definitivo ou encaminhado ao Instituto Nacional de Reforma Agrária (INCRA) e ser o titular da propriedade; ter idade mínima de 50 anos; disponibilizar pelo menos 0,5 hectare da propriedade para a instalação do SAF; escolher o arranjo agroflorestal a ser adotado na área e autorizar o livre acesso dos pesquisadores para monitoramento dos módulos agroflorestais.

$\mathrm{Na}$ terra firme foram selecionados 13 produtores, sendo 08 no ramal do Laranjal e 05 no ramal Nova Esperança, na área de várzea foram selecionadas 08 propriedades localizadas ao longo da margem direita do rio solimões totalizando 21 amostras (Figura 1). 


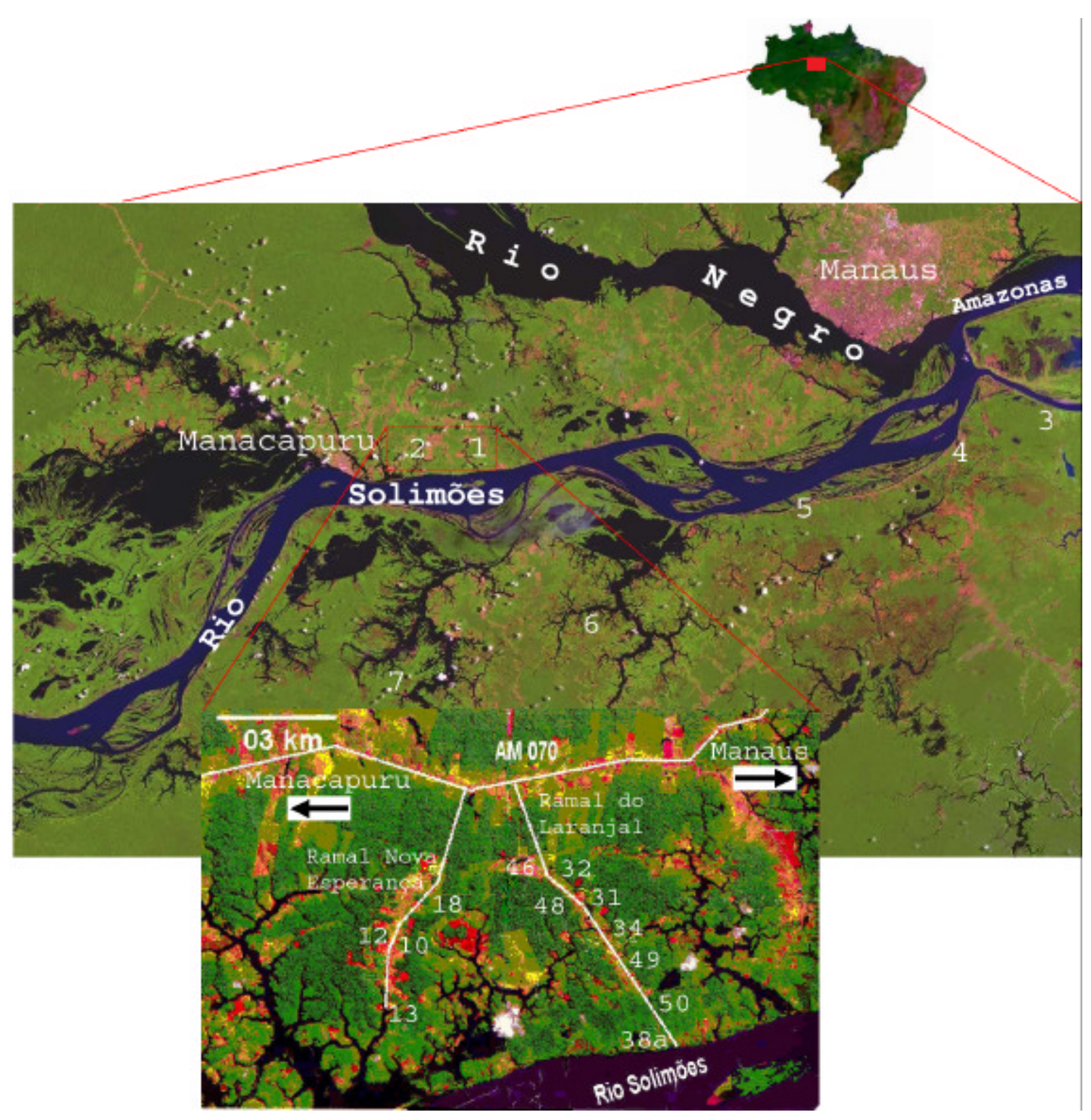

Figura 1- Mapa geral das áreas estudadas. 1 Ramal do Laranjal; 2. Ramal Nova Esperança ${ }^{4} 3$ Paraná do Careiro; 4 Curari; 5 Curari Grande; 6 Paraná do Barroso; 7 Costa do Marrecão.

\footnotetext{
${ }^{4}$ Nas áreas 1 e 2 estão localizadas as propriedades na área de terra firme nos ramais do Laranjal e Nova Esperança. Os números representam as propriedades para controle do INCRA.
} 
3.3 Geomorfologia do solo de terra firme

Segundo a classificação de Köppen, o clima da região de estudo é do tipo Am w, A umidade relativa do ar variando entre 75\% a 90\%, e apresenta uma estação seca de pequena duração nos meses de agosto e setembro (50 mm/mês). A precipitação máxima ocorre geralmente no mês de abril, com média de $320 \mathrm{~mm} / \mathrm{mês}$ (Figura 2). As temperaturas médias máximas mensais variam de $30,6^{\circ} \mathrm{C}$ a $33,8^{\circ} \mathrm{C}$, e as médias mínimas mensais variam de $22,0^{\circ} \mathrm{C}$ a $23,6^{\circ} \mathrm{C}$ (Figura 3), (Fisch et al., 1998; INMET, 2002).

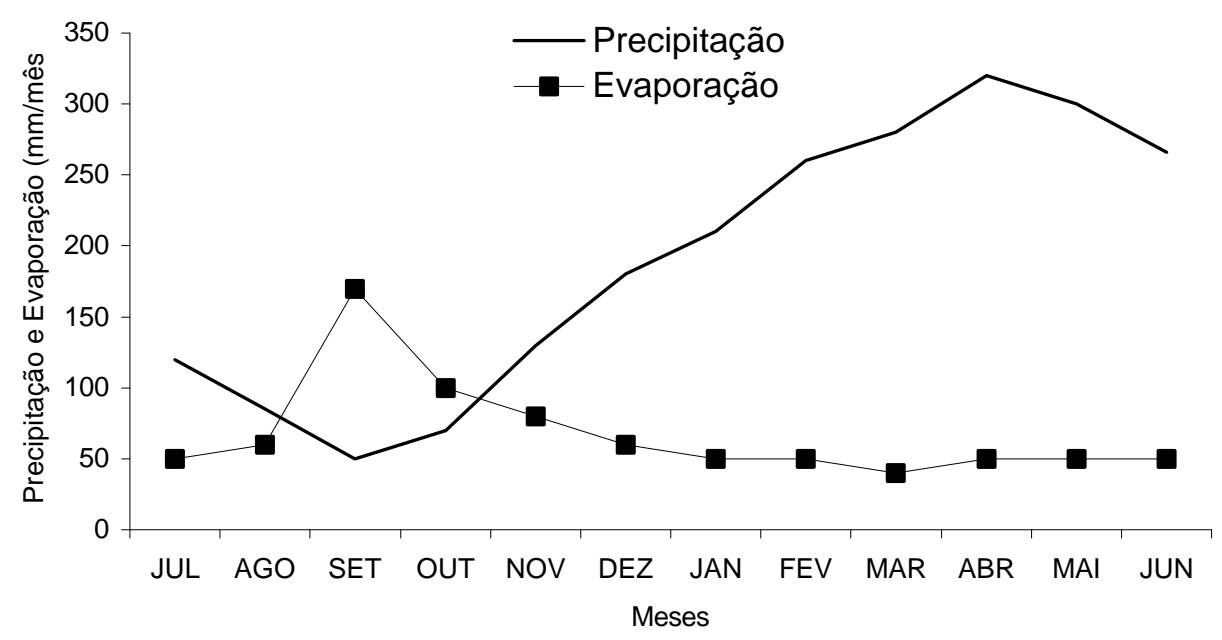

Figura 2- Precipitação e evapotranspiração (mm/mês), médias mensais da Região de Manacapuru-AM, 1990 a 2002. Fonte: INMET (2003) 


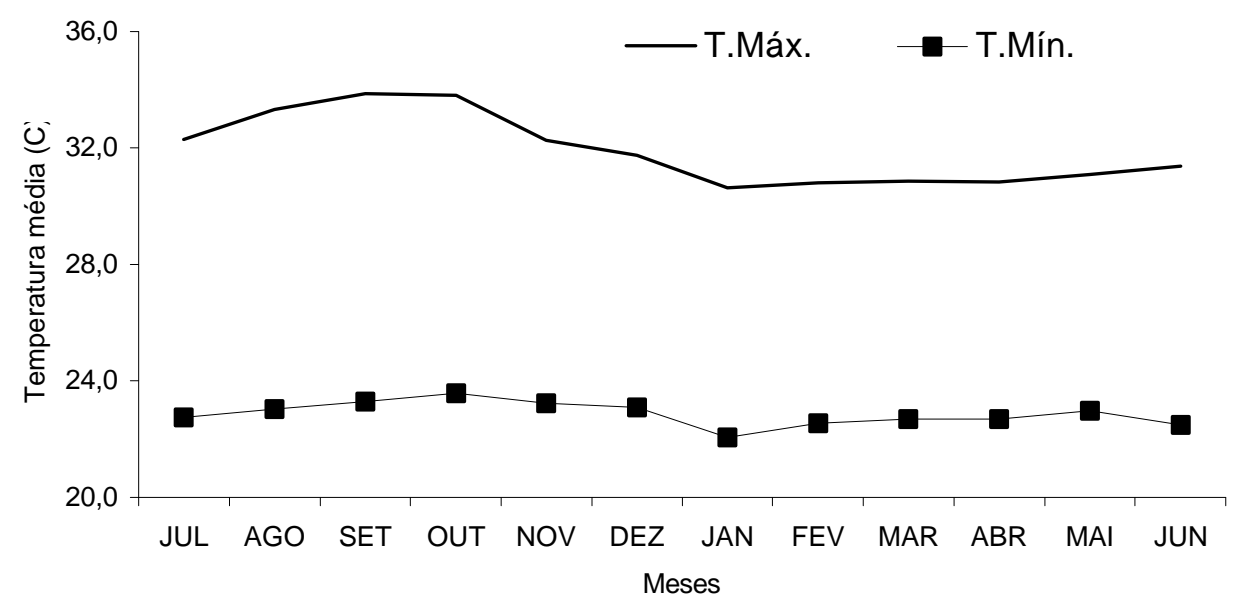

Figura 3- Temperaturas médias mensais máximas e mínimas $\left({ }^{0} \mathrm{C}\right)$ Região de Manacapuru-AM, 1990 a 2002. Fonte: INMET (2003)

Segundo o mapa do solo elaborado por Silva et al. (1970), a região de estudo (terra firme) possui as seguintes características: Latossolo amarelo textura argilosa, fase floresta equatorial úmida, relevo suave ondulado e ondulado; Podzol hidromórfico; e, Latossolo amarelo textura média, fase floresta equatorial úmida, relevo plano e suave ondulado. 
3.4 Geomorfologia dos solos da várzea

Os solos das várzeas são solos aluviais, formados pela sedimentação anual do rio. Essa sedimentação é positiva para a fertilização dos solos, mas, por outro lado, faz com que o processo de formação dos mesmos sofra um retardamento (normalmente o horizonte B não consegue se desenvolver). De acordo com a classificação da EMBRAPA (1999), os solos da várzea são classificados como Neossolos Flúvicos (Ta), glay húmico e pouco húmico

3.5 Determinação do padrão de variação estacional

A análise visa a estimação dos índices estacionais de preços dos produtos produzidos e comercializados nas feiras livres de Manaus, a partir dos dados fornecidos pela SEMAF e SEPROR. Os modelos clássicos de análise de séries temporais pressupõem a decomposição total dos dados em quatro componentes básicos, conforme descrito em santos, $(2000)$ :

a) variações de longo prazo ou tendência;

b) variações cíclicas;

c) variações estacionais; e,

d) variações aleatórias ou erráticas.

Matematicamente, estruturou-se o modelo a partir da hipótese multiplicativa, descrita por santana et al., (1992) e Santos et al. (2000), em estudos sobre preços agrícolas na Amazônia. A série original de preços mensais foi especificada da seguinte forma: 
- preço dos produtos no mês t, em R\$/und.;

- tendência da série temporal no período t;

- variação cíclica da série temporal no período t;

- variação estacional da série temporal no período t;

- variação aleatória ou irregular da série temporal no período t.

Para a estimação dos índices estacionais de preço, fez-se uso do método da média aritmética móvel centrada em 12 meses, descrita em Newbold (1994) e Santana et al., (1996) que permite filtrar as variações sazonais e aleatórias presentes nos dados originais, externalizando os componentes de tendência e cíclicas da série.

- cálculo dos índices estacionais de preço foi efetuado obedecendo aos seguintes passos:

a) deflacionou-se a variável preço, por meio do Índice Geral de Preços (IGP-DI, base dez. $2002=100$ ) da FGV;

b) calculou-se a média aritmética móvel centralizada em 12 meses (MM) dos preços deflacionados, Hoffmann (1991); e, finalmente,

c) os indices estacionais mensais foram obtidos dividindo-se as séries originais mensais de preços dos produtos, pela média móvel correspondente. 


\begin{abstract}
Os índices estacionais obtidos podem apresentar ainda, em sua estrutura, componentes aleatórios. Para eliminá-los, é necessário adotar o processo recomendado por Karmel \& Polasek (1973), que consiste em calcular uma média aritmética dos índices simples para cada mês, e o valor encontrado é o Índice Estacional Médio para o mês i ( IEM $\left._{i}\right)$.
\end{abstract}

Duas propriedades a serem destacadas neste método são:

- somatório dos índices estacionais igual a 1200 e - a média dos índices estacionais igual a 100 .

Para mensurar as flutuações dos índices estacionais em torno da média foi calculado o desvio-padrão para cada mês. A seguir, foram estabelecidos os limites de confiança superior e inferior que são obtidos, somando-se e subtraindo-se, ao índice estacional de preço ajustado, ao valor do desvio padrão.

\title{
3. 6 Cálculos econômicos dos produtos florestais
}

Os componentes florestais (madeireiros e frutíferos)

foram avaliados com base em quatro critérios de avaliação de projetos e comum horizonte temporal de 30 anos.

Segundo Faro (1972) e Santos (1996), os critérios propostos referem-se a uma alternativa de investimento. A análise econômica fundamentou-se na avaliação financeira do investimento, sendo os benefícios e custos quantificados a preços reais, pressupondo-se que, se houvesse inflação, esta incidiria de maneira semelhante nos preços dos produtos e dos insumos. 
Em cada sistema, foram isolados os fluxos de receitas e custos das culturas consorciadas, e depois avaliadas a partir da aplicação simultânea dos critérios adotados.

Os fluxos de caixa, representando as estimativas de entrada (receita) e saídas (custos) dos recursos monetários dos projetos foram estimados para todo o horizonte temporal. Os resultados líquidos desses fluxos foram calculados pela subtração das receitas das despesas. Nesse processo foi usado como referência um único momento no horizonte de tempo, para o qual todos os valores foram atualizados através de fórmulas financeiras de acumulação ou desconto de juros. Para facilitar os cálculos montados para o fluxo de caixa, foi elaborada uma planilha eletrônica, onde todas inferências estatísticas e econômicas estivessem disponíveis para o recebimento dos dados.

Para os cálculos dos indicadores econômicos, usou-se - argumento de Azevedo-Filho (1996). A avaliação de projetos foi feita utilizando os seguintes critérios: a Relação Benefício-Custo (RB/C); O Valor Presente Líquido (VPL); Taxa Interna de Retorno (TIR); e o Valor Esperado da Terra (VET). Os cálculos foram efetuados com taxas de desconto de 5\%, $10 \%$ e $12 \%$

Thuesen (1991) e Buarque (1982), comentam que o Valor Presente Líquido é a atualização do fluxo de caixa anual, descontada por uma determinada taxa de desconto, e indica a rentabilidade do investimento.

A Taxa Interna de Retorno, é a taxa de juros composta que iguala o valor presente das receitas ao valor presente dos custos, ou seja, é a taxa à qual o VPL=0 (Buarque 
1982). Ela é calculada com base nos próprios dados do fluxo de caixa, sem a necessidade de arbitrar-se uma taxa de desconto. Este índice permite calcular o percentual de retorno do investimento e compará-lo ao custo de oportunidade de mercado (Rego, 1996).

A Relação Benefício Custo ( $R B C$ ) é a divisão do valor presente dos benefícios futuros pelo valor presente dos custos futuros, para uma determinada taxa de desconto. Um projeto é considerado economicamente viável se a RBC for igual a 1 , sendo mais rentável quanto maior for esse valor. o contrário deste cenário, ou seja, se a RBC for inferior a 1, rejeita-se o projeto. Quando o valor da RBC for igual a 1, a taxa de desconto utilizada é a própria taxa interna de retorno do projeto (Silva, 2003; Rezende e Oliveira, 1993; Azevedo Filho, 1996; Castro \& Mokate, 1998).

Oliveira (1995), comenta que o Valor Esperado da Terra é um método usado e conhecido no setor florestal como fórmula de Faustman. Este método representa o VLP para uma série infinita de rotações de uma mesma atividade florestal.

Esta expressão normaliza o retorno líquido dos investimentos e possibilita a composição anual do cálculo da receita líquida para o período de corte de cada atividade. Este critério é o mais adequado para se comparar projetos que utilizam o componente arbóreo com diferentes horizontes. 


\begin{abstract}
Os dados utilizados para a avaliação econômica são projetados, o que a caracteriza como "ex-ante". As informações reais referem-se aos dois primeiros anos de implantação. A partir deste período, as projeções foram elaboradas com base nas descrições dos tratos culturais do sistema feitas pela equipe técnica do projeto/INPA, além das informações de fontes secundárias.
\end{abstract}




\title{
4 RESULTADOS E DISCUSSÃO
}

\begin{abstract}
Nesta seção são feitas análises descritivas e discussões dos dados levantados em campo, no que se refere à sazonalidade dos preços dos produtos utilizados pelos agricultores e comercializados no mercado local.

Numa primeira fase buscou-se a sazonalidade e a periodicidade dos fenômenos (precipitação e fluxo do rio) determinantes na relação da variação do preço dos produtos nos ecossistemas e suas implicações positivas e negativas para o ciclo das culturas nos dois ecossistemas.
\end{abstract}

4.1 Descrição das amostras

O estudo contou com 21 amostras, sendo 13 na área de terra firme e 8 na área de várzea (Tabela 1).

A escolha e o número das espécies dos produtos utilizados nas amostras foram correlacionados de acordo com o ecossistema (Tabela 2). 
Tabela 1. Relação dos agricultores por localização, Ecossistema e percentual de ocupação da área

\begin{tabular}{|c|c|c|c|c|c|c|c|}
\hline \multirow[t]{2}{*}{ No. } & \multirow[t]{2}{*}{ Nomes } & \multirow[t]{2}{*}{ Lote } & \multicolumn{2}{|c|}{ Ecossistema } & \multicolumn{2}{|c|}{$\begin{array}{c}\text { Uso da terra } \\
\text { (ha) }\end{array}$} & \multirow[b]{2}{*}{$(\%)$} \\
\hline & & & $\begin{array}{l}\text { Terra } \\
\text { firme }\end{array}$ & Várzea & Total & SAF & \\
\hline 01 & Admilton M. Maciel & 06 & & $\mathrm{CM}$ & 13,0 & 0,50 & 3,8 \\
\hline 02 & Anazildo da Silva & 49 & RL & & 5,25 & 0,12 & 2,0 \\
\hline 03 & Atadeu Pereira & 38 & $\mathrm{RL}$ & & 11,4 & 0,23 & 1,0 \\
\hline 04 & Daniel Moraes & 31 & $\mathrm{RL}$ & & 12,5 & 0,66 & 5,5 \\
\hline 05 & Diomar Brandão & 46 & RL & & 7,5 & 0,32 & 4,3 \\
\hline 06 & Edmilson Sales Angelim & 50 & RL & & 9,4 & 0,56 & 7,5 \\
\hline 07 & Eduardo Vasconcelos & 32 & $\mathrm{RL}$ & & 4,5 & 1,26 & 3,0 \\
\hline 08 & José Alves de Carvalho & 08 & & $\mathrm{CM}$ & 21,0 & 0,50 & 2,3 \\
\hline 09 & José Ramos & 16 & $\mathrm{NE}$ & & 9,0 & 0,30 & 3,6 \\
\hline 10 & José Venâncio do Carmo & 18 & $\mathrm{NE}$ & & 15,0 & 0,30 & 2,0 \\
\hline 11 & Jurandir P. da Silva & 01 & & $\mathrm{PC}$ & 32,0 & 0,50 & 1,5 \\
\hline 12 & Kleber Pinto Rego & 47 & $\mathrm{RL}$ & & 15,0 & 0,50 & 3,6 \\
\hline 13 & Manoel Gomes de Farias & 05 & & $\mathrm{CM}$ & 26,5 & 0,70 & 2,7 \\
\hline 14 & Manoel Gonzaga & 07 & $\mathrm{NE}$ & & 15,0 & 0,30 & 2,0 \\
\hline 15 & Manoel Julião & 06 & $\mathrm{NE}$ & & 10,0 & 0,40 & 4,0 \\
\hline 16 & Nicodemus da Cunha & 02 & & $\mathrm{~PB}$ & 28,0 & 0,80 & 2,8 \\
\hline 17 & Paulo Onete & 05 & & CG & 8,7 & 0,50 & 5,7 \\
\hline 18 & Pedro Brussio & 10 & $\mathrm{NE}$ & & 8,0 & 0,40 & 5,0 \\
\hline 19 & Raimundo Aquino & 34 & RL & & 12,0 & 0,65 & 3,6 \\
\hline 20 & Raimundo Jose de Souza & 03 & & $\mathrm{CU}$ & 12,3 & 0,60 & 5,0 \\
\hline 21 & Rufino Lima Filho & 07 & & $\mathrm{CM}$ & 12,0 & 0,50 & 4,1 \\
\hline Área & total das amostras e u & sada $n$ & OS SAFs & & 282,5 & 10,72 & \\
\hline
\end{tabular}

Legenda: CM (Costa Marrecão); CG (Curari Grande); CU (Curari); PB (Paraná do Barroso); PC (Paraná do Careiro); RL (Ramal Laranjal); NE (Nova Esperança) 
Tabela 2. Produtos cultivados pelos agricultores da amostra e comercializados nas feiras livres

\begin{tabular}{|c|c|c|c|}
\hline \multicolumn{2}{|l|}{ Produtos } & \multicolumn{2}{|c|}{ Ecossistemas } \\
\hline Científico & \multicolumn{2}{|c|}{ Anuais } & Várzea \\
\hline Manihot esculenta & Mandioca & $\mathrm{x}$ & $\mathrm{x}$ \\
\hline Lactuca sativa & Alface & & $x$ \\
\hline Ipomoea batatas & Batata doce & & $\mathrm{x}$ \\
\hline Cucumis sativus & Pepino & & $\mathrm{x}$ \\
\hline Cucumis anguria & Maxixe & & $\mathrm{x}$ \\
\hline \multicolumn{4}{|l|}{ Perenes } \\
\hline Pérsia americana & Abacate & $\mathrm{x}$ & $\mathrm{x}$ \\
\hline Pouteria caimito & Abiu & $\mathrm{x}$ & \\
\hline Mammea americana & Abricó & $\mathrm{x}$ & \\
\hline Euterpe oleraceae & Açaí & $\mathrm{x}$ & $\mathrm{x}$ \\
\hline Carapa guianensis & Andiroba & $\mathrm{x}$ & $\mathrm{x}$ \\
\hline Oenocarpus bacaba & Bacaba & $\mathrm{x}$ & $\mathrm{x}$ \\
\hline Platonia insignis & Bacuri & $\mathrm{x}$ & \\
\hline Rollinia mucosa & Biribá & $\mathrm{x}$ & \\
\hline Mauritia flexuosa & Buriti & $\mathrm{x}$ & \\
\hline Averrhoa carambola & Carambola & $\mathrm{x}$ & \\
\hline Bertholletia excelsa & Castanha & $\mathrm{x}$ & $\mathrm{x}$ \\
\hline Copaifera multijuga & Copaíba & $\mathrm{x}$ & \\
\hline Theobroma grandiflorum & Cupuaçu & $\mathrm{x}$ & $\mathrm{x}$ \\
\hline Annona muricata & Graviola & $\mathrm{x}$ & $\mathrm{x}$ \\
\hline Hymenaea coubari & Jatobá & $\mathrm{x}$ & \\
\hline Genipa americana & Jenipapo & $\mathrm{x}$ & \\
\hline Talisia esculenta & Pitomba & $\mathrm{x}$ & \\
\hline Bactris gasipaes & Pupunha & $\mathrm{x}$ & \\
\hline Alibertia edulis & Puruí & $\mathrm{x}$ & \\
\hline Manilkara sapota & Sapotilha & $\mathrm{x}$ & \\
\hline Couma utilis & Sorvinha & $\mathrm{x}$ & \\
\hline Bixia orellana. & Urucum & $\mathrm{x}$ & \\
\hline Endopleura uchi & Uxi & $\mathrm{x}$ & \\
\hline
\end{tabular}

Fonte: elaborado pelo autor com base nos dados coletados na pesquisa. 
4.2 Variação estacional da precipitação e do nível do rio

A metodologia descrita na seção 3 foi empregada para analisar o padrão estacional das precipitações mensais e a cota do rio ${ }^{5}$. Estas informações são determinantes para as atividades produtivas e para a vida dos moradores das regiões da várzea. O aumento do nível dos rios afeta o calendário agrícola e influência o ciclo de vida das populações da várzea e as suas estratégias de sobrevivência.

Inicialmente detectou-se a influência do ciclo do rio nas populações da várzea, e a estratégia de sobrevivência destes.

A regressão linear dos dados de nível do rio entre 1980 e 2002 indica uma tendência de aumento neste período. Entretanto, é importante observar que, em certos anos ocorrem flutuações extremas tanto positivas (1993) como negativas (1980, 1992 e 1998) (Figura 4).

Os dados de precipitação (Figura 5), apresentam também uma tendência positiva, sendo que em dois períodos consecutivos, 1988 e 1989, foram mais extremos.

${ }^{5}$ Os dados originais de precipitação e cota do rio encontra-se no apêndice 1 . 


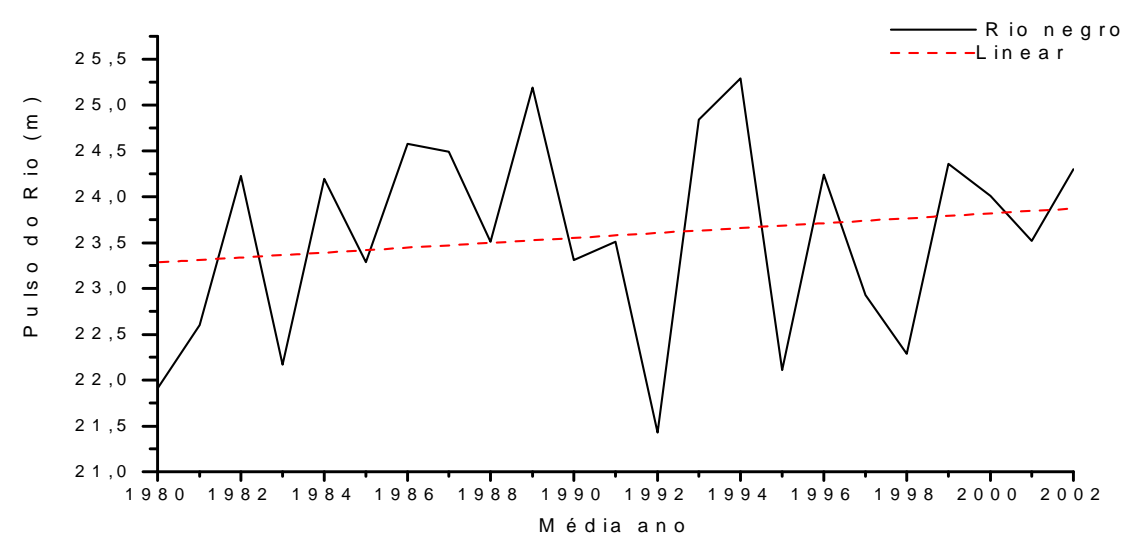

Figura 4 - Evolução da cota média do Rio Negro, medida no porto de Manaus, janeiro de 1980 a dezembro de 2003 em metros

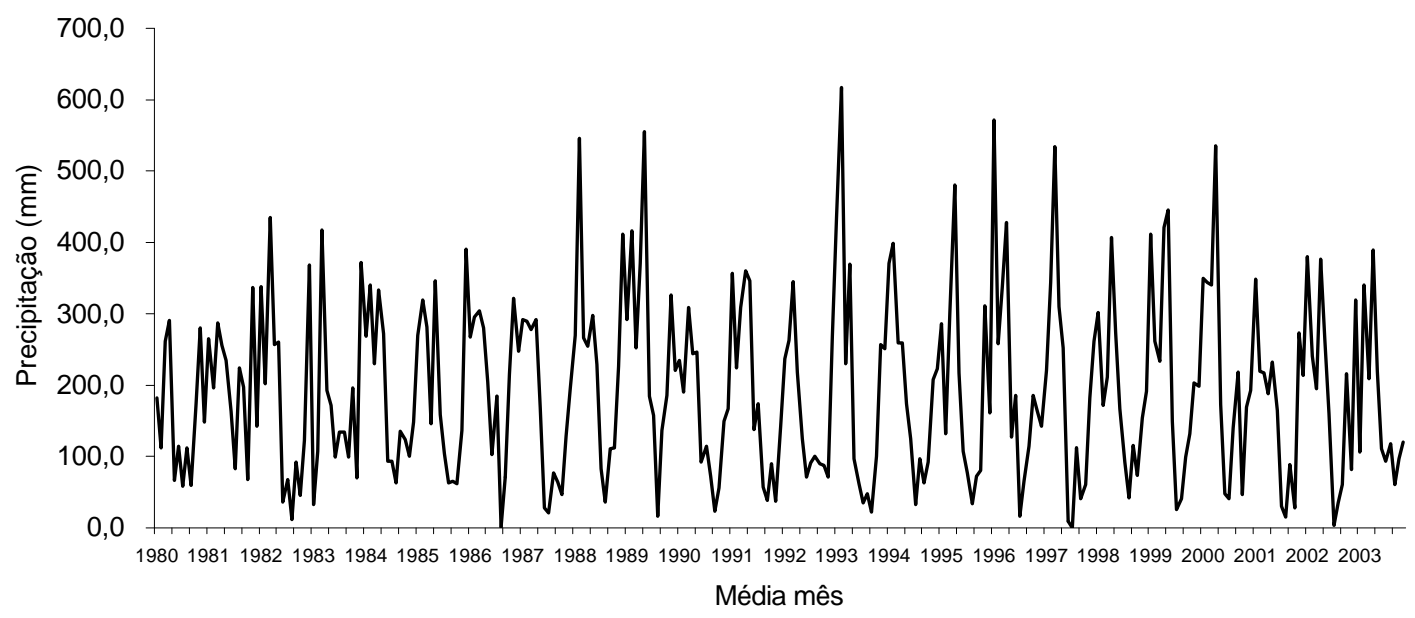

Figura 5 - Precipitação média da região de estudo, janeiro de 1980 a dezembro de 2003 em milímetros 
O seu padrão estacional, estimado pelo método da Média Geométrica Móvel Centralizada - MGMC (Figura 6), indica uma correlação entre a cota do rio e a precipitação. o interesse no estudo dessas variações foi comparar se ocorre algum reflexo em comparação aos preços dos produtos agrícolas praticados pelos agricultores.

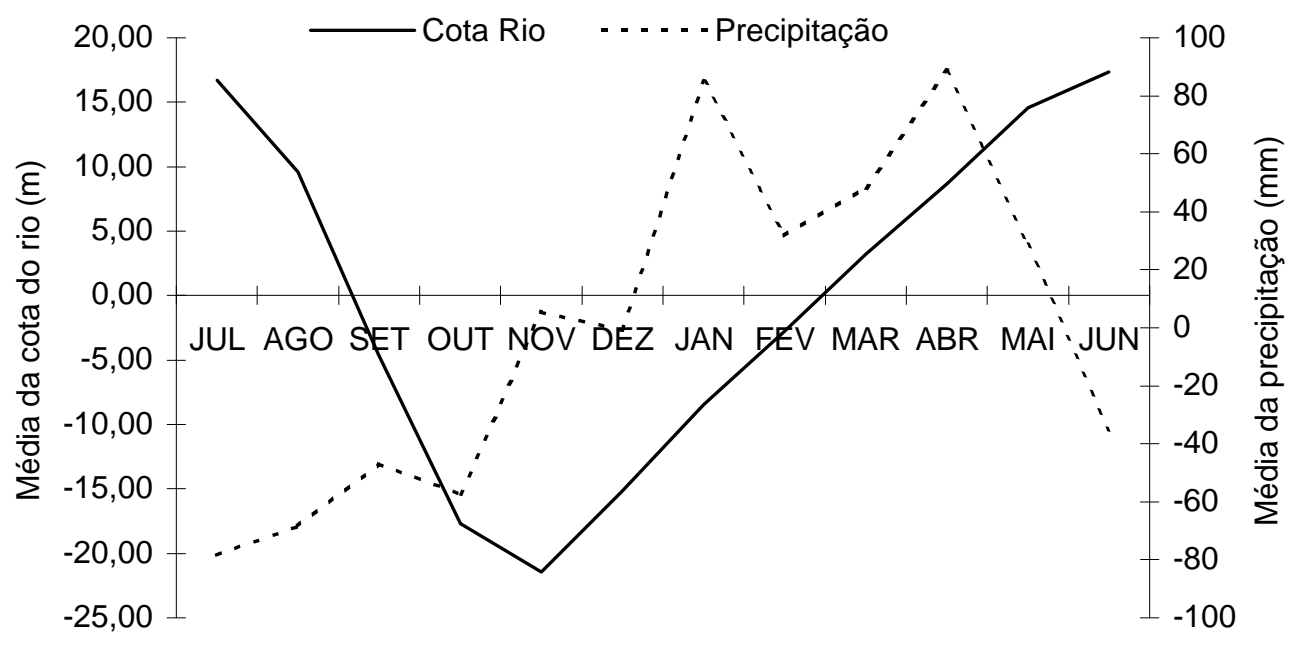

Meses

Figura 6 - Variação estacional da flutuação do rio e da precipitação obtida pelo método da média geométrica móvel centralizada no período de $1980-2003$

Fonte: Elaborado pelo autor com base em dados da Administração do Porto de Manaus 
Quando da aplicação do questionário, levantou-se dados informais no que se refere ao planejamento agrícola de cada amostra da várzea para o período de preparo da terra, plantio e colheita das culturas temporárias.

A razão do levantamento foi de detectar quais as estratégias usadas pelos agricultores na tomada de decisão para a escolha e aplicação da cultura. Segundo os resultados das amostras, um dos fatores mais importante no momento decisivo do plantio é a questão topografia da área, este item está associado com o nível da cota do rio, dependendo da situação da área o agricultor pode antecipar ou retardar a atividade de preparo da terra. Uma decisão correta significa a garantia da sua produção, e a venda dos produtos excedentes vai para o mercado local.

Observou-se que 25\% dos agricultores optam por preparar a terra no mês de setembro, garantindo uma produção sem risco de inundação (Figura 7).

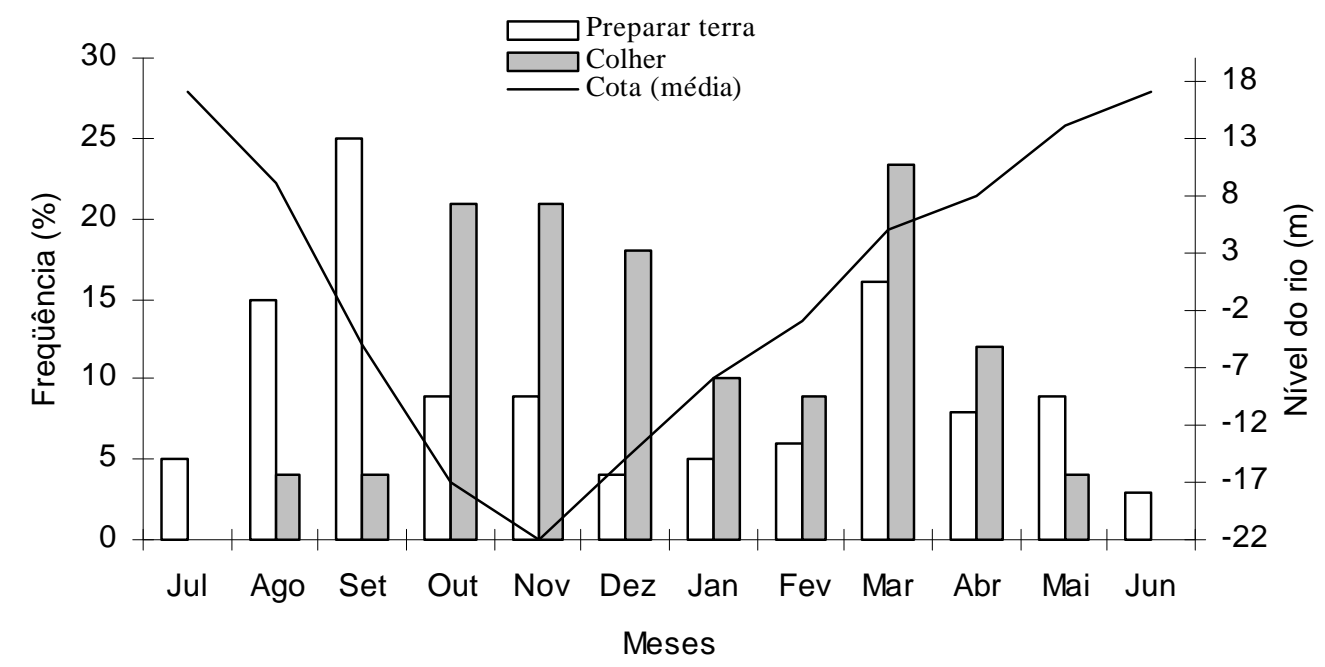

Figura 7 - Calendário agrícola das populações da área de várzea em relação ao fluxo do rio 
4.3 Análise da tendência

As culturas utilizadas foram escolhidas pelos próprios agricultores, de acordo com aptidão da área. Para a organização das análises, as culturas foram agrupadas de acordo com seus ciclos produtivos - temporárias (anuais ou hortaliças), semi-perenes e perenes.

Para o ecossistema de terra firme dependendo das condições econômicas, sociais e tecnológicas, o agricultor adotava das culturas temporárias, as hortaliças.

No que se refere aos aspectos econômicos, entende-se que o agricultor deve possuir uma rentabilidade mínima para adquirir e manter um espaço físico para manuseio e aplicação dos tratos culturais dos produtos.

Todavia, a composição familiar é um fator primordial para a condução e manutenção das culturas, a carência de mão-de-obra foi bem observada nas amostras estudadas.

No ecossistema de várzea, as culturas mais empregadas são as temporárias, principalmente as hortaliças, devido ao ambiente possuir uma sazonalidade de produção de aproximadamente seis meses. Os aspectos econômicos, sociais e tecnológicos também influenciam no momento da adoção de determinadas culturas. 
Na figura 8 observa-se que a média do preço da alface não segue um padrão de oscilação ao longo do tempo, quando aplicado o método da MGMC. Nota-se que ocorre uma oscilação mais homogenia e com essa regularidade é possível perceber que nos anos de 2000 e 2001 os preços do produto apresentaram queda. Segundo dados da SEPROR e SEMAF, essa queda esta associada ao aumento da produção.

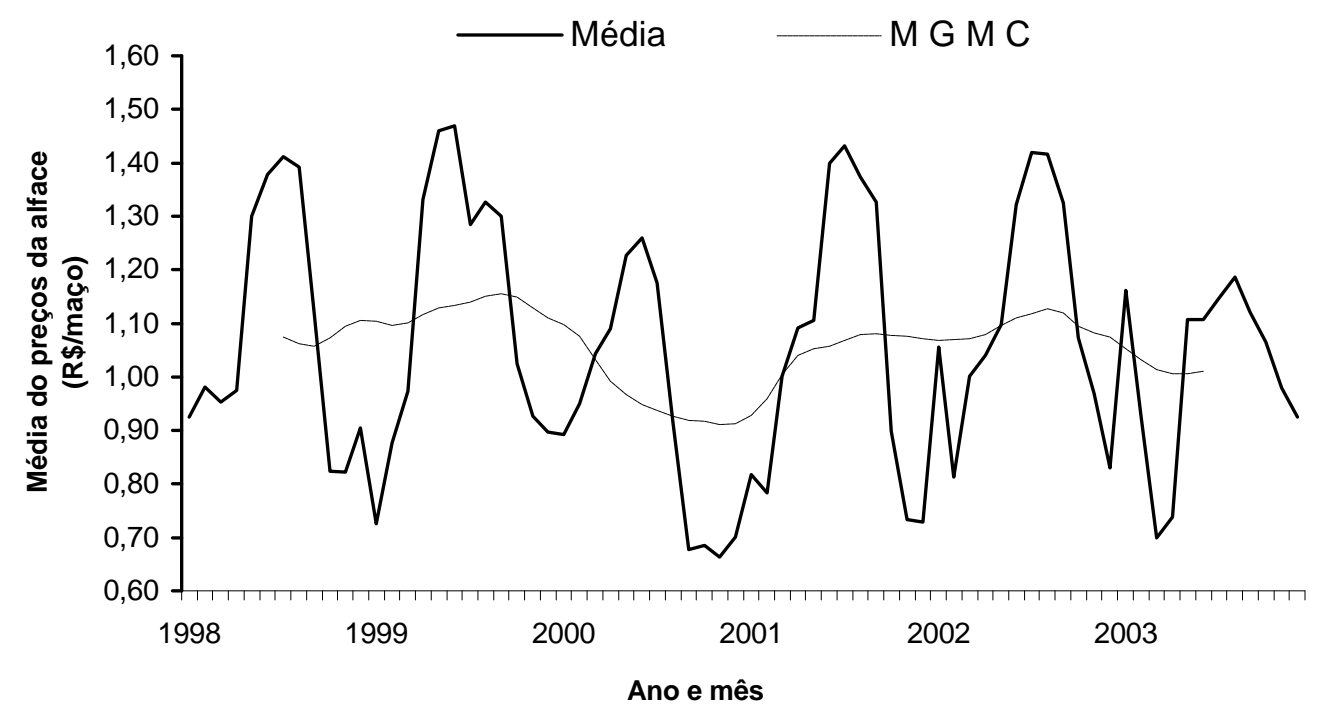

Figura 8 - Variação do preço da alface recebido pelos produtores nas feiras livres de Manaus, julho de 1998 a junho de 2003, de acordo com o método da média geométrica móvel centralizada 
A figura 9 apresenta 0 índice sazonal e o limite inferior e superior do preço da alface, verifica-se que o preço do produto cai à medida que a cota do rio baixa. De uma forma geral a variação sazonal determina as cotações altas e baixas dos preços do produto.

Nos mercados onde foram levantados os dados, os preços da alface atingiram seu mínimo nos meses de novembro e dezembro como revela a figura 8. Isso se deve ao fato do nível do rio estar em cota mais baixa que a normal. o oposto deste cenário ocorre nos meses de junho e julho com sua cota máxima.

Os menores índices sazonais ocorreram no período de novembro e dezembro, com $\mathrm{R} \$ 0,78$ no limite inferior; $\mathrm{R} \$$ 0,78 e 0,77 nos índices sazonais e limites superiores com R\$ 0,84 e 0,82 respectivamente.

Os maiores índices sazonais ocorrem no mês de junho com R\$ 1,25; com limite inferior de $\mathrm{R} \$ 1,14$ e limite superior $R \$ 1,38$. No mês de julho o preço da alface apresenta um ligeiro aumento no índice sazonal $R \$ 1,27$; $R$ \$ 1,17 no seu limite inferior e R\$ 1,37 no limite superior. 


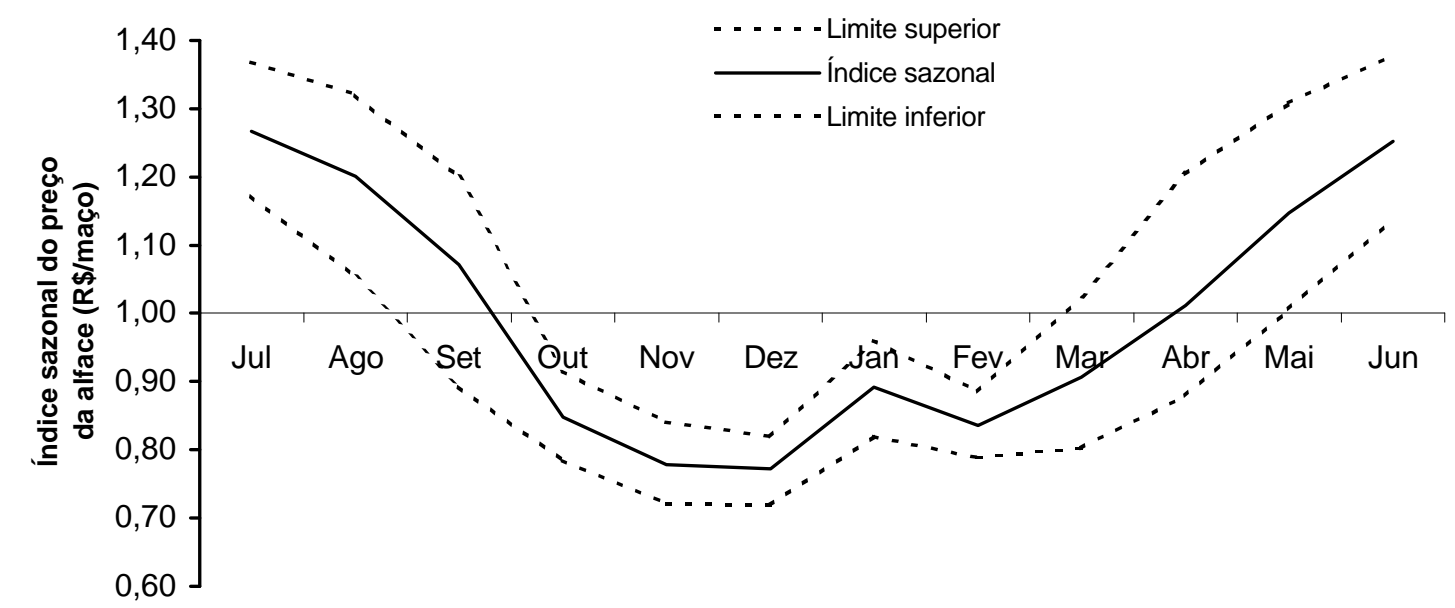

\section{Meses}

Figura 9- Índices sazonais e seus limites superiores e inferiores do preço da alface recebido pelos produtores. Obtido pelo método da média geométrica móvel centralizada utilizando preços correntes no período de 1998-2003

Uma tendência normal na queda do preço da alface em relação à flutuação da cota do rio é observada na figura 10, visto que os meses de setembro a abril são os meses onde as áreas agricultáveis estão livres das inundações, conseqüentemente ocorre um excedente de produção na região.

Nota-se que a variação do preço da alface sofre reflexo em relação às flutuações do rio e o mercado consumidor com período de até 30 dias. Vale ressaltar que, - período da vazante do rio é bem mais rápido que no período de cheia, este intervalo contribui para que 0 agricultor tenha perdas da sua produção. 


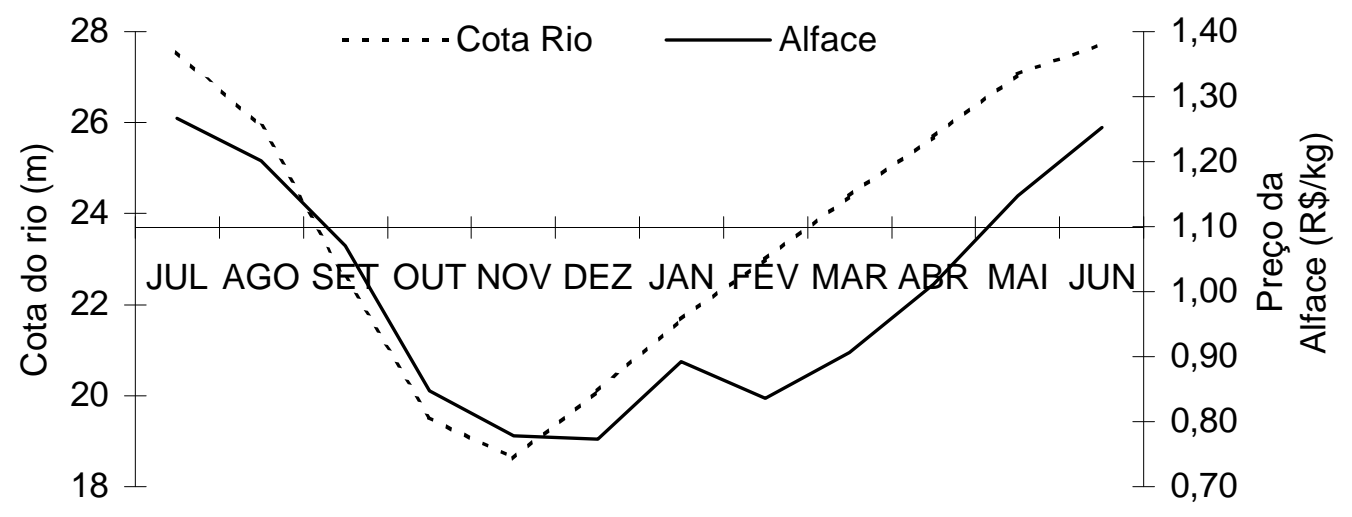

Meses

Figura 10- Variação do preço da alface em relação à variação da cota do Rio, de acordo com o método da média geométrica móvel centralizada

Pelos cálculos da média geométrica móvel (figura 11), - preço da batata doce apresenta oscilação harmônica em todo o período, com variação máxima de $\mathrm{R} \$ 1,51$ e mínima de R\$ 1,39 respectivamente ao longo do período.

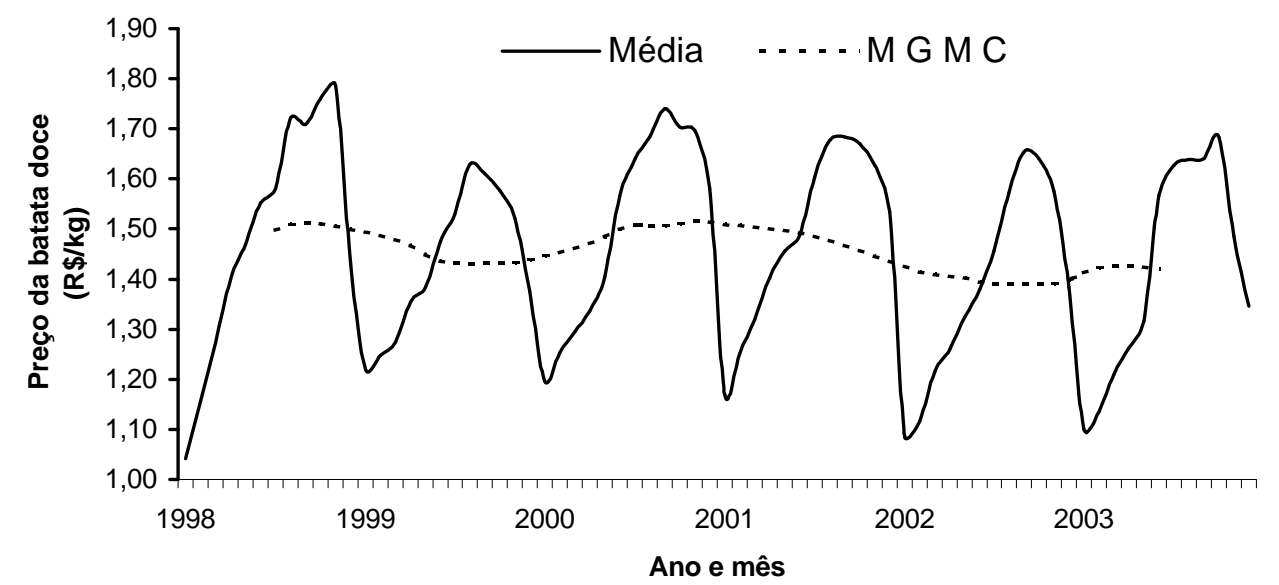

Figura 11 - Variação do preço da batata doce recebido pelos produtores nas feiras livres de Manaus de julho de 1998 a junho de 2003, de acordo com o método da média geométrica móvel centralizada 
A figura 12 apresenta 0 índice sazonal e os seus limites inferiores e superiores do preço da batata doce. Verificou-se que o preço do produto começou a baixar depois do mês de setembro quando atingiu seu máximo, chegando ao seu valor mínimo no mês de janeiro. De uma forma geral a variação sazonal determina as cotações inferiores ou superiores dos preços dos produtos.

A principio o preço não sofreu influência em relação à cota do rio, todavia o reflexo deste fenômeno começa a acontecer após 3 meses de vazante quando o preço do produto apresenta seu menor índice sazonal no mês de janeiro com R\$ 0,8 ; limite inferior de $\mathrm{R} \$ 0,7$ e limite superior de $\mathrm{R} \$$ 0,81 .

O maior índice sazonal da batata doce ocorreu no período de setembro (R\$ 1,10); limite inferior de $\mathrm{R} \$ 1,12$ limite superior de $\mathrm{R} \$ 1,17$. 


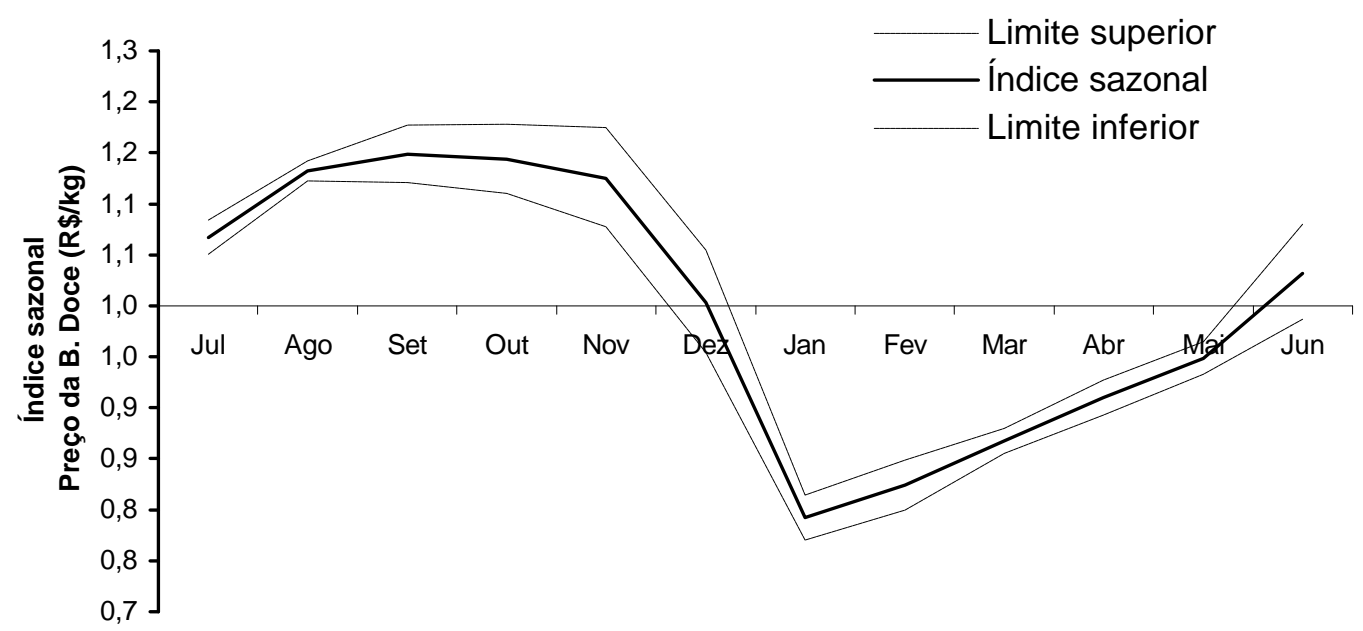

\begin{abstract}
Meses
Figura 12 - Índices sazonais e seu limites superiores e inferior do preço da batata doce recebido pelos produtores. obtido pelo método da média geométrica móvel centralizada utilizando preços correntes no período de 1998-2003
\end{abstract}

A Figura 13 apresenta uma tendência de queda dos preços da batata doce em relação à flutuação da cota do rio. Observa-se que a curva dos preços dos produtos apresenta um deslocamento de quatro meses em relação a vazante e a subida do rio. De acordo com os agricultores o momento ótimo de iniciar o plantio é entre os meses de agosto a novembro, período em que os solos da várzea não estão saturados, e ricos em matéria orgânica depositadas pelo rio. 


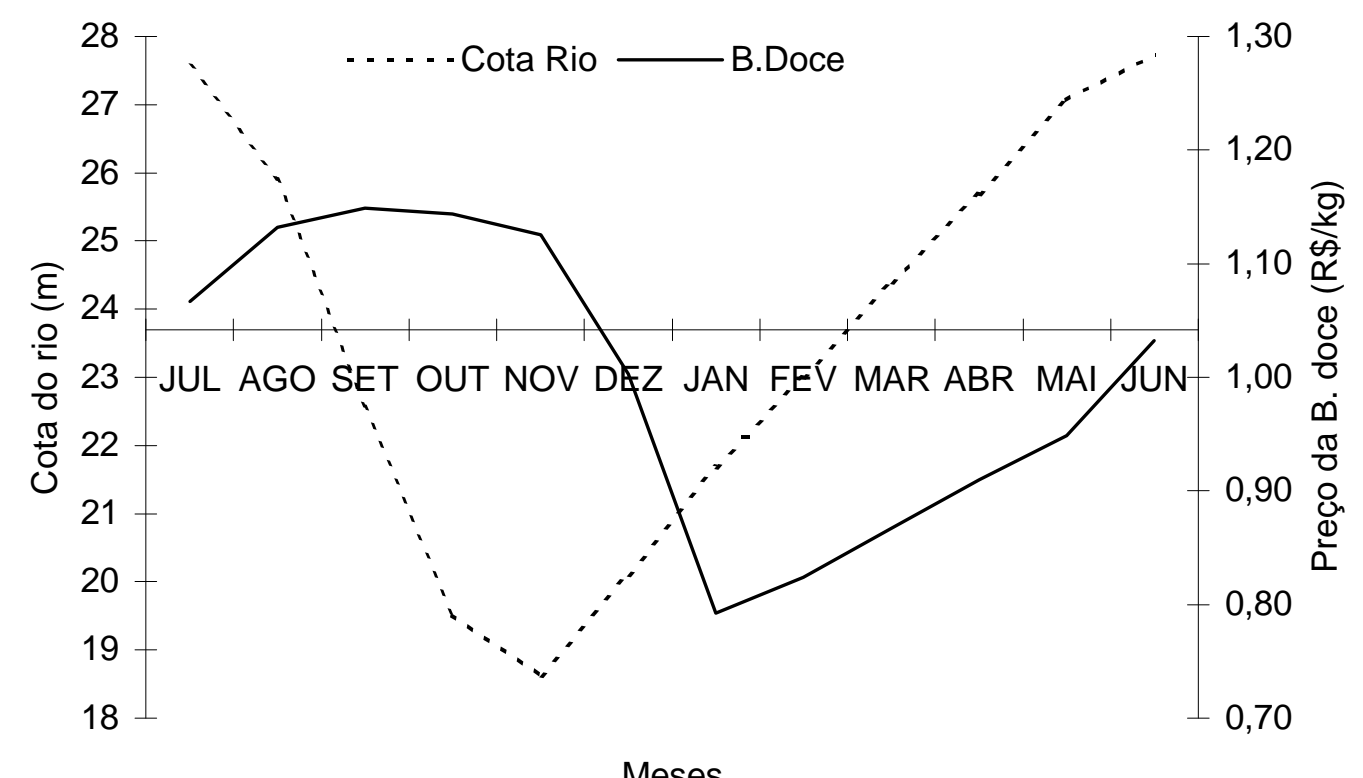

\footnotetext{
Figura 13- Variação do preço da batata doce em relação à variação da cota do rio, de acordo com o método da média geométrica móvel centralizada
}

A cultura do maxixe é considerada como secundária e é tipicamente de agricultura de subsistência, sendo encontrada geralmente associada a outras culturas, particularmente a do feijão, milho e mandioca. É uma cultura típica dos produtores de baixa renda e com pouca possibilidade de adoção de técnicas. 
A figura 14 apresenta os cálculos da média geométrica móvel do preço do maxixe. Percebe-se que a oscilação do preço é pequena ao longo do período, com variação mínima de R\$ 1,69 em 2000 e máxima $R \$ 1,83$ no ano de 2001, com variação média total em torno de $R \$ 1,76$ respectivamente.

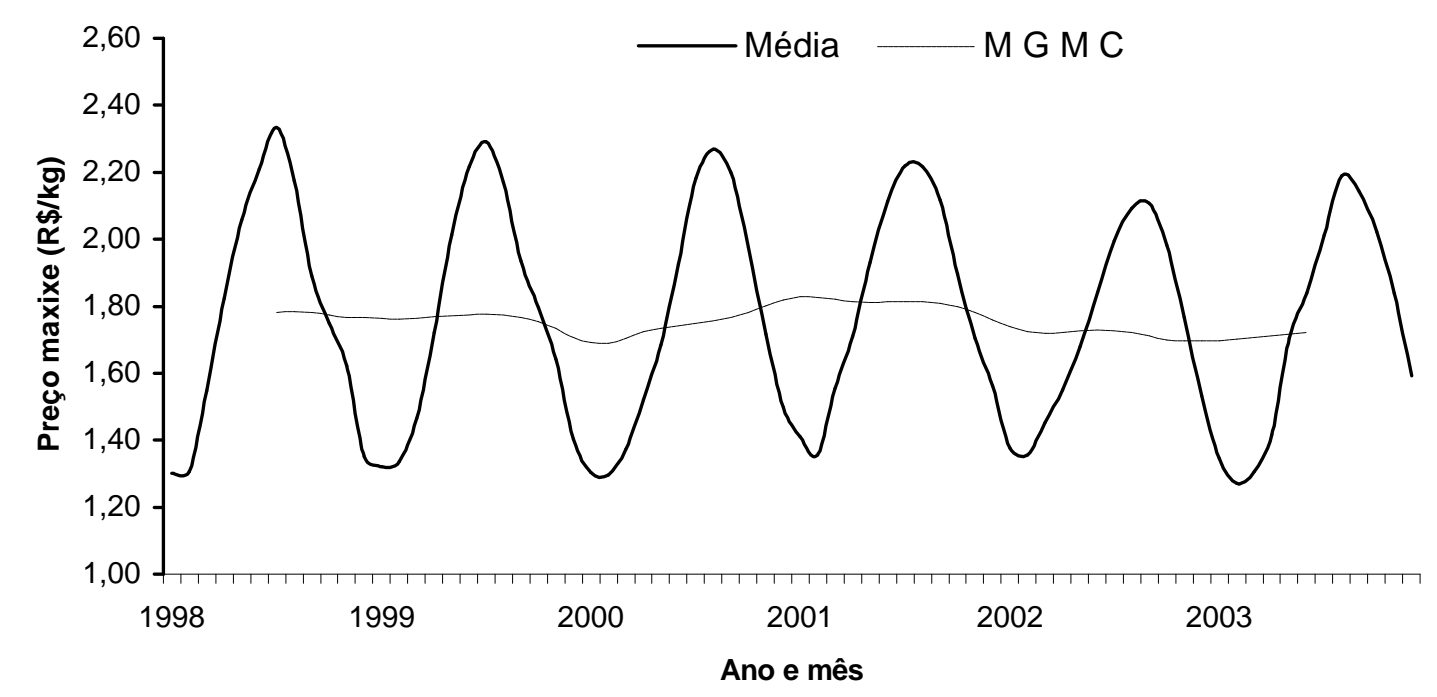

Figura 14- Variação do preço do maxixe recebido pelos produtores nas feiras livres de Manaus de julho de 1998 a junho de 2003, de acordo com o método da média geométrica móvel centralizada

A figura 15 apresenta $\circ$ índice sazonal e 0 limite inferior e superior do preço do maxixe, nota-se que o preço do produto começa cair no mês de agosto chegando ao valor mais baixo nos meses de janeiro e fevereiro com valor do índice sazonal em torno de $\mathrm{R} \$ 0,77$; limite inferior de $\mathrm{R} \$$ 0,75 e limite superior de $\mathrm{R} \$ 0,78$ respectivamente. 
No mês de março começa a haver uma reação na recuperação do preço do produto com índice sazonal em torno de $R \$ 0,80$ e seus limites inferior e superior por volta de $R \$ 0,83$ e $R \$ 0,85$, respectivamente atingindo seu valor máximo no mês de julho com índice sazonal de $R \$ 1,25$; limite inferior de $R \$ 1,18$ e limite superior de $R \$ 1,30$.

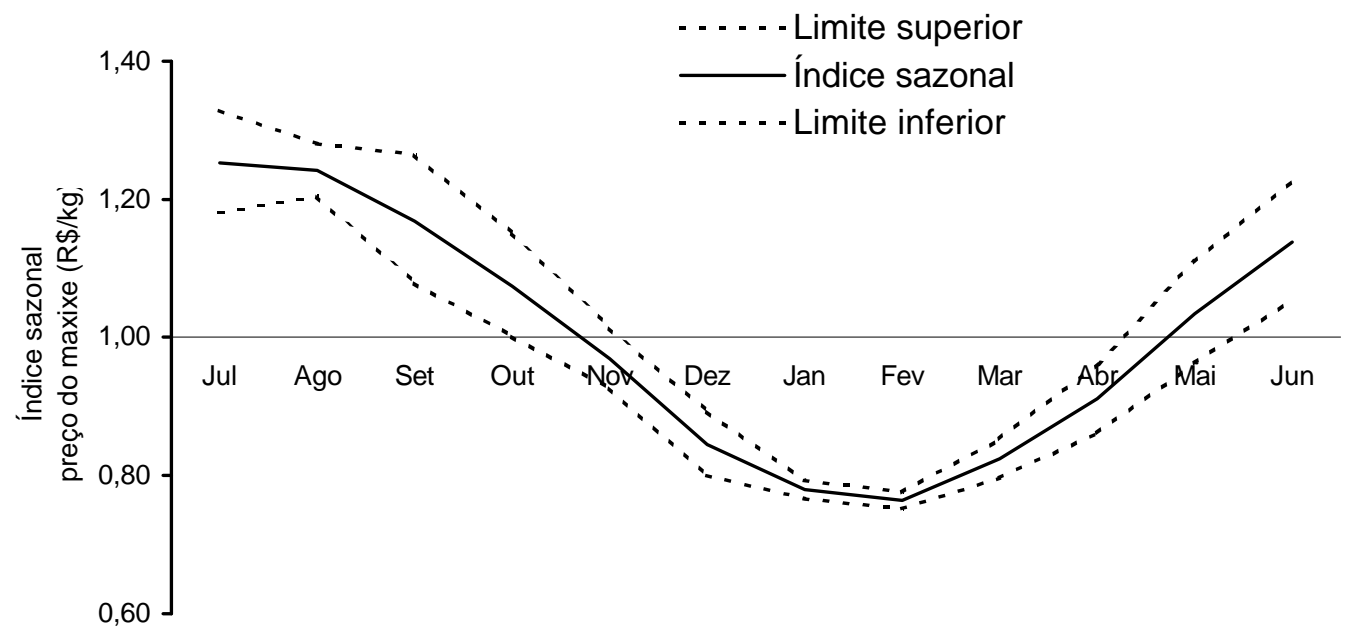

Meses

Figura 15 - Índices sazonais e seu limite superior e inferior do preço do maxixe recebido pelos produtores. Obtido pelo método da média geométrica móvel centralizada utilizando preços correntes no período de 1998-2003 
Observa-se na figura 16 uma tendência gradativa na queda do preço do maxixe em relação à variação da cota do rio. Percebe-se que existe um pequeno atraso de três meses na variação do preço em relação à cota do rio (novembro), ou seja, na época de vazante, e de três meses na época da cheia, ou seja, o reflexo do nível do rio nos preços do maxixe mantém um atraso aparentemente igual. E isso deve ser levado em conta no planejamento anual comercial do maxixe.

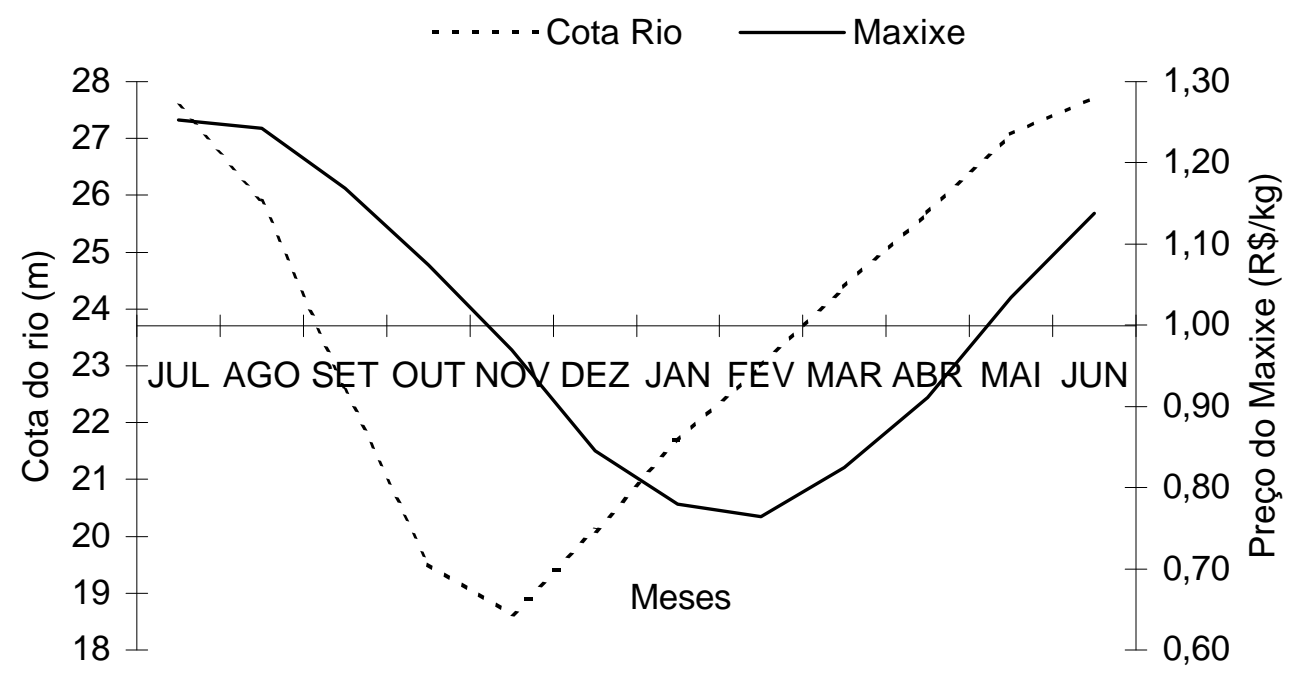

Figura 16 - Variação do preço do maxixe em relação a variação da cota do rio, de acordo com o método da média geométrica móvel centralizada 
Para a cultura do pepino, a aplicação da média geométrica móvel centralizada apresenta baixa flutuação ao longo do período (Figura 17). Percebe-se que a oscilação do preço é pequena ao longo do período estudado, com variação mínima de R\$ 1,08 em 1999 e máxima de $R \$$ 1,13 no ano de 1998, e com variação média total em torno de $\mathrm{R} \$$ 1,09. Respectivamente, a irregularidade do preço do pepino encontrado no mercado deve-se em grande parte, às práticas de cultivo inerente ao produto.

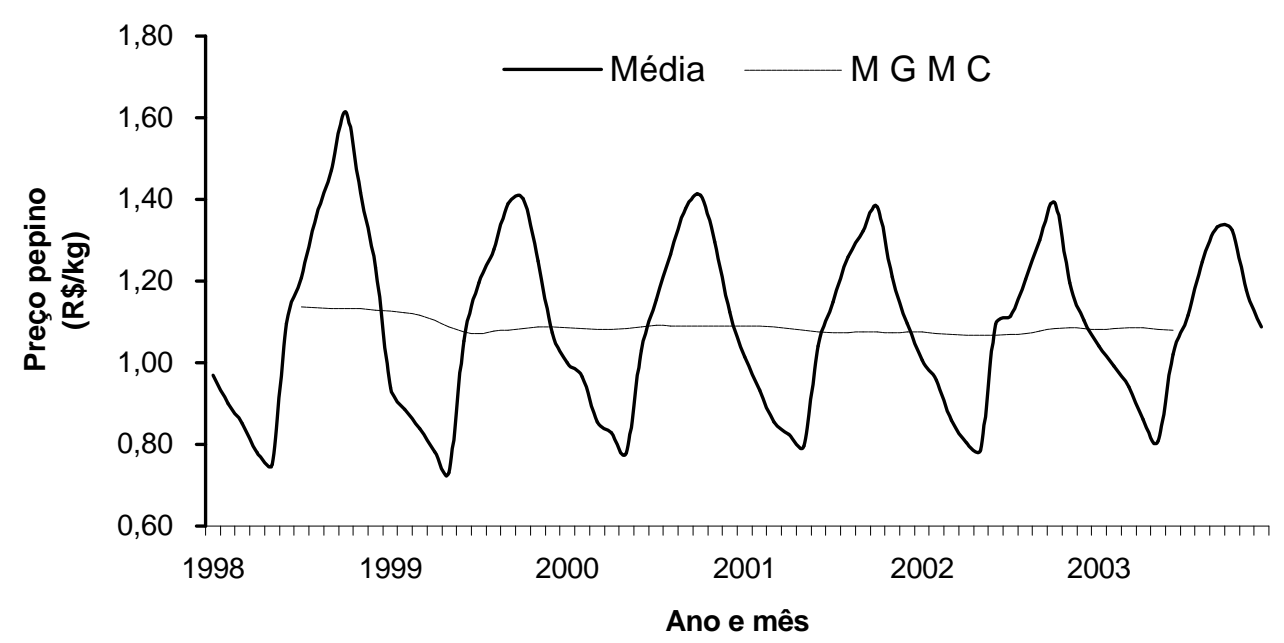

Figura 17- Variação do preço do pepino recebido pelos produtores nas feiras livres de Manaus de julho de 1998 a junho de 2003, de acordo com o método da média geométrica móvel centralizada 
Nos índices sazonais e seus limites inferiores e superiores obtidos a partir da média geométrica móvel do preço do pepino (Figura 18), observa-se que o preço do produto começa a cair no mês de agosto e chega ao valor mais baixo nos mês de outubro com o valor do índice sazonal em torno de $\mathrm{R} \$ 0,77$; limite inferior de $\mathrm{R} \$ 0,60$ e limite superior de $\mathrm{R} \$ 0,92$.

No mês de abril o preço do pepino tende a uma leve recuperação chegando ao índice sazonal máximo em torno de RS 1,31 e seus limites inferiores e superiores por volta de $\mathrm{R} \$ 1,45$ e $\mathrm{R} \$ 1,09$, respectivamente.

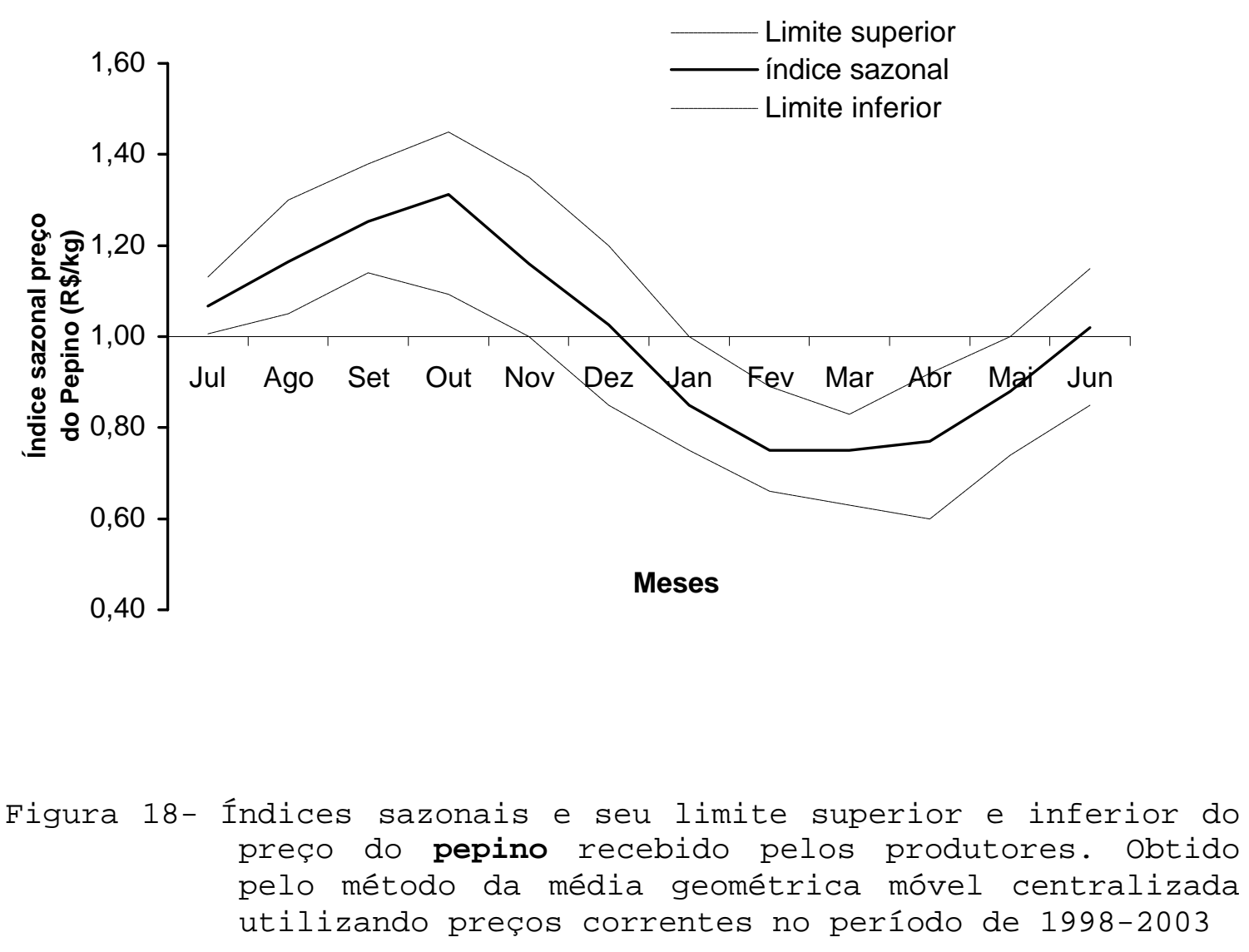


Observa-se na figura 19 uma tendência gradativa na queda do preço do pepino em relação à variação da cota do rio. Percebe-se que para esta cultura, o preço só é refletido após três meses em relação à cota média do rio (setembro), ou seja, no mês de dezembro. O preço do produto começa a subir (abril) após quatro meses de queda, enquanto o rio está enchendo novamente.

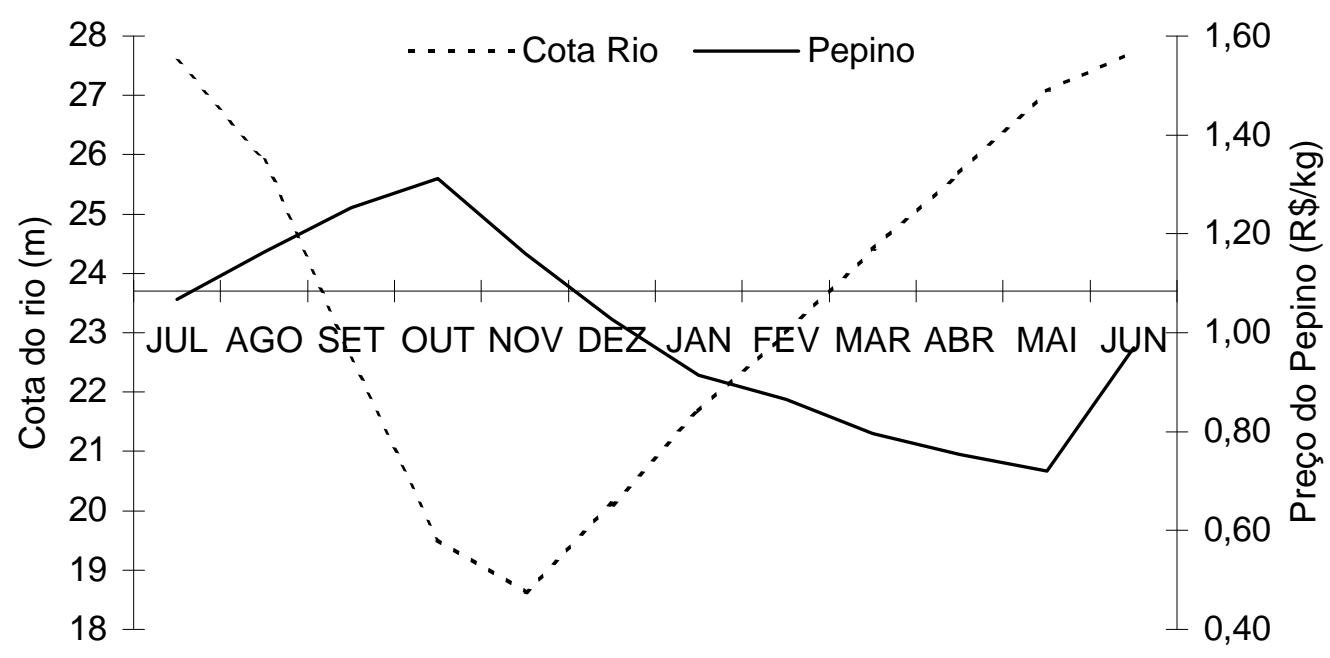

Mese

Figura 19 - Variação do preço do pepino em relação a variação da cota do rio, de acordo com o método da média geométrica móvel centralizada 
4.4 Análise de rentabilidade das culturas perenes

Como descrito na seção 3 (sub-item 3.6), as análises econômicas das atividades florestais utilizadas nos SAFs considerou um horizonte temporal médio para exploração de 30 anos, por se tratar de espécies com crescimento muito lento.

Detectou-se que do total das amostras estudadas, quatro tiveram alguma falência, sendo que a amostra TF-49 foi inviável economicamente em todas as taxas de desconto aplicadas (5\%, $10 \%$ e 12\%), e as amostra TF-38, TF-31 e TF16, não apresentaram rentabilidade econômica quando foram utilizadas taxas de desconto de 10\% e 12\% (Tabela 3).

Três fatores foram decisivos na falência da amostra Tr-49. O primeiro fator está relacionado com a escassez de mão-de-obra familiar. De acordo com a aplicação do diagnóstico, detectou-se que a composição familiar é formada por dez integrantes, fora o chefe da família e esposa, os demais possuem idade entre 1 a 13 anos. 0 segundo fator é o tamanho do SAF adotado na amostra, ou seja, por ser uma área reduzida, toda a produção é direcionada ao consumo familiar, não existindo excedente para o mercado, outras fontes como caça e pesca auxiliam no complemento da dieta básica. 
E por último, a riqueza e diversidade dos produtos que contribuíram para os resultados apresentados na Tabela 5 .

No caso das amostras $\mathbf{T F - 3 8}$ e $\mathbf{T F}-\mathbf{1 6}$, os resultados que tornaram os projetos economicamente inviáveis quando aplicadas taxas de desconto de 10\% e 12\% (Tabela 3), tiveram como fatores decisivos à escassez de mão-de-obra familiar e riqueza e diversidade das espécies adotadas no sistema (Tabela 4).

A amostra TF-31 apresentou inviabilidade econômica para a prática quando aplicadas taxas de descontos de $10 \%$ e 12\% (Tabela 3). Esta amostra contrasta a todos os fatores decisivos mencionados anteriormente, pois possui uma área significativa para a atividade (Tabela 4) e utilizou uma diversidade e riqueza de espécies, com potencial de mercado (Tabela 5). Porém, apesar de possuir disponibilidade de mão-de-obra, esta não é aplicada gerando perda da produção em todas as fases de condução das culturas (plantio, tratos culturais e colheita) ${ }^{5}$.

\footnotetext{
5 Os resultados detalhados das analises econômicas das amostras dos ecossistemas da terra firme e várzea encontram-se no apêndice 3 .
} 
4.5 As análises econômicas dos produtores da várzea

A avaliação econômica dos agricultores da várzea mostra que das oito amostras analisadas, somente três não foram viáveis economicamente (taxa de desconto de 12\%). As demais amostras apresentaram viabilidade econômica favorável em todas as taxas de desconto (Tabela 5).

As três amostras que não atenderam os objetivos econômicos a $12 \%$ estão sujeitas aos aspectos fundamentais das áreas de várzea, primeiramente no que se refere à influência do nível e flutuação do rio que interfere diretamente na escolha e adoção da cultura a ser praticada na amostra, e o segundo aspecto recai sobre o grau de diversidade e riqueza na adoção das culturas (Tabela 4).

A diversidade dos produtos neste ambiente é insuficiente, e as culturas em sua maioria são anuais como as hortaliças, e tendo como cultura padrão à mandioca por se tratar de um sistema de subsistência familiar. As potencialidades das áreas foram favoráveis a produção (Tabela 4). O estabelecimento do componente arbóreo no sistema agroflorestal torna o projeto inviável economicamente, visto que por se tratar de espécie de crescimento lento, as flutuações do rio aumentam o risco de perda desses indivíduos, tornando o projeto dispendioso. 
Tabela 3. Comparação econômica geral dos agricultores de terra firme

\begin{tabular}{|c|c|c|c|c|c|c|c|c|c|c|}
\hline \multirow{3}{*}{ Amostras } & \multicolumn{10}{|c|}{ Critérios de seleção para analises econômicas } \\
\hline & \multicolumn{3}{|c|}{ VPL } & \multicolumn{3}{|c|}{$\mathrm{B} / \mathrm{C}$} & \multicolumn{3}{|c|}{ VET } & \multirow{2}{*}{$\begin{array}{l}\text { TIR } \\
\left(\frac{\circ}{0}\right)\end{array}$} \\
\hline & $5 \%$ & $10 \%$ & $12 \%$ & $5 \%$ & $10 \%$ & $12 \%$ & $5 \%$ & $10 \%$ & $12 \%$ & \\
\hline $\mathrm{TF}-49$ & $-427,00$ & $-394,00$ & $-381,00$ & 0,74 & 0,96 & 0,68 & $-665,00$ & $-446,00$ & $-420,00$ & 0,0 \\
\hline $\mathrm{TF}-38$ & 772,00 & $-579,00$ & 171,00 & 1,19 & 0,99 & 0,93 & 940,00 & $-9,14$ & $-176,00$ & 9,6 \\
\hline $\mathrm{TF}-31$ & 280,00 & $-334,00$ & $-470,00$ & 1,10 & 0,85 & 0,77 & 364,00 & $-354,00$ & $-486,00$ & 6,4 \\
\hline $\mathrm{TF}-46$ & 969,00 & 474,00 & 354,00 & 1,34 & 1,22 & 1,18 & 1260,00 & 502,00 & 366,00 & 24,0 \\
\hline $\mathrm{TF}-50$ & 909,00 & 363,00 & 239,00 & 1,23 & 1,14 & 1,10 & 1183,00 & 384,00 & 247,00 & 18,0 \\
\hline $\mathrm{TF}-32$ & 205,00 & 63,00 & 33,00 & 1,05 & 1,02 & 1,01 & 267,00 & 67,00 & 34,00 & 15,0 \\
\hline $\mathrm{TF}-47$ & 1866,00 & 824,00 & 574,00 & 2,57 & 1,84 & 1,63 & 2428,00 & 847,00 & 593,00 & 23,0 \\
\hline $\mathrm{TF}-34$ & 1110,00 & 412,00 & 266,00 & 1,31 & 1,18 & 1,13 & 1445,00 & 437,00 & 276,00 & 19,0 \\
\hline $\mathrm{TF}-16$ & 55,60 & $-48,00$ & $-107,00$ & 1,01 & 0,98 & 0,94 & 58,00 & $-51,00$ & $-112,00$ & 8,0 \\
\hline $\mathrm{TF}-18$ & 388,00 & 84,00 & 18,41 & 1,09 & 1,03 & 1,01 & 505,00 & 89,00 & 19,00 & 12,0 \\
\hline $\mathrm{TF}-07$ & 443,00 & 171,00 & 101,00 & 1,30 & 1,06 & 1,04 & 576,00 & 181,00 & 104,00 & 16,0 \\
\hline $\mathrm{TF}-06$ & 726,00 & 228,00 & 117,00 & 1,15 & 1,07 & 1,04 & 945,00 & 242,00 & 121,00 & 15,0 \\
\hline $\mathrm{TF}-10$ & 1420,00 & 435,00 & 234,31 & 1,21 & 1,10 & 1,06 & 1856,00 & 458,00 & 242,00 & 15,0 \\
\hline
\end{tabular}


Tabela 4. Diversidade e riqueza das espécies utilizadas nos arranjos de cultivos mais freqüentes encontrados nas amostras estudadas.

\begin{tabular}{|c|c|c|c|c|c|c|c|c|c|c|c|c|c|c|c|c|c|c|c|c|c|c|}
\hline \multirow[t]{2}{*}{ Espécies } & \multicolumn{21}{|c|}{ Arranjos agroflorestais mais freqüentes utilizados pelos agricultores } & \multirow{2}{*}{$\begin{array}{l}\text { Ocor } \\
\text { rência }\end{array}$} \\
\hline & VZ1 & vz2 & vz3 & VZ4 & Vz5 & VZ 6 & $\mathrm{TF} 6$ & $\mathrm{TF} 7$ & VZ7 & VZ8 & $\mathrm{TF} 10$ & TF16 & TF 18 & TF31 & TF32 & $\mathrm{TF} 34$ & TF38 & $\mathrm{TF} 46$ & $\mathrm{TF} 47$ & TF49 & $\mathrm{TF} 50$ & \\
\hline Abacate & & & & & & 20 & 12 & 4 & 10 & & & & & & & & & 6 & & & & 05 \\
\hline Abiu & & & & & & & & 15 & & & 12 & & 4 & 6 & & 9 & & 12 & 4 & & 14 & 08 \\
\hline Abricó & & & & & & & & & & & 8 & & & & & & & & & & & 01 \\
\hline Açaí & & & & & & & 10 & 19 & 20 & & 3 & & & 26 & 20 & 16 & 20 & 10 & & & & 09 \\
\hline Andiroba & & & & & & 15 & & & & & & 20 & 13 & & 10 & & & & 11 & & & 05 \\
\hline Bacabinha & & & & & & & 10 & & & & & & & & & & & 100 & & & & 02 \\
\hline Bacuri & & & & & & & 7 & 7 & & & 8 & & & & & & & & & & & 02 \\
\hline Biribá & & & & & & & 36 & & & & & & & 6 & & & & 6 & & 5 & 10 & 05 \\
\hline Buriti & & & & & & & & & & & & & 4 & & & & & & & & & 01 \\
\hline Carambola & & & & & & & & & & & & 23 & 10 & & & & & & 5 & & 5 & 04 \\
\hline Cardeiro & & & & & & & 6 & & & & & & & & & & & & & & & 01 \\
\hline Castanha & & & & & & & 12 & 7 & & & 6 & & & 22 & 58 & 9 & & & & & & 06 \\
\hline Cedro & 30 & & & & & & & & & & & & 5 & & 20 & & & & & & & 03 \\
\hline Copaíba & & & & & & & & & & & & & & & & & & & & & & 01 \\
\hline Cupuaçu & 200 & 100 & 120 & 80 & 50 & 100 & 200 & 270 & 150 & 200 & 200 & 180 & 200 & 500 & 220 & 200 & 324 & 116 & & 200 & 600 & 20 \\
\hline Graviola & & & & 10 & & & & 10 & & & & 30 & 10 & & & & & 24 & 4 & & 10 & 07 \\
\hline Anuais & $\mathbf{x}$ & $\mathbf{x}$ & $\mathbf{x}$ & $\mathbf{x}$ & $\mathbf{x}$ & $\mathbf{x}$ & & $\mathbf{x}$ & & $\mathrm{x}$ & & & & & & & & & & & & 08 \\
\hline Jacareúba & & & & & & & & & & & & & & & 21 & & & & & & & 01 \\
\hline Jatobá & & & & & & & & & & & & & 5 & 1 & & & & 3 & 3 & & & 04 \\
\hline Jenipapo & & & & & & & 6 & & & & & & & 2 & & & & 4 & 1 & & & 04 \\
\hline Mogno & & & & & & & 6 & & & & & & & & & & & & & & & 01 \\
\hline Muiratinga & & & & & & & & & & & & & 5 & & 20 & & & & & & & 02 \\
\hline Pajurá & & & & & & & & & & & & & 5 & & & & & & & & 5 & 02 \\
\hline Pitomba & & & & & & & & & & & 8 & & & & & & & & & & & 01 \\
\hline Pupunha & & & & & & & 25 & 34 & 40 & & 25 & & 25 & 30 & 27 & 23 & 23 & 30 & 2 & 21 & 23 & 13 \\
\hline Puruí & & & & & & & & & & & & & 5 & 5 & & & & & & & 3 & 03 \\
\hline Sapotilha & & & & & & & & & & & 8 & & & & & & & & & & & 01 \\
\hline Sorvinha & & & & & & & & & & & & & 5 & & & & & & 3 & & 9 & 03 \\
\hline Urucum & & & & & & & & & & & 300 & & & & & & & & & & & 01 \\
\hline Uxi & & & & & & & & & & & & & 9 & & & & & & 3 & & & 02 \\
\hline Total & 03 & 02 & 02 & 03 & 02 & 04 & 11 & 09 & 04 & 02 & 10 & 04 & 14 & 09 & 09 & 06 & 03 & 10 & 09 & 03 & 09 & \\
\hline Legenda: & 0 & núm & ero & re & pres & sent & $a$ & q & uant & idac & & de & lanta & & por & espéc & ie; & $\mathrm{X}=\mathrm{An}$ & nuais & & ultur & as \\
\hline
\end{tabular}


Tabela 5. Comparação econômica geral dos agricultores da várzea

\begin{tabular}{|c|c|c|c|c|c|c|c|c|c|c|}
\hline \multirow{3}{*}{ Amostras } & \multicolumn{10}{|c|}{ Critérios de sel } \\
\hline & \multicolumn{3}{|c|}{ VPL } & \multicolumn{3}{|c|}{$\mathrm{B} / \mathrm{C}$} & \multicolumn{3}{|c|}{ VET } & \multirow{2}{*}{$\begin{array}{l}\text { TIR } \\
\left(\frac{\circ}{0}\right)\end{array}$} \\
\hline & $5 \%$ & $10 \%$ & $12 \%$ & $5 \%$ & $10 \%$ & $12 \%$ & $5 \%$ & $10 \%$ & $12 \%$ & \\
\hline $\mathrm{VZ}-08$ & 792,00 & 398,00 & 299,00 & 1,12 & 1,08 & 1,07 & 1031,00 & 422,00 & 309,00 & 23,0 \\
\hline VZ-07 & 781,00 & 326,00 & 20,900 & 1,08 & 1,05 & 1,03 & 1016,00 & 346,00 & 216,00 & 17,0 \\
\hline $\mathrm{VZ}-06$ & 471,00 & 145,00 & 86,00 & 1,08 & 1,04 & 1,03 & 543,00 & 154,00 & 89,00 & 16,0 \\
\hline $\mathrm{VZ}-01$ & 1347,00 & 289,00 & 129,00 & 1,11 & 1,04 & 1,02 & 1752,00 & 307,00 & 133,00 & 14,0 \\
\hline$V Z-05$ & 178,00 & 3,31 & $-43,00$ & 1,05 & 1,0 & 0,98 & 232,00 & 3,51 & $-44,00$ & 10,0 \\
\hline VZ-02 & 979,00 & 442,00 & $-794,00$ & 1,06 & 1,01 & 0,99 & 295,00 & 27,00 & $-27,00$ & 10,0 \\
\hline$V Z-04$ & 180,00 & 104,00 & 81,00 & 1,08 & 1,06 & 1,05 & 466,00 & 170,00 & 120,00 & 23,0 \\
\hline $\mathrm{VZ}-03$ & 67,00 & 1,18 & $-18,00$ & 1,04 & 1,0 & 0,99 & 175,00 & 2,0 & $-27,00$ & 10 \\
\hline
\end{tabular}


4.6 Aspectos sócio econômicos dos agricultores da terra firme

De acordo com a aplicação do LRR, foi possível detectar algumas inferências em se tratando da composição familiar em relação a viabilidade dos SAFs.

A figura 20, mostra a estrutura da fôrça de trabalho disponível nas amostras da área de terra firme, pode-se perceber que nas nas amostras, existe um componente da fôrça de trabalho, porém em algumas situações esta mão-deobra é composta na sua maioria da fôrça feminina. De acordo com o cenário exposto, obrigatóriamente o agricultor necessita contratar mão-de-obra externa nas suas atividades diárias.

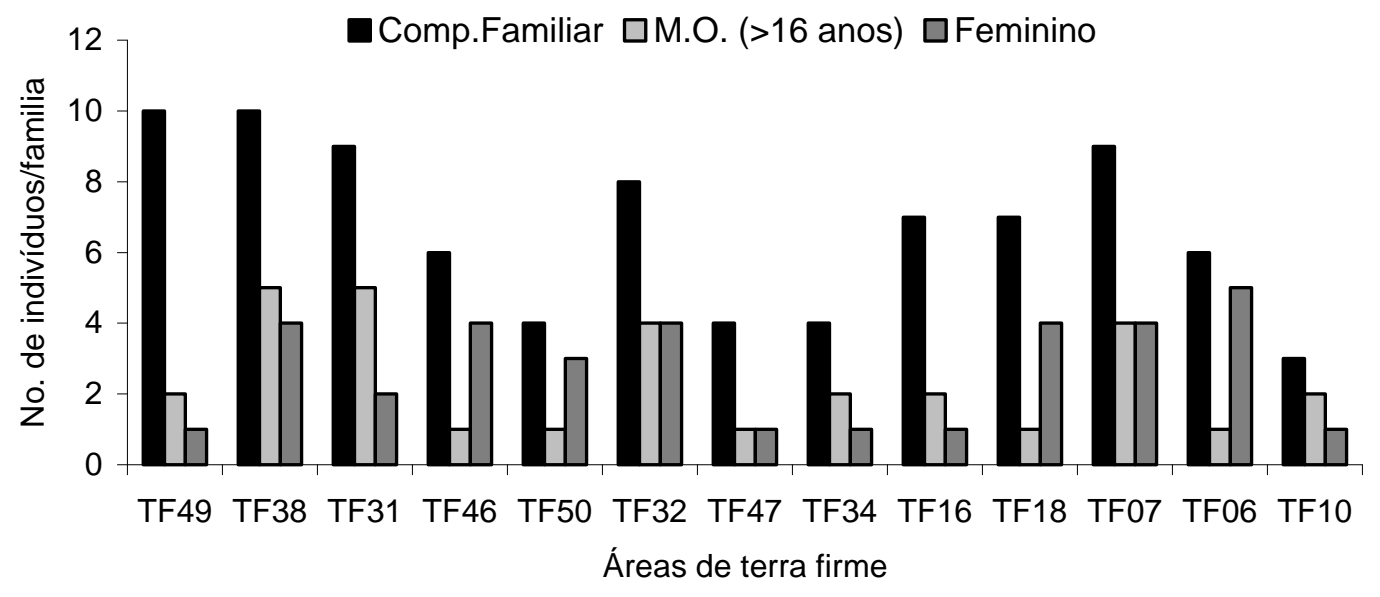

Figura 20 - Composição da fôrça de trabalho nas áreas de terra firme 
A figura 21 apresenta a migração do componente familiar para os centro urbanos, este deslocamento está relacionado a carência de escolas do ensino médio próximos as comunidades. Pelo que foi observado na aplicação do LRR, essa fôrça de trabalho não retornará as zonas rurais, ou seja induzindo o agricultor a contratar mão-de-obra na manutenção da propriedade.

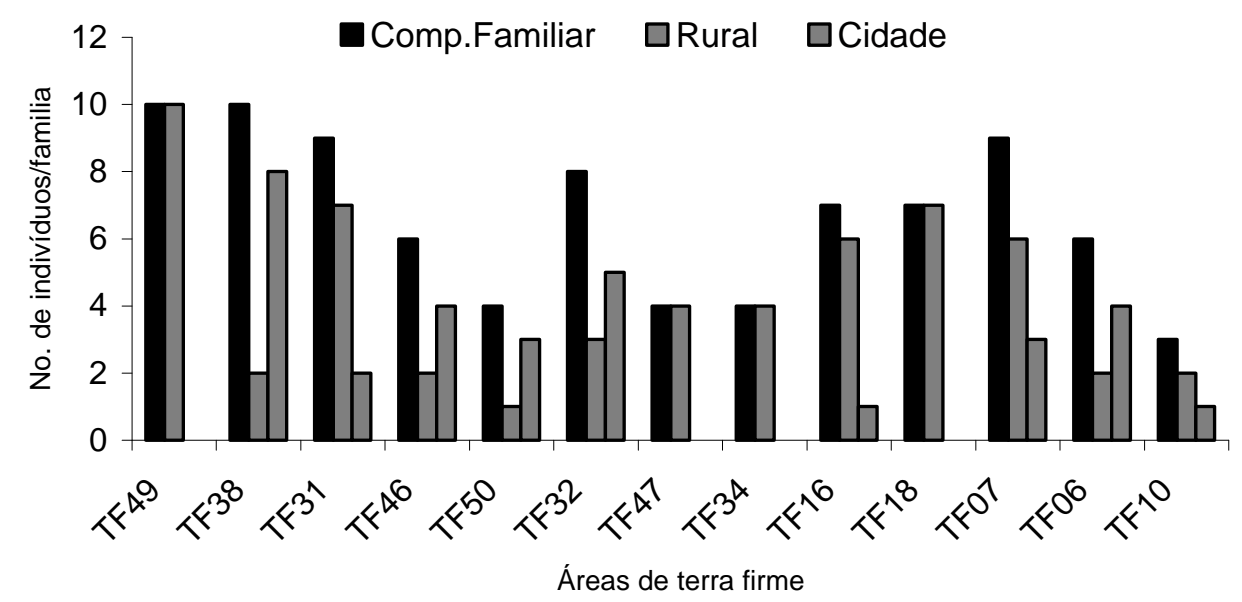

Figura 21 - Evasão de membros das familis das zonas rurais de terra firme para os centro urbanos. 
$\mathrm{Na}$ figura 22, são apresentadas as médias da composição familiar, nota-se que 50\% da mão-de-obra local migra para os centros urbanos sendo que 56\% desse efetivo é composta por gênero o que justifica a contratação da mãode-obra externa.

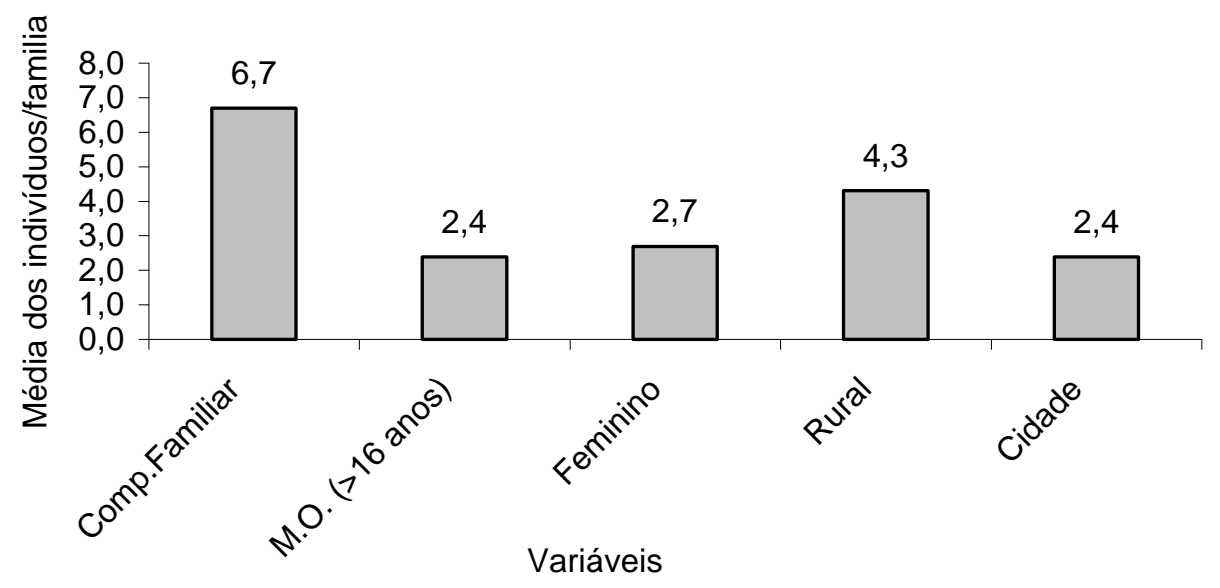

Figura 22 - Composição familiar média das propriedades de terra firme 
4.7 Aspecto sócio econômico dos agricultores da várzea

\begin{abstract}
Seguindo o mesmo princípio metodologico dos agricultores da terra firme, identificou-se que a composição familiar nas áreas de várzea (Figura 23) possui potencial de mão-de-obra local, como o ecossistema várzea depende de aproximadamente seis meses devido a flutuação do rio, este setor contrata fôrça de trabalho externo.
\end{abstract}

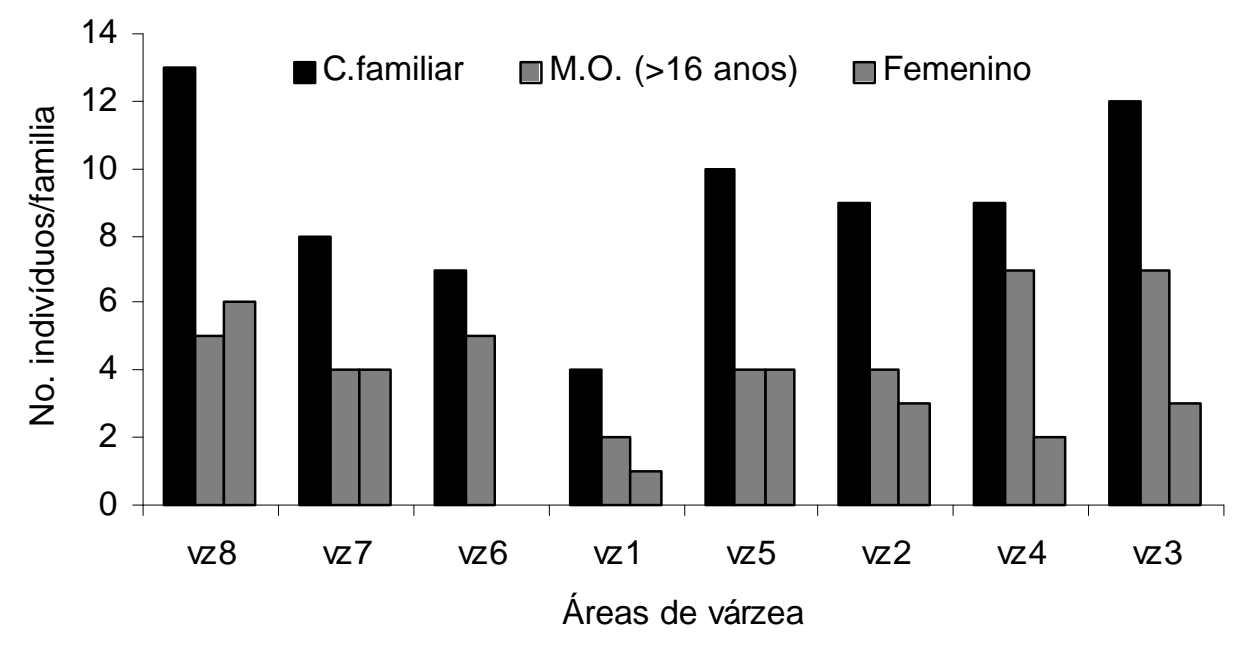

Figura 23 - Composição da fôrça de trabalho nas áreas de várzea 
Na figura 24, é apresentada a migração do componente familiar das áreas de várzea para os centro urbanos, observa-se que este deslocamento é menor que o grupo da terra firme. A razão pela baixa evasão, esta associada a: limitação, distância e precariedade do uso de transporte para as cidades vizinhas.

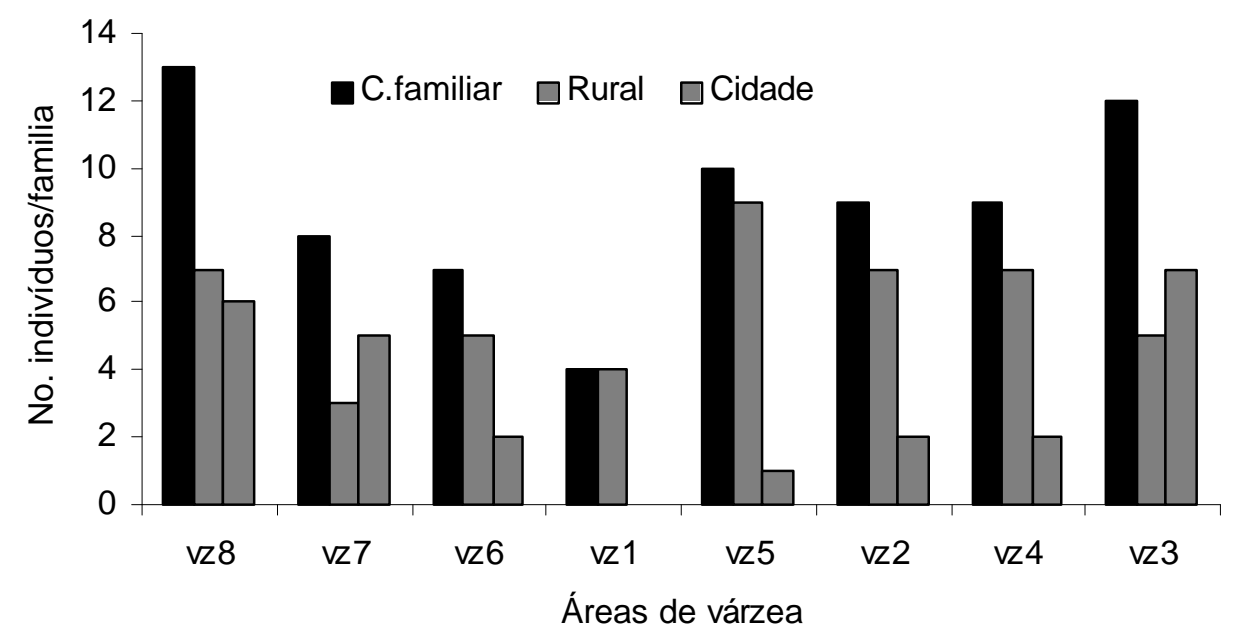

Figura 24 - Evasão de membros das familias das zonas rurais da várzea para os centro urbanos. 
A figura 25 apresenta a média da composição familiar das áreas de várzea, percebe-se que mais de 50\% dos membros da familia residem na proriedade, o que vem a confirma as dificuldades de deslocamento para os centros urbanos.

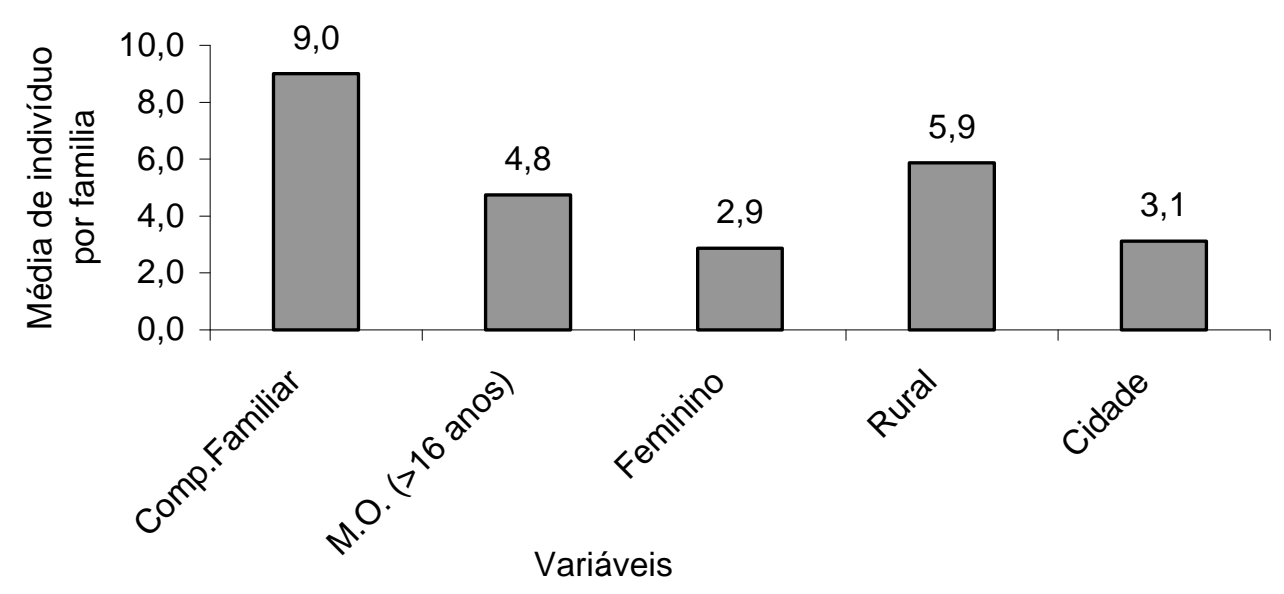

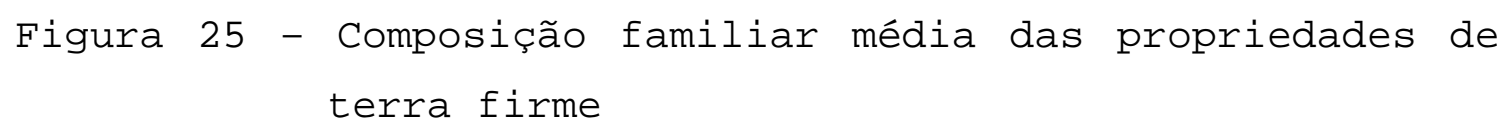




\title{
5 CONCLUSÕES
}

\author{
Este trabalho foi desenvolvido para discutir alguns \\ aspectos ligados à viabilidade econômica dos SAFs. E, \\ também, para orientar a gestão econômico-financeira \\ relacionada ao sistema de produção agroflorestal envolvendo \\ a produção de dois ecossistemas na Amazônia. Para isso, o \\ estudo apresentou, numa discussão objetiva, aspectos \\ teóricos sobre o processo de decisão ao nível de gestor \\ rural. Para indicar a melhor decisão apresentou os \\ critérios de avaliação de projetos VPL, RBC, TIR e VET, \\ envolvendo fluxos de caixa num período de 30 anos. Para \\ isso utilizou dados de 21 observações de SAFs por pequenos \\ produtores, indicando quais as alternativas mais rentáveis, \\ dados os preços e custos utilizados em diferentes momentos \\ em relação ao fluxo do rio.
}




\begin{abstract}
Tomando como base os objetivos determinados no presente estudo e diante das condições em que se encontram os agricultores da terra firme e da várzea da região do entorno de Manaus, chegou-se às seguintes conclusões:
\end{abstract}

1) Os agricultores que utilizaram espécies frutíferas como (cupuaçu, graviola, pupunha e açaí) tiveram um desempenho financeiro mais significativo que os demais, portanto economicamente viáveis e reproduzíveis;

2) A variação do preço dos produtos comercializados nos mercados locais sofre influência do nível do rio;

3) A concepção de um sistema agroflorestal está bem consolidada entre os agricultores. Não só pela diversificação de combinações de espécies, mas, sobretudo pela sensibilidade e prudência no momento de compor o arranjo no sistema;

4) Percebeu-se que ainda existe uma grande barreira por parte de alguns agricultores na adoção do componente madeireiro nos sistemas agroflorestais, visto que o horizonte temporal de rentabilidade é em longo prazo; e,

5) Agricultores da terra firme que conseguem manter suas áreas bem irrigadas conseguem manter uma produtividade significativa em relação aos produtores da várzea. 
Durante o desenvolvimento do estudo foram detectadas algumas limitações. Sabe-se que os Sistemas Agroflorestais (SAFs) implantados por pequenos produtores na Amazônia ainda é um assunto extremamente complexo por várias razões. Destacam-se os seguintes aspectos relacionados com: terra, capital (crédito), mercado, tecnologias apropriadas, infraestrutura e condições sócio-econômicas.

A viabilidade econômica e a longevidade produtiva são requisitos importantes para sistemas de uso da terra na Amazônia. A sustentabilidade e o sucesso dos SAFs está relacionado à tentativa de aproximação ao ecossistema natural, o que não ocorre na região com a maioria dos agricultores.

Entretanto, a implantação de incentivos como políticas públicas na forma de apoio institucional, crédito, fomento ao plantio de árvores entre outras poderiam contribuir para maior expansão dos SAFs entre os pequenos agricultores da região.

Ainda é necessário que o produtor rural tenha visão clara dos benefícios financeiros decorrentes desta atividade. Tais informações nem sempre estão disponíveis ao lado das informações técnicas sobre esta modalidade de sistema do uso da terra.

No caso dos produtores que utilizam o sistema de agricultura itinerante na Amazônia, não existe garantia que, no longo prazo, esse sistema seja sustentável. 
Alternativamente, poderia ser planejada a introdução de modificações, como por exemplo os SAFs, visando maximizar a utilização dos recursos naturais de forma apropriada, como as constadas neste estudo. Uma outra estratégia seria explorar a diversificação de espécies para atender a demanda familiar e de mercado. Os casos de alguns agricultores que fizeram parte do estudo são exemplos que ilustram este tipo de estratégia.

Adicionalmente, os SAFs poderiam ser beneficiados pelo desenvolvimento e disponibilização de tecnologias para a exploração e o aproveitamento mais nobre do seu componente madeireiro.

Finalmente, recomenda-se, ainda, estudos que quantifiquem economicamente os benefícios indiretos dos SAFs, que poderiam ser potencialmente mais significativos que os benefícios diretos mensurados no presente estudo. 
ANEXOS 


\section{LEVANTAMENTO RÁPIDO RURAL \\ (Aplicação do diagnóstico participativo) \\ INPA/CPCA- ESALQ/USP}

Data:

Questionário No.

Entrevistador:

Nome do Produtor e/ou entrevistado:

$\underline{\text { Local e condições do Entrevistado }}$
a) Município:
b) Travessão:
c) Lote:

d) Condições do entrevistado: Chefe da amília/esposa/filho(a)/outros:

Migração, História pessoal (Chefe do domicílio)

Idade? anos

Tempo de moradia no local ? anos meses

Estado onde nasceu?

Como chegou ao município?

Informações gerais sobre as propriedades:

Quantas propriedades possui?

Composição familiar próxima

\begin{tabular}{|c|c|c|c|c|c|c|c|c|c|}
\hline Nome & Parentesco & Idade & Sexo & Escolaridade & Residência & \multicolumn{4}{|c|}{ Atividade/trabalho } \\
\hline & & & & & & estudo & Propr. & $\begin{array}{l}\text { Outra } \\
\text { propr }\end{array}$ & cidade \\
\hline & & & & & & & & & \\
\hline & & & & & & & & & \\
\hline & & & & & & & & & \\
\hline & & & & & & & & & \\
\hline & & & & & & & & & \\
\hline & & & & & & & & & \\
\hline & & & & & & & & & \\
\hline
\end{tabular}


Fonte externa de renda (anual/mensal/semanal)

Membros da família de fora da propriedade contribuem? Sim ( ) Não ( ) R\$

Outras fontes de renda

FUNRURAL

Atividade Comercial

Contribuição de terceiros

Outros

$\%$ das outras contribuições na renda total da propriedade
Sim ( ) Não ( ) R\$

Sim ( ) Não ( ) R\$

Sim ( ) Não ( ) R\$

( )

$\mathrm{R} \$$

$-50 \%()+50 \%($ )

Condição Econômica da Família, da Casa, da Propriedade

Disponibilidade de bens pela família:

Fogão á gás

Máquina de costura

Geladeira

Televisão

Antena parabólica

Bicicleta

Carro

Rádio/Som

Casa na cidade $\underline{\text { no início }}$

Sim Não

( ) ( )

( ) ( )

( ) ( )

( ) ( )

( ) ( )

( ) ( )

( ) ( )

( ) ( )

( ) ( ) agora

Sim Não

( ) ( )

( ) ( )

( ) ( )

( ) ( )

( ) ( )

( ) ( )

( ) ( )

( ) ( )

( ) ( )

Casa onde mora a família:

Poço

Parede madeira

Parede alvenaria

Parede barro

Eletricidade
( ) ( )

( ) ( )

( ) ( )

( ) ( )

( ) ( )
( ) ( )

( ) ( )

( ) ( )

( ) ( )

( ) ( )

Máquinas e equipamentos:

$\begin{array}{lllll}\text { Motoserra } & (\text { ) } & (\text { ) } & (\text { ) } & (\text { ) } \\ \text { Gerador } & (\text { ) } & (\text { ) } & (\text { ) } & (\text { ) } \\ \text { Casa de farinha } & (\text { ) } & (\text { ) } & (\text { ) } & (\text { ) } \\ \text { Trator } & (\text { ) } & (\text { ) } & (\text { ) } & (\text { ) } \\ \text { Carro } & (\text { ) } & (\text { ) } & (\text { ) } & (\text { ) }\end{array}$




\section{$\underline{\text { Conflitos }}$}

Há ou houve disputa em relação aos limites da suas terras?

Esses conflitos foi devido a:

Sim ( ) Não ( )

( ) problemas de limites

( ) entrada de fogo

( ) invasão de posseiros

( ) outros. Qual /quais:

Há ou houve disputa em relação aos limites da terras nesta área?

Caso afirmativo, a quantos quilômetros de distâncias ?

Sim ( ) Não ( ) $\mathrm{km}$

Como são resolvidos essas disputas?

( ) vigilância pessoal

( ) polícia

( ) discussão na associação/comunidade

( ) advogados

( ) chamar o INCRA

( ) outros

O Sr. Gostaria de mudar o sistema produtivo atual (combinação de cultua ou aumento/redução de área cultivada)? $\quad \operatorname{Sim}($ ) Não ( )

Qual(is) atividade(s)/cultura(s) gostaria de expandir/introduzir ou reduzir?

$\begin{array}{ll}\text { Abacate: } & \text { ( ) expandir/introduzir ( ) reduzir ( ) inalterado } \\ \text { Abiu: } & \text { ( ) expandir/introduzir ( ) reduzir ( ) inalterado } \\ \text { Açaí: } & \text { ( ) expandir/introduzir ( ) reduzir ( ) inalterado } \\ \text { bacabinha: } & \text { ( ) expandir/introduzir ( ) reduzir ( ) inalterado } \\ \text { biribá: } & \text { ( ) expandir/introduzir ( ) reduzir ( ) inalterado } \\ \text { castanha: } & \text { ( ) expandir/introduzir ( ) reduzir ( ) inalterado } \\ \text { cupuaçu: } & \text { ( ) expandir/introduzir ( ) reduzir ( ) inalterado } \\ \text { jatobá: } & \text { ( ) expandir/introduzir ( ) reduzir ( ) inalterado } \\ \text { jenipapo: } & \text { ( ) expandir/introduzir ( ) reduzir ( ) inalterado } \\ \text { laranja: } & \text { ( ) expandir/introduzir ( ) reduzir ( ) inalterado } \\ \text { mandioca: } & \text { ( ) expandir/introduzir ( ) reduzir ( ) inalterado } \\ \text { mata/floresta: } & \text { ( ) expandir/introduzir ( ) reduzir ( ) inalterado } \\ \text { piquiá: } & \text { ( ) expandir/introduzir ( ) reduzir ( ) inalterado } \\ \text { pupunha: } & \text { ( ) expandir/introduzir ( ) reduzir ( ) inalterado } \\ \text { puruí: } & \text { ( ) expandir/introduzir ( ) reduzir ( ) inalterado } \\ \text { pesca: } & \text { ( ) expandir/introduzir ( ) reduzir ( ) inalterado } \\ \text { caça: } & \text { ( ) expandir/introduzir ( ) reduzir ( ) inalterado } \\ & \text { ( ) expandir/introduzir ( ) reduzir ( ) inalterado }\end{array}$


Porque?:

O sr. Gostaria de expandir? reduzir a área do SAF?

( ) expandir/introduzir ( ) reduzir ( ) inalterado

Porque?:

Quais as mais importantes razões para a expansão das atividades produtivas?:

( ) aumento da renda

( ) declínio na produção (perene)

( ) obtenção/disponibilidade de crédito

( ) problemas com fogo (perene)

( ) disponibilidade de mão-de-obra

( ) degradação da terras

( ) pragas

( ) preço alto/atrativo

Quais as mais importantes razões para a redução das atividades produtivas?:

( ) declínio na produção (perene)

( ) custo de produção muito alto

( ) não tem credito de custeio

( ) problemas com fogo (perene)

( ) disponibilidade de mão-de-obra

( ) degradação da terras

( ) pragas

( ) preço baixo/não lucrativo

( ) não tem mercado

Ocupação de área e produção nos últimos 12 meses.

Cultura No.pés Qtd.produzida

\% autoconsumo Mês

Abacate:

Abiu:

Açaí:

bacabinha:

biribá:

castanha:

cupuaçu:

jatobá:

jenipapo:

laranja:

mandioca:

mata/floresta:

piquiá: 
pupunha:

puruí:

pesca:

caça:

Outros:

Qual seria o menor valor que o Sr. Aceitaria p/ deixar de plantar e se aposentar?

$\mathrm{R} \$$ :

Benfeitoria e Melhoramentos:

\begin{tabular}{|c|c|c|c|c|c|c|}
\hline Item & Tipo & Data & Tamanho & \multicolumn{2}{|c|}{ Valor R\$ } & \multirow{2}{*}{$\begin{array}{l}\text { Vida útil } \\
\text { adicional }\end{array}$} \\
\hline Casa & & & & Novo & Atual & \\
\hline \multicolumn{7}{|c|}{ Depósito/galpão } \\
\hline \multicolumn{7}{|l|}{ Cerca } \\
\hline \multicolumn{7}{|c|}{ Casa farinha } \\
\hline \multicolumn{7}{|c|}{ Estrada interna } \\
\hline \multicolumn{7}{|c|}{ Represa/açude } \\
\hline \multicolumn{7}{|c|}{ Eletricidade } \\
\hline \multicolumn{7}{|c|}{ Viveiro } \\
\hline Canoa & & & & & & \\
\hline
\end{tabular}

$\underline{\text { Veículos (marca/modelo/ano/valoratual/vida útil): }}$

\begin{tabular}{|l|l|l|l|l|l|}
\hline Tipo & Marca & Modelo & Ano & Valor atual & Vida util \\
\hline Automóvel & & & & & \\
\hline Moto & & & & & \\
\hline Bicicleta & & & & & \\
\hline Carroça & & & & & \\
\hline Trator & & & & & \\
\hline
\end{tabular}


$\underline{\text { Máquinas/equipamentos }}$

\begin{tabular}{|l|l|l|l|l|l|}
\hline Tipo & Marca & Modelo & Ano & Valor atual & Vida util \\
\hline Motoserra & & & & & \\
\hline Bomba dágua & & & & & \\
\hline Motor barco & & & & & \\
\hline Gerador & & & & & \\
\hline Pulverizador & & & & & \\
\hline & & & & & \\
\hline & & & & & \\
\hline & & & & & \\
\hline
\end{tabular}

$\underline{\text { Ferramentas }}$

\begin{tabular}{|l|l|l|l|l|l|}
\hline Tipo & Marca & Modelo & Ano & Valor atual & Vida util \\
\hline Machado & & & & & \\
\hline Enxada & & & & & \\
\hline Foice & & & & & \\
\hline Facão & & & & & \\
\hline Encho & & & & & \\
\hline Cavadeira & & & & & \\
\hline & & & & & \\
\hline & & & & & \\
\hline
\end{tabular}


$\underline{\text { Identificação do Lote (se + que 1): }}$

Em que ano adquiriu a propriedade?

Qual a área da propriedade:

área inicial?

área atual?

$\underline{\text { Ocupação e titulação da propriedade }}$

Como o Sr. Obteve essa área

$\begin{array}{ll}\text { Comprou } & (\text { ) } \\ \text { Trocou por outra área } & (\text { ) } \\ \text { Invadiu } & \text { ( ) } \\ \text { Herança } & \text { ( ) } \\ \text { Recebeu do INCRA } & \text { ( ) }\end{array}$

Este lote é titulado? Sim

Condição do titulo: provisório ( )

Definitivo ( )

Emitido pelo:

Há quanto tempo?

( )

Já comprou com titulo

Não

Processo de titulação

( )

Quando pretende obtê-lo?

$\begin{array}{ccc}\text { Condição } & 1 \text { ano } & (\text { ) } \\ & 2 \operatorname{anos} & (\text { ) } \\ & 3 \operatorname{anos} & (\text { ) } \\ & 4+\operatorname{anos} & (\text { ) } \\ & \text { não em processo } & \text { ( ) }\end{array}$

Foi demarcado?

Sim ( ) Não ( )

É o primeiro dono

$\operatorname{Sim}($ ) Não ( )

Quanto quilômetro fica da estrada?

Na sua chegada quantos hectares existiam de:

$\begin{array}{lr}\text { Pasto_ } & \text { ha } \\ \text { Capoeira } & \text { ha } \\ \text { Mata nativa } & \text { ha } \\ \text { Culturas } & \text { ha }\end{array}$


Quantos hectares exitem hoje:

$\begin{array}{lr}\text { Pasto_ } & \text { ha } \\ \text { Capoeira } & \text { ha } \\ \text { Mata nativa ha } & \text { ha } \\ \text { Culturas } & \text { há }\end{array}$

$\underline{\text { Financiamento e assistência técnica }}$

Este lote pode ser oferecido como garantia de empréstimo? Sim ( ) Não ( )

Tem ou já teve financiamento?

Sim ( ) Não ( )

Em caso afirmativo, p/ qual(is) finalidade(s):

$\begin{array}{ll}\text { Agricultura anuais: } & \text { ( ) Qto?/Qdo? } \\ \text { Perenes: } & \text { ( ) Qto?/Qdo?_ ( ) Qto?/Qdo? } \\ \text { Pecuaria __ } & \text { Qto?/Qdo? }\end{array}$

O Sr. Já teve ajuda do governo (sementes, assistência técnica ) Sim ( ) Não ( )

Caso afirmativo, que tipo?

O Sr. Já teve ajuda de ONG (sementes, assistência técnica , dinheiro, insumos etc)?

$\operatorname{Sim}($ ) Não ( )

Caso afirmativo, de quem e de que tipo?

Venda da produção de culturas anuais e perenes nos 12 últimos meses:

Anuais

Qtd. vendida

$\underline{\text { Preço médo }}$

abacaxi

feijão

mamão

milho

mandioca 
Perenes

Qtd. vendida

$\underline{\text { Preço médo }}$

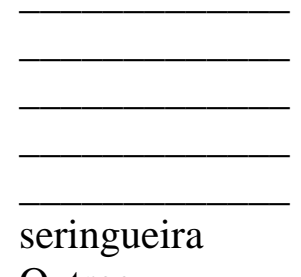

Outros

$\underline{\text { Produção animal e pastagem (nos últimos } 12 \text { meses) }}$

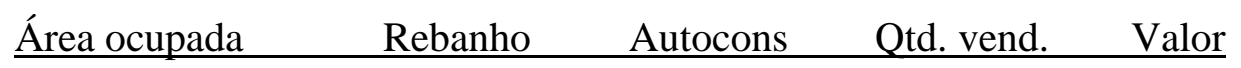

Aves

Bovinos

Caprinos

Suínos

Outros

$\underline{\text { Tecnologia de produção: }}$

Faz adubação química periódica?

Sim ( ) Não ( )

Roçagem periódica?

Sim ( ) Não ( )

Coloca fogo?

Anualmente

Sim ( ) Não ( )

Cada 2 anos

Sim ( ) Não ( )

Mais de 2 anos

Sim ( ) Não ( )

Curral de gado

Sim ( ) Não ( )

Quantidade de cerca (tipo e quantidade)

Já entrou fogo na propriedade?

Sim ( ) Não ( )

Caso sim, quais foram os prejuízos (última vez)?

Uso de insumos e medicamentos nas culturas e criações nos últimos 12 meses

Inseticida

Fungicida

Herbicida

Adubo químico

Adubo orgânico não/sim: tipo/Qtd/valor: não/sim: tipo/Qtd/valor: não/sim: tipo/Qtd/valor: não/sim: tipo/Qtd/valor: não/sim: tipo/Qtd/valor:
$\mathrm{R} \$$

$\mathrm{R} \$$

$\mathrm{R} \$$

$\mathrm{R} \$$

$\mathrm{R} \$$ 
Vacina/antibiótico

Sal mineral

Outro não/sim: tipo/Qtd/valor: não/sim: tipo/Qtd/valor: não/sim: tipo/Qtd/valor:
$\mathrm{R} \$$

$\mathrm{R} \$$

$\mathrm{R} \$$

Contratou mão-de obra nos últimos 12 meses?

Sim ( ) Não ( )

Em caso afirmativo, informar: cultura beneficiada, atividade executada, quantidade de diárias, época e valor das diárias.

\begin{tabular}{|l|l|l|l|l|}
\hline Cultura & Atividade & No. diárias & Época & Valor \\
\hline & & & & \\
\hline & & & & \\
\hline & & & & \\
\hline & & & & \\
\hline & & & & \\
\hline & & & & \\
\hline
\end{tabular}

$\underline{\text { Uso da Floresta/Madeira }}$

Tinha madeira de valor comercial no lote quando o Sr. Chegou? Sim ( ) Não ( )

Já tirou madeira de valor do lote?

Sim ( ) Não ( )

Ainda tem madeira de valor comercial no lote?

Sim ( ) Não ( )

Caso sim, o Sr. Pretende: tirar tudo o mais rápido possível

Sim ( ) Não ( )

Manter como reserva, e só tirar quando necessário

Sim ( ) Não ( )

Nesta região, qual é o valor dos seguintes tipos de terra?

Mata virgem

Mata após extração de madeira

Área desmatada recentemente

Área desmatada há mais de __anos

Área de capoeira

Áreas c/ SAF implantada recentemente

Áreas c/ SAF mais antiga

Por quanto venderia esta propriedade? 
REFERÊNCIAS BIBLIOGRÁFICAS

ABRAMOVAY, R. Paradigmas do capitalismo agrário em questão.

São Paulo: Anpocs; Unicamp: Hucitec, 1992. 150p.

ALBUQUERQUE, J. L. Avaliação econômica de alternativas de

financiamento da produção florestal no Estado de Minas

Gerais. Viçosa 1993. 102p. Dissertação (Mestrado)-

Universidade Federal de Viçosa

ALLEGRETTI, M. Reservas de extración: uma altrenativa para compatibilizar el desarrollo y la conservación en la Amazonia. In: ANDERSON, A. (Ed.). Alternativas a la Deforestación. Equador:Ediciones ABAYALA, 1990. p.395416 .

ALMEIDA, A.L.O. de. Colonização dirigida na Amazônia. Rio de Janeiro: IPEA, 1992. 482p. (IPEA, Série IPEA, 135).

ALVIM, P. T. Floresta amazônica: equilíbrio entre utilização e conservação. ILHEUS:CEPLAC/CEPEC, 1977. 20 $\mathrm{p}$.

ALVIM, P. T. Agricultura apropriada para uso contínuo dos solos na região amazônica. Espaço, Ambiente Planejamento, V. 11, n. 2, p. 1-72, 1990.

ALVIM, R.; VIRGENS,A. de C.E; ARAUJO,A.C. Agrossilvicultura como ciência de ganhar dinheiro com a terra: recuperação e renumeração de capital no estabelecimento de culturas perenes arbóreas. Ilhéus: CEPLAC/CEPEC 1989. 36 p. (Boletim Técnico) 
Assessoria e Serviços a Projetos em Agricultura Alternativa

A Horta Intensiva Familiar. AS-PTA, Rio de Janeiro-RJ, 1991. 50p.

AVILA, M. The economics of agroforestry systems. Faia: Financial and Economic Analysis of Agroforestry Systems, 1992. p. 77-94.

AZEVEDO, O. R. Agricultura familiar e reforma agrária. In. Programa de apoio à reforma agrária, V.1, n.3, p. 19-22, 1996.

BEER, J.; LUCAS, C.; KAPP, G. Reforestacion con sistemas agrosilviculturales permanentes vrs plantaciones puras. Agroforestería en las Américas, v. 1, n. 3, p. 21- 25, 1994 .

BENAVIDES, J.E. (Ed.) Arboles y arbustos forrajeros en América Central. Turrialba, Cost Rica: CATIE 1994. v. 2. $720 \mathrm{p}$.

BLUM, R. Agricultura familiar: estudo preliminar da definição, classificação e problemática. Passo Fundo: EDIUPF, 1999. 394p.

BROONKIRD, S.A.; FERNANDES, E.C.M.; NAIR, P.K.R. Forest villages: an agrofloresty approach to rehabilitating forest land degraded by shifiting cultivation in Thailand. Agroflorestry Systems, v.2, p. 87-102, 1984. BROWN, S.; LUGO, A.E. Tropical secondary forest. Journal of Tropical Ecology, V.6, p.1-32, 1990.

BRYANT, R. L. The Rise and fall of Taungya social forestry in defense of the empire. The Ecologist, v.24, n.1, p. 21-26, 1994 .

BUARQUE, C. Avaliação econômica de projetos. Rio de Janeiro: Editora Campus, 1984. p.130-178. 
BUDOWSKI, G. Na attempt to quantify some current agrofloresty practices in Costa Rica. In: HUXLEY, P.A. (Ed.). Plant Research and agroflorestry, ICRAF, Nairobi:, 1983. p.43-62.

BUDOWSKI G. Living fences in tropical America, a widespread agroforestry practice. In: GHOLZ, H. L. Agroforestry, realities and potentials. Dordrecht, Ho: Martinus Nijhoff 1987. p. 169-178.

CARVALHO,B.P. Cattle Ranching in the Amazon Part I Produção Pecuária na Região Amazônica e Desflorestação. Série de Estudos de Desenvolvimento e Gestão de Sistemas, v.2, n.4, p.18, 1996.

CARVALHO, E. F. Unidade didática e centro de treinamento para uma agricultura sustentável, lucrativa e adaptada às condições pedoclimáticas da região tropical úmida. Rio Branco-AC, 1999. 110p.

CASTRO,C.F.A. Biodiversidade e quintais. Rio de janeiro: FASE, 1999. p.27-33: Biodiversidade (Caderno de proposta, 3) .

CASTRO,R.;MOKATE,K. Evaluación económica y social de proyectos. Ediciones Uniandes: Colombia, 1998. 200p.

CAYRES, G.M.V. Nazarenos e Marias do rio Capim: análise de gênero em uma comunidade amazônica. Belém, 1999. 175p. Dissertação de (Mestrado)-Universidade Federal do Pará. COMBE, J.;BUDOWSKI, G. Classificación de las técnicas agroforestales: una revisión de literatura. TALLER SistemAs AgROFOREStALES EN AMERICA LATINA, Turrialba, 1979. Taller... Turrialba, Gonzalo de Las Salas, 1979. p. $17-48$. 
DANIEL,O.;COUTO,L.;VITORINO, A.C.T. Sistemas agroflorestais como alternativas sustentáveis à recuperação de pastagens degradadas. In: SIMPÓSIO SUSTENTABILIDADE DA PECUÁRIA DE LEITE NO BRASIL, 1, 1999, Juíz de Fora. Anais...Juíz de Fora: CNPGL, 1999. p.151-170.

DUBOIS, J.C.L. Manual agroflorestal para a Amazônia. Rio de Janeiro: REBRAF, 1996. V.1 74p.

ELEVITCH, C.;WILKINSON, K. A guide for orchard alley cropping for fertility, mulchand soil conservation http://www.agroforester.com.br/articules.html\# Anchor400038 (14 jun. de 2003).

ENGEL, V.L. Introdução aos sistemas agroflorestais. Botucatu: FEPAF, 1999. 70p.

Food and Agriculture Organization. Tropical Forest Resources. FAO, Rome, It. 1982. 1v.

FARO, C. Engenharia Econômica: elementos. São Paulo: APEC, 1972. 338p.

FEARNSIDE,P.M. Agricultura na Amazônia e tipos de agricultura: Padrões e Tendências. Núcleo de Altos Estudos Amazônicos. Belém: UFPa. 1989. p.197-252. (Cadernos do NAEA, 10).

FEARNSIDE,P.M. Reconsiderações do cultivo contínuo na Amazônia. Revista Brasileira de Biologia, v.50, n.4, p.833-840, 1990 .

FEARNSIDE,P.M. Agrosilvicultura na política de desenvilvimento na amazônia brasileira: A importância e os limites de seu uso em áreas degradadas. In: GASCON, C.; MOUTINHO, P. (Ed.) Floresta Amazônica: Dinâmica, Regeneração e Manejo. Instituto nacional de Pesquisas da Amazônia(INPA), Manaus: INPA 1998. p.293-312. 
FEARNSIDE,P.M.;BARBOSA,R.I. Soil carbon changes from conversion of forest to pasture in Brazilian Amazonia. Forest Ecology and Management, v.108, p.147-166, 1998.

FERREIRA, A.B.H., Novo Dicionário Aurélio. S.L: S.E, 1975. $1499 \mathrm{p}$.

FERREIRA, F.S.J.;REICHARDT,K.;MIRANDA, S.A.F. Características físicas de sedimentos e solos de dois lagos de várzea na amazônia central. Acta Amazônica, v.120, p.582-587, 1999. FERNANDES, E. C. M.; SERRÃO, E. A. S. Protótipo e modelos agrossilvipastoris sustentáveis. In: SIMDAMAZÔNIA: SEMINÁRIO INTERNACIONAL SOBRE MEIO AMBIENTE, Pobreza e Desenvolvimento da Amazônia. Belém, 1992. Anais. Belém: Secretaria de Estado de Ciência, Tecnologia e Meio Ambiente, p.245-251, 1992.

FERNANDES,E.C.M.; NEVES,E.J.M.; MATOS,J.C.S. Agroforestry, managed fallows and forest plamtations for rehabilitaiting deforested areas in The brazilian amazon. In: Forestry for Development: POLICY, ENVIROMENT, TECHNOLOGY AND MARKETS. PANAMERICAN FORESTRY CONGRESS, BRAZILIAN FORESTRE CONGRESS, 1994. Brazilian Society of Silvilculture Brazilain Society of Foretry, SP. Brasil, 1994 . p.96-101.

FERNANDES,E.C.M.;NAIR,P.K.R. An evaluation of the structure and function of tropical homegardens. Agricultural Systems, V.21, p.279-310, 1986.

FISCH, G.; MARENGO, J.A.; NOBRE,C.A. Uma revisão geral sobre o clima da Amazônia. Acta Amazônica,v.28, n.2, p.101-126, jun. 1998 . 
FLEBES, N. A. La diversidad biológica y cultural, raiz de la vida rural (Documentos BIODIVERSIDADE Sustentos y culturas, compendio 1997-1999). WwW.biodiversidad.org/documentos/documentos105.htm (18 de mayo 2002) .

FRANCO, A. A. Revegetação de solos degradados. In: WORKSHOP SOBRE RECUPERAÇÃO DE ÁREAS DEGRADADAS, 1., Itaguaí, RJ. 1990. Anais. Rio de Janeiro: Universidade Federal do Rio de Janeiro, 1991. p.133- 157.

FRANKE, I.L.A.; EUFRANF.L.; AURENYM.P. Sistemas Agroflorestais

no Estado do Acre: problemática geral, perspectivas, estado atual de conhecimento e pesquisa. Rio Branco: EMBRAPA, CPAF/AC, 1998. p.41 (Embrapa-CPAF/AC, documentos, 38).

GERWING, J. Degradation of forests through logging and fire in the eastern brazilian amazon. Forest Ecology and Management, V.157, n.1, p.131-141, 2002.

HARTMANN, W.D. Levantamento rápido rural (LRR). Belém: IBAMA, 1991.16 p. (Mimeografado).

HERNÁNDEZ, S ; BENAVIDES, J. Potencial forrajero de especies leñosas de los bosques secundarios de El Petén, Guatemala. Agroforestería en las Américas, V.2, n.6, p.15-22, 1995 .

HODNETT,M.G.; PIMENTEL,H.R. Seasonal soil water storange changes beneath central amazonian rainforest and pasture. Journal of Hydrology, v.170, p.233-254. 1995. HOFFMANN, R. Estatística para economista. 2. ed. São Paulo: Livraria Pioneira, 1991. 426p. 
HOMMA, A. K. O. A extração de recursos naturais renováveis: ocaso do extrativismo vegetal na amazônia. Viçosa, 1989. 575p. Tese de (Doutorado).-Universidade Federal de Viçosa.

HOMMA, A.K.O. Extrativismo vegetal na Amazônia: limites e oportunidades. Brasília: EMBRAPA/SPI, 1993. 362p.

HOMMA, A.K.O.; CONTO, A.J.; FERREIRA, C.A.P.; CARVALHO, R.A.; WALKER, R.T. A dinâmica da extração madeireira no Estado do Pará. In: HOMMA, A.K.O. (Ed.). Amazônia meio ambiente e desenvolvimento agrícola. Brasília: Embrapa, 1998. p.298-307.

HUXLEY,P.A. Plant Research and Agroflorestry. (ICRAF), Naiorobi, Ke: International Council for Research in Agrofloresty, 1983. 617p.

INSTITUTO NACIONAL DE METEOROLOGIA. http://www.inmet.gov.br/climátologia. (20 maio 2003) .

INSTITUO NACIONAL DE PESQUISAS ESPACIAIS (INPE). Amazônia: Deforestation 1995-1997. http://www.inpe.gov.Br. São José dos Campos, SP. Brasil. (17 junho 1998).

JONG, W. Swieden-fallow agroforestry in Amazônia: diversity at close distance. Agroforestry systems. v.34, p.277-290, 1996 .

JUNIOR, S. B.; YARED, J. A.G. Agroforestry systems as an ecological approach in the Brazilian Amazon development. Forest Ecology Manage, v.45, p319-323,1991.

JUNK, W. J. General aspects of floodplain ecology with reference to Amazonian floodplains. In: JUNK, W. J. (Ed.). The Central Amazon Floodplain - Ecological Stuies, v.126, Berlin: Springer-Verlag, 1997. p.3-20 
JUNK, W. J.; BAYLEY, P. B.; SPARKS, R. E. The flood pulse concept in river - floodplain systems In: DODGE, D. P. (Ed.). Proc Int Large River Symp (Lars). Canadian Spec Publ of Fish Aquatic Science, v.106, p.110-127. 1989.

KANG,B.T.; WILSON,G.F. The development of Alley Cropping as an promising agroforestry technology. In: STEPPLERS, $H$. A.E.; NAIR,P.K.R. (Ed.). Agroforestry, a decade of development. 1987. p.227-243.

KARMELL, P. H.; POLASEK, M. Estatística geral e aplicada à Economia. São Paulo: Atlas, 1973. 380 p.

KITAMURA, P.C. Agricultura migratória na Amazônia: um sistema de produção viável? Belém: EMBRAPA/CPATU, 1982. p.20 (EMBRAPA/CPATU, Documentos, 12).

KITAMURA, P. C. A Amazônia e o desenvolvimento sustentável. Brasilia: Embrapa-SPI 1994a. p.182.

KITAMURA, P.C. Desenvolvimento Sustentável: Uma abordagem para as questões Ambientais da Amazônia. Tese de (Doutorado) - Universidade de Campinas, 1994b. 298p.

KUBITZKI,K. The ecogeographical differentiation of Amazonian inundation forests. Plant system Evolution, $\mathrm{V} .162, \mathrm{p} .285-304,1989$.

LIMA JUNIOR, V. B. Determinação da taxa de desconto para uso na avaliação de projetos de investimento florestal. Viçosa, 1995. 90p. Dissertação (Mestrado)-Universidade Federal de Viçosa

LOPES CAVALCANTE, A. Variedades diferentes no bananal garantem bom lucro. Rio de Janeiro-RJ. Manchete Rural p.12-14, 1995 . 
$M^{\text {ac. }}$ DICKEN, K. G.; VERGARA, N. T. Agorofrestry: Classification and management. New York: John Wiley, 1990. $382 \mathrm{p}$.

MACEDO, M.C.M. Pastagens no ecossistema do cerrado: pesquisas para o desenvolvimento sustentável. In: ANDRADE, R.P.; BARCELOS, A.O.; ROCHA, C.M.C. (Ed.). SIMPÓSIO SOBRE PASTAGENS NOS ECOSSISTEMAS BRASILEIROS PESQUISAS PARA O DESENVOLVIMENTO SUSTENTÁVEL, 32 , Brasília, 1995. Anais Brasília: SBZ, 1995. p.28-62.

MACEDO, M.C.M; ZIMMER, A.H. Sistema pasto-lavoura e seus efeitos na produtividade agropecuária. In SIMPÓSIO SOBRE ECOSSISTEMAS DE PASTAGENS, 2., Jaboticabal, 1993. Anais. Jaboticabal: FUNEP, 1993. p.216- 245.

MACEDO, R.L.G. Sistemas agroflorestais com leguminosas arbóreas para recuperar áreas degradadas por atividades agropecuárias. In: SIMPÓSIO NACIONAL SOBRE RECUPERAÇÃO DE ÁREAS DEGRADADAS, 1., Curitiba, 1992. Anais. Curitiba: UFPR/FUPEF, 1992. p. 136-147.

MACEDO, R.L.G. Conservação e utilização sustentável da biodiversidade tropical através de sistemas agroflorestais. In: ENCONTRO NACIONAL DE ESTUDOS SOBRE O MEIO AMBIENTE, 4. Cuiabá, 1993. Anais . Cuiabá: UFMT, 1993. p.245-250.

MAYDELL, H. J. Agroforestry for tropical rainforest. Agroforestry Systems, V.13, p.259-267, 1991.

MEIRELLES, N.M.F. Degradação de pastagens: critérios de avaliação. In: ENCONTRO SOBRE RECUPERAÇÃO DE PASTAGENS, 1, Nova Odessa, 1993. Anais. Nova Odessa: Instituto de Zootecnia, 1993. p. 27-48. 
MITLESWSKI, B. Levantamento rápido rural (LRR). Belém: IBAMA, 1994. 8 p. (Mimeografado).

MONTAGNINI, F. (coord.). Sistemas agroflorestales: princípios y aplications en los tropicos. San José, Costa Rica: IICA, 1992. 622p.

MOROKAWA, T. Uso e manejo de florestas nativas. In: WORKSHOP SOBRE RECUPERAÇÃO DE ÁREAS DEGRADADAS, 1. Itaguaí, RJ, 1990. Anais Rio de Janeiro: Universidade Federal Rural do Rio de Janeiro, 1991. p. 33-54.

NACIONAL RESEARCH COUNCIL, Sustainable Agriculture and The Environment in the Humid Tropics. Sustainable Land Use Opitions, National Academy Press, Washington DC: 1993. p. 66-237.

NAIR, P. K. R. Classification of agroforestry systems. Agroforestry Systems, v.3, p.97-128, 1985.

NAIR, P.K.R. Agroforestry systems inventory. Agroforestry Systems, V.5, p.301-317, 1987.

NAIR, P. K. R. Na introduction to Agroforestry. Dordrecht: Kluwer, ICRAF. 1993. 499p.

NAIR,P.K.R.; FERNANDES,E. Agroforestry as an alternative to shifiting cultivation. In: Improved production systems as an alternative to shifiting cultivation. FAO. Rome: 1984. p.183-197. (FAO Soils Bulletins. 53).

NEWBOLD, P. Statistics for business and economics. 4.ed. New Jessy: Pruntice-Hall, 1994. 1v.

NODA, H.; NODA, S.N. Produção agropecuária. In: Amazônia: uma proposta interdisciplinar de educação ambiental. Brasília: IBAMA, 1994. p.133-153. 
OKIGBO, B. N. Improved permanent production systems as na alternative to shifting cultivation. Rome, It: FAO, 1985. p. 1-100. (FAO Soils Bulletin, 53).

OLIVEIRA, E. Um sistema computadorizado de prognose do crescimento e produção de Pinus com critérios quantitativos para a avaliação técnica e econômica de regimes de manejo. Curitiba, 1995. 134p. Tese (Doutorado) - Universidade Federal do Paraná.

OLIVEIRA, A. D.; MACEDO, R. L. G. Sistemas agroflorestais: considerações técnicas e econômicas. Lavras, MG: UFLA, 1996. 255p. (Projeto de consultoria).

ORGANIZATION TROPICAL STUDIES/CENTRO AGRONÓMICO TROPICAL DE INVESTIGACIÓN Y ENSEÑANZA. Sistemas agroforestales: principios y apllicaciones en los tropicos. San Jose: Organización para Estudios Tropicales/CATIE, 1986. 818p. PIRES, J. M. Tipos de vegetação da Amazônia. Publicação Avulsa. Museu Goeldi, v.20, p.179-202, 1973. PRANCE, G. T. The origin and evolution of the Amazon flora. Interciencia, v.3, p.207-230, 1978 . PRANCE, G. T. Notes on the vegetation of Amazonia III. The terminology of Amazon forest types subject to inundation. Brittonia, v.31, p.26-38, 1979.

PRANCE, G. T. American Tropical Forests. In: LIETH, H.; WERGER, M. J. A. (Ed.) Tropical rain forest ecosystems. Ecosystems of the word 14B. Amsterdam: Elsevier, 1989. p. 99-132.

PRICE, C. Economic evaluation of financial and no-financial costs and benefits in agroforestry development and value of sustainability. Agroforetry systems, v.30, p.75-86, 1995 . 
PORTO, M.S.G.; SIQUEIRA, D.E. A pequena produção no Brasil: entre os conceitos técnicos e as categorias empíricas. Cadernos de Sociologia. V.6, p.76-88, 1994.

REEVES, T. G. Susteinable Intensification of Agriculture. México: CYMMYT. 1998. 73p.

RÊGO, J. F. (coord). Análise econômica de sistemas básicos de produção familiar rural no vale do Acre. Rio Branco: UFAC, 1996. 53p. (Projeto de Pesquisa do Depto. De Economia da UFAC) .

REZENDE, J. L. P.; OLIVEIRA, A. D. Avaliação de projetos florestais Viçosa: UFV, 1993. 47p.

RODRIGUES, M. R. S.; SANTOS, J. A.; BARCELOS, E. Carbono e nitrogênio na biomassa aérea de cultivo de dendê em Latossolo Amarelo na Amazônia Ocidental. In.: CONGRESSO BRASILEIRO DE SISTEMAS AGROFLORESTAIS, Manaus-Am. 2000. Anais// Manaus: Editora, 2000. V.1.

SANCHEZ, M. D. Sistemas agroforestales para intensificación de manera sostenible la producción animal en América Latina. In: SÁNCHEZ, M. D.; MENDEZ, M. R. (Ed.). Agroforesteria para la producción animal en América Latina. 1999. Rome: FAO, 1999, p.1-13. (Estudio FAO Producción y Sanidad Animal).

SANCHEZ, P. A.; HOUTEN, VAN HELEN, Alternative to Slashand-Burn Agriculture. IN: INTERNATIONAL SOIL SCIENCE CONGRESS, Acapulco, Mexico, 1994. Anais. Acapulco: (editora) 1994. 119p.

SANTANA, A.C. de Análise econômica da produção agrícola sob condição de risco numa comunidade amazônica. Revista de Economia e Sociologia Rural, v.30, n.2, p.159-170, 1992. 
SANTANA, A.C.; QUEIROZ FILHO, E. S. P; TOURINHO, M. M. Exploração sustentável dos recursos pesqueiros na Amazônia: o caso da comunidade centro comercial. Belém: FCAP, 1996. 24 p. (FCAP. Informe Técnico, 19).

SANTANA, A. C, TOURINHO, M. M. Notas sobre AVALIAÇÃO SÓCIOECONÔMICA AGROFLORESTAIS NA AMAZÔNIA. In: Congresso Brasileiro de Economia e Sociologia rural, 36, Poços de Caldas: Sober, 1998. p 165-177.

SANTOS, M. J. C. Avaliação econômica de quatro modelos agroflorestais em áreas degradadas por pastagens na Amazônia Ocidental. Piracicaba, 2000. 75p. Dissertação (Mestrado) - Escola Superior de Agricultura "Luiz de Queiroz", Universidade de São Paulo.

SANTOS, M. A. S.; REBELLO, F.K.; LOPES, M.L. Análise de preços e margens de comercialização do frango de corte no Estado do Pará. Belém: BASA, 2000. 23 p. (Série Rural, 5).

SCHNEIDER, S. A pluriatividade na agricultura familiar. Porto Alegre: Editora da UFRGS, 2003. 359 p.

SILVA, E.S.O. Estudos sobre agricultura familiar no Estado do Rio de Janeiro: a ausência do PRONAF na Região Noroeste Fluminense. Geo UERJ - Revista do Departamento de Geografia, Rio de Janeiro, n. 13, p. 75-81. $1^{\circ}$ semestre de 2003 .

SKOLE, D.; TUCKER, C. Tropical deforestation and habitat fragmentation in the Amazon satellite data from 1978 to 1988. Science, V.260, p.1905-1910, 1993. 
SENA GOMES, A. R. Sistemas agrossilviculturais do sudeste da Bahia. In: ENCONTRO BRASILEIRO DE ECONOMIA E PLANEJAMENTO FLORESTAL. Curitiba, PR, 1991. Anais Curitiba: EMBRAPA/CNP Floresta, 1991.p. 109-122.

SERRÃO,E.A.S.; TOLEDO, J. M. The search for sustainability in amazonian pastures. In: ANDERSON, A. B. (Ed.) Alternatives to deforestation: Steps toward sustainable use of the Amazon forest. New York: Columbia University Press, 1990. p195-214.

SERRÃO, E.A.; NEPSTAD D.C.; WALKER, R. T. Desenvolvimento agropecuário e florestal de terra firme na Amazônia: sustentabilidade, criticabilidade e resiliência. In: HOMMA, A.K.O. (Ed.) Amazônia meio ambiente desenvolvimento agrícola. Brasília: Embrapa, 1998. Cap.14, p.367-386.

SERRÃO, E. A. S.; HOMMA, A. K. O. Agriculture in the amazon: The question of sustainability. S.L: S.Ed., 1991. SERRÃO,E.A. Modelo de Desenvolvimento Agropecuário e Floresta Sustentável para a Amazônia: A Proposta da Embrapa. In: CONGRESSO NACIONAL sobre essências nativas conservação e biodiversidade. Revista do Instituto Florestal v.4, p.413-426, 1992./Resumos.

SILVA, J. G. "Considerações acerca do futuro do campesinato no Brasil". IN:. CONGRESSO BRASILEIRO DE ECONOMIA E SOCIOLOGIA RURAL, 33. Curitiba, 1995. Anais. Curitiba: SOBER, 1995, 777p.

SILVA, L. F. da Manejo dos recursos naturais nos trópicos, contradições e pespectivas de uso com agricultura sustentável. In: MANEJO DE LOS RECURSOS NATURALES EN ECOSISTEMAS TROPICALES PARA UMA AGRICULTURA SOSTENIBLE Bagotá, Co. 1990. Anais Bogotá, Colômbia, 1990. 14p. 
SILVA, R. P. Simulação e avaliação econômica de um programa plurianual de reflorestamento para fins de planejamento da empresa florestal. Viçosa, 1990. 56p. Dissertação (Mestrado)-Universidade Federal de Viçosa.

SIOLI, H. Amazônia. Fundamentos da ecologia da maior região de florestas tropicais. 3. Ed. Petrópolis: Vozes, 1991. $72 \mathrm{p}$.

SMITH, N. J. H.; FALESI, I. C.; ALVIN, P. T. Agroforestry trajectories among smallholders in the Brazilian Amazon: innovation and resiliency in pioneer and older settled areas. Ecological Economics, v. 18, n. 1, p. 15-27, 1996. SOMARRIBA, E. Guayaba en potreros: establecimiento de cercas vivas y recuperación de pasturas degradadas en las américas. Agroforesteria en las Americas, v2, n.6, p. 27$29,1995$.

SWINKELS, R. A.; SCHERR, S. J. Economic analysis of agroforestry technologies: an annoted bibliography. Nairobi: ICRAF, 1991. 215 p.

SZOTT, L. T.; FERNANDES, E. C. M.; SANCHEZ, P. A. Soielplant interactions in agroforestry systems. Forest Ecology Mananger, v.45, p.127-152, 1991.

THUESEN, H. G; FABRYCKY, W. J; TAVESEN, G. J. Ingenieria economica. Madrid: 1991. 592p.

VAN-LEEUWEN, J.; GOMES, B. M. O pomar caseiro na região de Manaus, Amazonas, um importante sistema agroflorestal tradicional.http://www.inpa.gov.br/cpca/joha-pomar.html. (30 nov. 2001). 
VAN-LEEUWEN, J.; PEREIRA, M. M.; COSTA, F. C. T.; CATIQUE, F. A. Transforming shifting cultivation fields into productive forests. In: CONGRESSO BRASILEIRO SOBRE SISTEMAS AGROFLORESTAIS, $1 . ;$ ENCONTRO SOBRE SISTEMAS AGROFLORESTAIS NOS PAÍSES DO MERCOSUL, 1., Porto Velho, 1994. Anais. Colombo: EMBRAPA, 1994. v.2, p. 431-438.

VICENTE, C. M. "Novos dados sobre a estrutura social do desenvolvimento agrícola em São Paulo". Revista Reforma Agrária, v. 25, n. ${ }^{\circ}$ 2/3, p.215, 1995.

VIDAL, E.; VIANA,V.; BATISTA, JLF. Crescimento de florestas tropicais após colheita de madeira com e sem manejo florestal na Amazônia Oriental. Scientia Florestal, v. 61 p.133-143, 2002 .

VILAS BOAS, O. Uma breve descrição dos sistemas agroflorestais na América Latina. IF. Série Registros São Paulo, n.8, p.1-16, 1991.

VÍQUEZ, E. P. A.; OÑORO, P.; SOLANO, R. Caracterización del huerto mixto tropical. "La asunción", masatepe, Nicaragua. Agroforesteria en las Américas, v.1, n.2, p.5-9, 1994 .

WANDERLEY, M. N. B. Brasil: exploração familiar ou latifúndio? In: LAMARCHE, H. A Agricultura Familiar. Paris: L'Harmattan, 1994. v. 2, p. 20-27.

WEBSTER, C. C.; WILSON, P. N. Agriculture en the Tropics. London, UK: Longaman, 1980. p.390-400.

WILSON, J. R. Agrossilvicultura e fertilidade do solo. A décima primeira hipótese: Sombra. Agroforestry Today, v.2, n.1, p.14-15, 1990 . 
WINKLERPRINS, A. M. G. A. Between the Floods: soils and agriculture on the Lower Amazon Floodplain, Brazil. Madison, 1999, 362p. Thesis (PhD)-University of Wisconsin.

WINKLERPRINS, A. M. G. A.;D. G. McGrath, Smallholder Agriculture Along the Lower Amazon Floodplain, Brazil. PLEC News and Views, v.16, p.34-42, 2000.

WINKLERPRINS, A., M. G. A. Why context matters: local soil knowledge and management among an indigenous peasantry on the Lower Amazon floodplain, Brazil. Etnoecológica, v.5, n.7, p.6-20, 2001 .

YOUNG, A. Agroforetry for soil conservation. C.A.B. International. 1991. 276p.

ZIMMER, A.H.; MACEDO, M.C.M.; BARCELLOS, A.O.; KICHEL, A.N. Estabelecimento e recuperação de pastagens de Brachiaria. In: SIMPÓSIO SOBRE MANEJO DE PASTAGEM, 11. Piracicaba, 1994. Anais. Piracicaba: FEALQ, p. 153-208, 1994. 
APÊNDICES 


\section{Apêndice 1}

Informações originais dos dados de flutuação da cota do rio e precipitação na região de Manaus. 
Tabela 8: Valores originais da cota do Rio Negro, em metros, na região de Manaus. (AM), durante o período de 1980-2003.

\begin{tabular}{|c|c|c|c|c|c|c|c|c|c|c|c|c|c|}
\hline \multicolumn{14}{|c|}{ Meses } \\
\hline $\operatorname{lnos}$ & JAN & FEV & MAR & ABR & MAI & JUN & JUL & AGO & SET & OUT & NOV & DEZ & Médi \\
\hline$\overline{180}$ & 20,7 & 21,1 & 20,8 & 23,0 & 24,8 & 25,9 & 25,6 & 23,8 & 19,4 & 17,9 & 19,6 & 20,5 & 21, \\
\hline 181 & 20,8 & 21,8 & 23,8 & 25,3 & 26,2 & 26,7 & 26,2 & 25,1 & 21,4 & 18,1 & 17,3 & 18,4 & 22, \\
\hline 182 & 21,9 & 23,6 & 24,9 & 26,3 & 28,0 & 28,9 & 28,4 & 26,5 & 23,4 & 19,5 & 18,7 & 20,7 & 24 , \\
\hline 183 & 22,5 & 22,8 & 23,0 & 24,4 & 26,0 & 26,4 & 25,1 & 21,5 & 19,0 & 17,6 & 18,2 & 19,7 & 22, \\
\hline 184 & 22,0 & 23,5 & 25,2 & 26,1 & 27,2 & 27,9 & 27,7 & 26,3 & 23,6 & 20,5 & 19,9 & 20,4 & 24 , \\
\hline 185 & 22,9 & 23,5 & 23,1 & 23,4 & 24,4 & 25,8 & 26,0 & 24,9 & 23,3 & 20,8 & 20,1 & 21,2 & 23 , \\
\hline 186 & 21,8 & 22,5 & 24,2 & 25,7 & 26,8 & 27,6 & 28,1 & 27,0 & 23,9 & 21,7 & 22,4 & 23,2 & 24, \\
\hline 187 & 23,5 & 24,1 & 25,3 & 26,3 & 27,6 & 27,8 & 26,9 & 24,6 & 21,4 & 28,6 & 18,2 & 19,7 & 24 , \\
\hline 188 & 21,5 & 23,4 & 24,8 & 25,2 & 26,6 & 27,6 & 27,5 & 26,0 & 21,4 & 18,1 & 18,8 & 21,3 & 23, \\
\hline 189 & 22,1 & 24,2 & 26,1 & 27,4 & 28,3 & 27,2 & 29,2 & 28,2 & 25,6 & 21,6 & 21,7 & 20,8 & 25 , \\
\hline 190 & 18,9 & 22,4 & 24,9 & 24,3 & 27,6 & 28,2 & 27,8 & 26,5 & 23,3 & 18,2 & 17,4 & 20,4 & 23, \\
\hline 191 & 23,0 & 23,6 & 23,8 & 25,4 & 26,9 & 27,9 & 28,0 & 26,9 & 23,4 & 18,4 & 16,6 & 18,3 & 23 , \\
\hline 192 & 19,0 & 19,6 & 21,3 & 24,2 & 25,3 & 25,1 & 23,8 & 22,1 & 20,5 & 18,8 & 17,3 & 20,1 & 21, \\
\hline 193 & 22,7 & 24,1 & 25,5 & 27,3 & 28,3 & 28,7 & 28,2 & 26,3 & 23,4 & 20,4 & 20,4 & 23,0 & 24, \\
\hline 194 & 24,3 & 25,2 & 26,1 & 27,1 & 28,1 & 28,9 & 28,8 & 27,5 & 25,3 & 22,1 & 19,7 & 20,3 & 25 , \\
\hline 195 & 21,9 & 22,0 & 22,3 & 24,1 & 25,9 & 27,0 & 26,9 & 24,8 & 18,8 & 15,5 & 16,4 & 19,9 & 22, \\
\hline 196 & 21,9 & 23,4 & 25,4 & 26,6 & 27,6 & 28,4 & 28,2 & 26,5 & 23,2 & 19,4 & 19,6 & 20,7 & 24, \\
\hline 197 & 21,8 & 22,8 & 25,0 & 27,1 & 28,3 & 28,8 & 27,8 & 25,3 & 20,1 & 15,3 & 15,2 & 17,8 & 22 , \\
\hline 198 & 20,0 & 21,1 & 22,4 & 24,1 & 26,2 & 27,3 & 27,5 & 25,6 & 20,9 & 16,3 & 17,0 & 19,1 & 22, \\
\hline 199 & 20,8 & 23,9 & 26,1 & 27,0 & 28,4 & 29,2 & 29,0 & 27,8 & 24,8 & 19,9 & 17,6 & 17,8 & 24, \\
\hline 100 & 20,5 & 21,9 & 23,4 & 25,5 & 27,4 & 28,4 & 28,4 & 27,4 & 24,9 & 21,5 & 19,8 & 19,1 & 24, \\
\hline 101 & 20,6 & 23,4 & 25,0 & 26,6 & 27,5 & 28,1 & 27,7 & 26,1 & 22,6 & 18,7 & 17,4 & 18,7 & 23 , \\
\hline 102 & 22,1 & 22,7 & 24,4 & 26,1 & 27,6 & 28,7 & 28,7 & 27,4 & 24,8 & 19,7 & 18,7 & 20,9 & 24, \\
\hline 103 & 21,6 & 23,4 & 25,5 & 26,7 & 27,8 & 28,1 & 29,2 & 29,0 & 28,8 & 26,1 & 20,1 & 18,4 & 25 , \\
\hline dia & 21,61 & 22,92 & 24,27 & 25,62 & 27,03 & 27,69 & 27,52 & 25,95 & 22,79 & 19,77 & 18,67 & 20,01 & \\
\hline
\end{tabular}

Fonte: Portobras, 2003 . 
Tabela 9: Valores originais de precipitação, em milímetros, na região de Manaus.(AM), durante o período de 1980-2003.

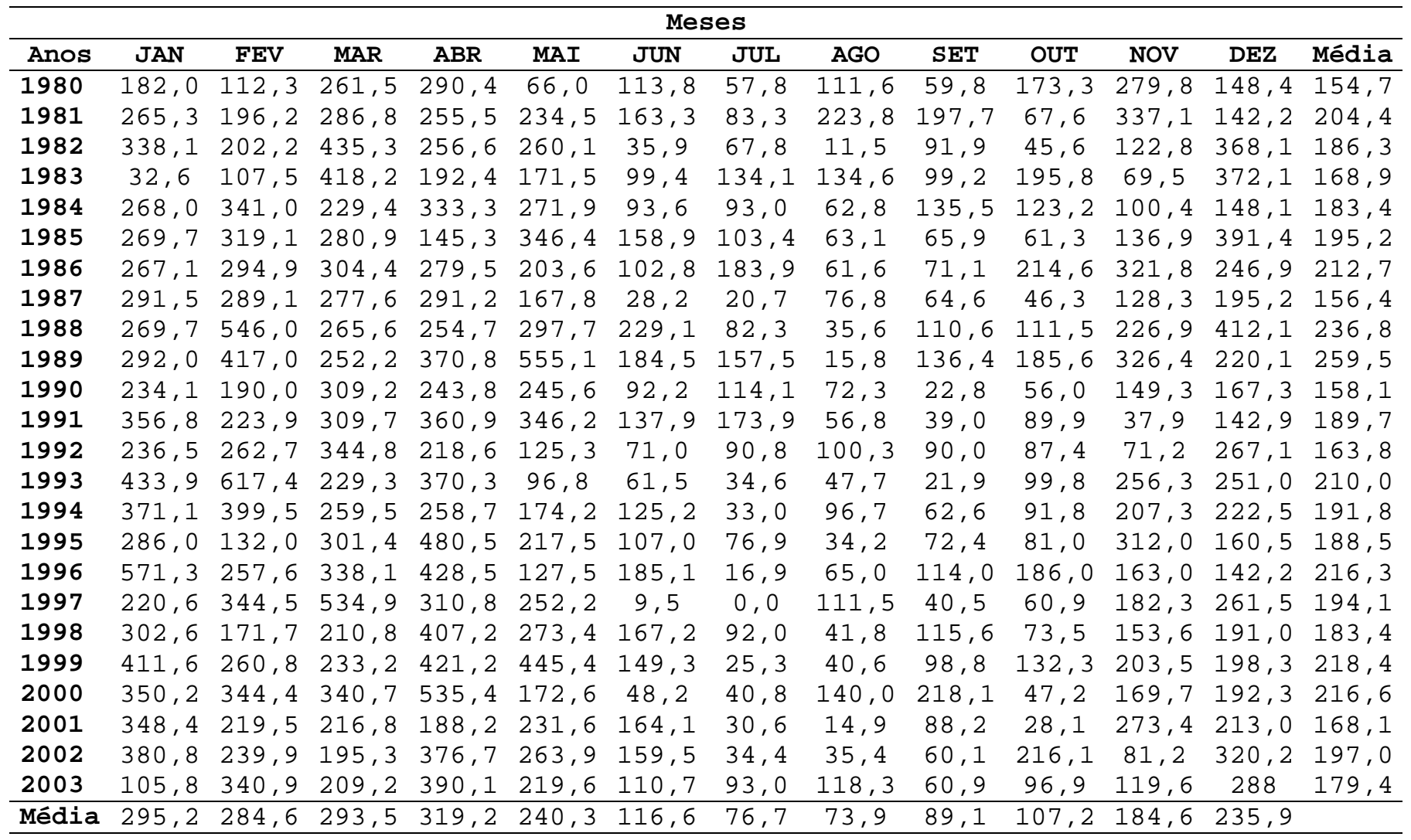

Fonte: $1^{\circ}$ Distrito de Meteorologia- $1^{\circ} \mathrm{DISME} / \mathrm{AM} / \mathrm{AC} / \mathrm{RR}-$ SEOMA, INMET, 2003. 


\section{Apêndice 2}

Informações originais dos preços de hortaliças praticadas nas feiras livre de Manaus. 
Tabela 10: Valores originais da Alface praticada nas feiras livre na região de Manaus. (AM), durante o período de 1980-2003.

\begin{tabular}{|c|c|c|c|c|c|c|c|c|}
\hline \multirow[b]{3}{*}{ Ano } & \multirow[b]{3}{*}{ Mês } & \multirow{2}{*}{$\begin{array}{l}\text { Feiras } \\
\text { Mns. }\end{array}$} & \multirow{2}{*}{$\begin{array}{l}\text { livres } \\
\text { Alvor }\end{array}$} & \multicolumn{3}{|c|}{ na região de Manaus } & \multirow{3}{*}{$\begin{array}{c}\text { Comp . } \\
2 \\
\end{array}$} & \multirow{3}{*}{$\begin{array}{c}\text { Média } \\
\text { (R\$) }\end{array}$} \\
\hline & & & & Zona & & ADolfo & & \\
\hline & & Moderna & 1 & Leste & Panair & Lisboa & & \\
\hline 1998 & Jan & 0,93 & 0,85 & 0,79 & 1,00 & 1,00 & 0,98 & 0,92 \\
\hline & Fev & 1,00 & 1,00 & 0,98 & 0,95 & 1,00 & 0,96 & 0,95 \\
\hline & Mar & 1,01 & 0,90 & 0,95 & 1,00 & 1,00 & 0,86 & 0,92 \\
\hline & Abr & 1,03 & 0,98 & 1,02 & 0,87 & 1,00 & 0,95 & 0,95 \\
\hline & Mai & 1,00 & 1,45 & 1,08 & 1,40 & 1,50 & 1,37 & 1,29 \\
\hline & Jun & 1,02 & 1,52 & 1,50 & 1,50 & 1,43 & 1,30 & 1,40 \\
\hline & Jul & 1,10 & 1,43 & 1,51 & 1,51 & 1,50 & 1,42 & 1,42 \\
\hline & Ago & 1,50 & 1,37 & 1,30 & 1,35 & 1,48 & 1,35 & 1,39 \\
\hline & Set & 1,20 & 1,32 & 1,25 & 1,10 & 0,95 & 0,90 & 1,10 \\
\hline & Out & 0,83 & 1,01 & 0,57 & 1,00 & 1,00 & 0,53 & 0,78 \\
\hline & $\mathrm{Nov}$ & 0,59 & 1,00 & 0,89 & 1,00 & 0,95 & 0,50 & 0,78 \\
\hline & Dez & 0,65 & 1,01 & 0,89 & 1,20 & 1,10 & 0,58 & 0,85 \\
\hline 1999 & Jan & 0,51 & 0,55 & 0,63 & 0,95 & 0,90 & 0,82 & 0,70 \\
\hline & Fev & 0,61 & 0,82 & 0,90 & 1,00 & 1,01 & 0,92 & 0,87 \\
\hline & Mar & 0,95 & 0,80 & 1,00 & 1,10 & 0,99 & 1,00 & 0,97 \\
\hline & Abr & 1,00 & 1,20 & 1,35 & 1,54 & 1,52 & 1,38 & 1,36 \\
\hline & Mai & 1,20 & 1,60 & 1,50 & 1,56 & 1,50 & 1,40 & 1,41 \\
\hline & Jun & 1,58 & 1,50 & 1,50 & 1,34 & 1,40 & 1,50 & 1,47 \\
\hline & Jul & 1,02 & 1,58 & 1,06 & 1,49 & 1,51 & 1,05 & 1,24 \\
\hline & Ago & 1,10 & 1,22 & 1,50 & 1,61 & 1,53 & 1,00 & 1,26 \\
\hline & Set & 1,10 & 1,22 & 1,40 & 1,58 & 1,50 & 1,00 & 1,23 \\
\hline & Out & 0,92 & 1,01 & 1,20 & 1,00 & 1,02 & 1,00 & 1,02 \\
\hline & $\mathrm{Nov}$ & 0,59 & 1,10 & 1,00 & 1,02 & 1,00 & 0,85 & 0,87 \\
\hline & Dez & 0,62 & 1,01 & 0,86 & 1,00 & 1,21 & 0,68 & 0,88 \\
\hline 2000 & Jan & 0,62 & 1,17 & 1,13 & 0,82 & 0,82 & 0,79 & 0,89 \\
\hline & $\mathrm{Fev}$ & 1,12 & 1,18 & 0,71 & 0,89 & 0,85 & 0,95 & 0,92 \\
\hline & Mar & 0,76 & 1,05 & 1,06 & 1,20 & 1,25 & 0,94 & 1,01 \\
\hline & Abr & 1,09 & 1,20 & 1,15 & 1,00 & 1,10 & 1,00 & 1,07 \\
\hline & Mai & 1,11 & 1,20 & 1,20 & 1,50 & 1,25 & 1,10 & 1,19 \\
\hline & Jun & 1,12 & 1,20 & 1,22 & 1,52 & 1,35 & 1,15 & 1,25 \\
\hline & Jul & 1,00 & 1,00 & 1,15 & 1,50 & 1,30 & 1,10 & 1,15 \\
\hline & Ago & 1,03 & 0,92 & 0,57 & 1,05 & 1,03 & 0,89 & 0,86 \\
\hline & Set & 0,83 & 0,90 & 0,58 & 0,54 & 0,58 & 0,64 & 0,67 \\
\hline & Out & 0,66 & 0,87 & 0,67 & 0,67 & 0,71 & 0,53 & 0,67 \\
\hline & Nov & 0,65 & 0,80 & 0,76 & 0,54 & 0,69 & 0,54 & 0,65 \\
\hline & Dez & 0,65 & 0,80 & 0,89 & 0,53 & 0,69 & 0,65 & 0,68 \\
\hline 2001 & Jan & 0,79 & 1,20 & 0,80 & 0,61 & 0,63 & 0,88 & 0,81 \\
\hline & Fev & 0,88 & 1,10 & 0,59 & 0,96 & 0,53 & 0,64 & 0,76 \\
\hline & Mar & 0,95 & 1,10 & 1,14 & 1,08 & 0,79 & 0,95 & 0,94 \\
\hline & Abr & 1,03 & 1,11 & 1,11 & 1,14 & 1,16 & 1,00 & 1,07 \\
\hline & Mai & 1,11 & 1,15 & 0,86 & 1,20 & 1,11 & 1,20 & 1,08 \\
\hline & Jun & 1,20 & 1,50 & 1,50 & 1,30 & 1,50 & 1,40 & 1,36 \\
\hline & Jul & 1,35 & 1,50 & 1,50 & 1,34 & 1,40 & 1,50 & 1,41 \\
\hline & Ago & 1,20 & 1,48 & 1,44 & 1,30 & 1,40 & 1,42 & 1,32 \\
\hline & Set & 1,10 & 1,22 & 1,50 & 1,61 & 1,53 & 1,00 & 1,26 \\
\hline
\end{tabular}




\begin{tabular}{|c|c|c|c|c|c|c|c|c|}
\hline & Out & 0,75 & 1,00 & 0,79 & 0,85 & 1,00 & 1,00 & 0,83 \\
\hline & Nov & 0,60 & 0,99 & 0,85 & 0,76 & 0,70 & 0,50 & 0,71 \\
\hline & Dez & 0,70 & 0,72 & 0,81 & 0,74 & 0,72 & 0,68 & 0,70 \\
\hline \multirow{12}{*}{2002} & Jan & 0,98 & 1,00 & 1,20 & 1,15 & 1,00 & 1,00 & 1,03 \\
\hline & Fev & 0,97 & 1,19 & 0,59 & 0,96 & 0,53 & 0,64 & 0,81 \\
\hline & Mar & 0,95 & 1,10 & 1,14 & 1,08 & 0,79 & 0,95 & 0,94 \\
\hline & $\mathrm{Abr}$ & 0,86 & 1,33 & 0,97 & 1,15 & 1,32 & 0,61 & 0,97 \\
\hline & Mai & 0,86 & 1,54 & 1,14 & 1,08 & 0,97 & 1,00 & 1,03 \\
\hline & Jun & 1,00 & 1,45 & 1,08 & 1,40 & 1,50 & 1,50 & 1,30 \\
\hline & Jul & 1,02 & 1,50 & 1,50 & 1,50 & 1,50 & 1,50 & 1,40 \\
\hline & Ago & 1,10 & 1,42 & 1,50 & 1,51 & 1,50 & 1,47 & 1,42 \\
\hline & Set & 1,10 & 1,37 & 1,30 & 1,36 & 1,47 & 1,35 & 1,33 \\
\hline & Out & 1,10 & 1,00 & 1,00 & 0,95 & 1,20 & 1,19 & 1,06 \\
\hline & Nov & 1,00 & 0,95 & 0,85 & 0,80 & 1,10 & 1,11 & 0,97 \\
\hline & Dez & 0,65 & 1,01 & 0,89 & 0,82 & 0,82 & 0,79 & 0,83 \\
\hline \multirow[t]{12}{*}{2003} & Jan & 1,38 & 1,16 & 0,87 & 1,20 & 1,40 & 0,96 & 1,14 \\
\hline & Fev & 1,03 & 1,01 & 0,57 & 1,05 & 1,03 & 0,89 & 0,87 \\
\hline & Mar & 0,83 & 1,00 & 0,58 & 0,54 & 0,61 & 0,64 & 0,69 \\
\hline & $\mathrm{Abr}$ & 0,66 & 1,10 & 0,76 & 0,67 & 0,71 & 0,53 & 0,70 \\
\hline & Mai & 1,11 & 1,38 & 0,93 & 1,01 & 1,25 & 0,96 & 1,10 \\
\hline & Jun & 1,13 & 1,08 & 1,20 & 1,11 & 1,13 & 0,99 & 1,10 \\
\hline & Jul & 1,24 & 1,20 & 0,98 & 1,13 & 1,38 & 0,95 & 1,13 \\
\hline & Ago & 1,10 & 1,40 & 1,06 & 1,15 & 1,21 & 1,20 & 1,17 \\
\hline & Set & 1,36 & 1,08 & 0,96 & 1,13 & 1,25 & 0,95 & 1,10 \\
\hline & Out & 1,02 & 1,20 & 0,91 & 1,00 & 1,30 & 0,96 & 1,05 \\
\hline & Nov & 0,89 & 1,00 & 0,89 & 1,00 & 1,10 & 1,00 & 0,96 \\
\hline & Dez & 0,75 & 0,98 & 0,89 & 0,92 & 1,02 & 0,99 & 0,91 \\
\hline
\end{tabular}

Fonte: SEMAF, SEPROR, 2003. 
Tabela 11: Valores originais da Batata Boce praticada nas feiras livre na região de Manaus.(AM), durante o período de 1980-2003.

\begin{tabular}{|c|c|c|c|c|c|c|c|c|}
\hline & & Feiras & livres & na reg: & ão de & Manaus & & \\
\hline Ano & Mês & $\begin{array}{c}\text { Mns. } \\
\text { Moderna }\end{array}$ & $\begin{array}{c}\text { Alvor } \\
1\end{array}$ & $\begin{array}{l}\text { Zona } \\
\text { Leste }\end{array}$ & Panair & $\begin{array}{l}\text { ADolfo } \\
\text { Lisboa }\end{array}$ & $\begin{array}{c}\text { Comp. } \\
2\end{array}$ & $\begin{array}{c}\text { Média } \\
\text { (R\$) }\end{array}$ \\
\hline \multirow[t]{12}{*}{1998} & Jan & 1,00 & 1,00 & 0,95 & 1,00 & 1,30 & 1,00 & 1,04 \\
\hline & Fev & 1,19 & 1,10 & 1,00 & 1,30 & 1,35 & 1,00 & 1,16 \\
\hline & Mar & 1,26 & 1,18 & 1,20 & 1,40 & 1,45 & 1,15 & 1,27 \\
\hline & Abr & 1,30 & 1,20 & 1,50 & 1,55 & 1,60 & 1,25 & 1,40 \\
\hline & Mai & 1,35 & 1,50 & 1,50 & 1,50 & 1,61 & 1,35 & 1,47 \\
\hline & Jun & 1,50 & 1,50 & 1,51 & 1,60 & 1,80 & 1,40 & 1,55 \\
\hline & Jul & 1,51 & 1,53 & 1,60 & 1,62 & 1,74 & 1,48 & 1,58 \\
\hline & Ago & 1,52 & 1,60 & 1,61 & 2,00 & 2,10 & 1,50 & 1,72 \\
\hline & Set & 1,52 & 1,60 & 1,63 & 2,00 & 2,00 & 1,50 & 1,71 \\
\hline & Out & 1,53 & 1,65 & 1,65 & 2,10 & 2,10 & 1,53 & 1,76 \\
\hline & Nov & 1,53 & 1,65 & 1,66 & 2,12 & 2,11 & 1,65 & 1,79 \\
\hline & Dez & 1,30 & 1,25 & 1,50 & 1,50 & 1,55 & 1,50 & 1,43 \\
\hline \multirow[t]{12}{*}{1999} & Jan & 1,10 & 1,10 & 1,12 & 1,30 & 1,50 & 1,20 & 1,22 \\
\hline & Fev & 1,12 & 1,15 & 1,15 & 1,35 & 1,50 & 1,22 & 1,25 \\
\hline & Mar & 1,15 & 1,18 & 1,13 & 1,36 & 1,60 & 1,23 & 1,28 \\
\hline & Abr & 1,18 & 1,20 & 1,15 & 1,50 & 1,85 & 1,25 & 1,36 \\
\hline & Mai & 1,19 & 1,25 & 1,20 & 1,52 & 1,85 & 1,30 & 1,39 \\
\hline & Jun & 1,20 & 1,30 & 1,35 & 1,60 & 1,95 & 1,45 & 1,48 \\
\hline & Jul & 1,28 & 1,33 & 1,40 & 1,66 & 2,00 & 1,50 & 1,53 \\
\hline & Ago & 1,35 & 1,30 & 1,60 & 2,00 & 2,00 & 1,52 & 1,63 \\
\hline & Set & 1,36 & 1,34 & 1,55 & 2,00 & 1,90 & 1,51 & 1,61 \\
\hline & Out & 1,30 & 1,31 & 1,50 & 1,85 & 2,00 & 1,50 & 1,58 \\
\hline & Nov & 1,25 & 1,30 & 1,31 & 1,81 & 1,97 & 1,49 & 1,52 \\
\hline & Dez & 1,21 & 1,20 & 1,25 & 1,50 & 1,80 & 1,30 & 1,38 \\
\hline \multirow[t]{12}{*}{2000} & Jan & 1,10 & 1,10 & 1,08 & 1,30 & 1,40 & 1,20 & 1,20 \\
\hline & Fev & 1,20 & 1,20 & 1,15 & 1,35 & 1,42 & 1,20 & 1,25 \\
\hline & Mar & 1,20 & 1,21 & 1,28 & 1,38 & 1,50 & 1,20 & 1,30 \\
\hline & Abr & 1,25 & 1,25 & 1,35 & 1,40 & 1,52 & 1,25 & 1,34 \\
\hline & Mai & 1,30 & 1,30 & 1,38 & 1,55 & 1,60 & 1,30 & 1,41 \\
\hline & Jun & 1,30 & 1,38 & 1,50 & 2,00 & 1,90 & 1,31 & 1,57 \\
\hline & Jul & 1,30 & 1,41 & 1,52 & 2,10 & 2,00 & 1,50 & 1,64 \\
\hline & Ago & 1,36 & 1,50 & 1,64 & 2,00 & 2,00 & 1,60 & 1,68 \\
\hline & Set & 1,45 & 1,50 & 1,65 & 2,12 & 2,10 & 1,62 & 1,74 \\
\hline & Out & 1,48 & 1,50 & 1,50 & 2,00 & 2,00 & 1,74 & 1,70 \\
\hline & Nov & 1,50 & 1,53 & 1,45 & 2,00 & 2,00 & 1,70 & 1,70 \\
\hline & Dez & 1,38 & 1,50 & 1,35 & 1,90 & 1,85 & 1,50 & 1,58 \\
\hline \multirow[t]{7}{*}{2001} & Jan & 1,05 & 1,10 & 1,06 & 1,30 & 1,31 & 1,20 & 1,17 \\
\hline & Fev & 1,10 & 1,11 & 1,15 & 1,45 & 1,50 & 1,20 & 1,25 \\
\hline & Mar & 1,15 & 1,17 & 1,20 & 1,60 & 1,60 & 1,20 & 1,32 \\
\hline & Abr & 1,20 & 1,20 & 1,21 & 1,71 & 1,70 & 1,40 & 1,40 \\
\hline & Mai & 1,25 & 1,21 & 1,22 & 1,80 & 1,80 & 1,45 & 1,46 \\
\hline & Jun & 1,25 & 1,30 & 1,22 & 1,80 & 1,85 & 1,50 & 1,49 \\
\hline & Jul & 1,28 & 1,35 & 1,50 & 1,89 & 2,00 & 1,60 & 1,60 \\
\hline
\end{tabular}




\begin{tabular}{|c|c|c|c|c|c|c|c|c|}
\hline & Ago & 1,45 & 1,40 & 1,65 & 1,95 & 2,00 & 1,61 & 1,68 \\
\hline & Set & 1,50 & 1,50 & 1,60 & 2,00 & 2,00 & 1,50 & 1,68 \\
\hline & Out & 1,51 & 1,55 & 1,58 & 2,00 & 1,90 & 1,48 & 1,67 \\
\hline & Nov & 1,53 & 1,51 & 1,50 & 2,00 & 1,90 & 1,32 & 1,63 \\
\hline & Dez & 1,25 & 1,45 & 1,50 & 1,90 & 1,80 & 1,30 & 1,53 \\
\hline \multirow[t]{12}{*}{2002} & Jan & 1,10 & 1,02 & 1,06 & 1,10 & 1,12 & 1,12 & 1,09 \\
\hline & Fev & 1,10 & 1,10 & 1,00 & 1,15 & 1,20 & 1,15 & 1,12 \\
\hline & Mar & 1,12 & 1,12 & 1,12 & 1,23 & 1,50 & 1,20 & 1,22 \\
\hline & Abr & 1,20 & 1,15 & 1,20 & 1,30 & 1,50 & 1,21 & 1,26 \\
\hline & Mai & 1,25 & 1,20 & 1,25 & 1,50 & 1,52 & 1,23 & 1,33 \\
\hline & Jun & 1,27 & 1,30 & 1,30 & 1,50 & 1,60 & 1,31 & 1,38 \\
\hline & Jul & 1,31 & 1,30 & 1,32 & 1,50 & 2,00 & 1,30 & 1,46 \\
\hline & Ago & 1,42 & 1,37 & 1,50 & 1,64 & 2,00 & 1,50 & 1,57 \\
\hline & Set & 1,50 & 1,62 & 1,50 & 1,70 & 2,10 & 1,50 & 1,65 \\
\hline & Out & 1,30 & 1,50 & 1,43 & 2,00 & 2,15 & 1,46 & 1,64 \\
\hline & Nov & 1,25 & 1,50 & 1,30 & 2,00 & 2,10 & 1,30 & 1,58 \\
\hline & Dez & 1,20 & 1,23 & 1,20 & 1,50 & 1,90 & 1,28 & 1,39 \\
\hline \multirow[t]{12}{*}{2003} & Jan & 1,10 & 1,10 & 1,08 & 1,12 & 1,20 & 1,00 & 1,10 \\
\hline & Fev & 1,11 & 1,10 & 1,10 & 1,15 & 1,30 & 1,05 & 1,14 \\
\hline & Mar & 1,13 & 1,10 & 1,13 & 1,30 & 1,50 & 1,10 & 1,21 \\
\hline & Abr & 1,20 & 1,12 & 1,20 & 1,32 & 1,56 & 1,18 & 1,26 \\
\hline & Mai & 1,20 & 1,21 & 1,20 & 1,50 & 1,60 & 1,19 & 1,32 \\
\hline & Jun & 1,35 & 1,25 & 1,50 & 1,95 & 1,95 & 1,40 & 1,57 \\
\hline & Jul & 1,38 & 1,25 & 1,50 & 2,00 & 2,00 & 1,63 & 1,63 \\
\hline & Ago & 1,40 & 1,30 & 1,53 & 2,00 & 2,10 & 1,50 & 1,64 \\
\hline & Set & 1,42 & 1,30 & 1,60 & 2,00 & 2,00 & 1,52 & 1,64 \\
\hline & Out & 1,50 & 1,32 & 1,66 & 2,00 & 2,00 & 1,62 & 1,68 \\
\hline & Nov & 1,30 & 1,25 & 1,50 & 1,80 & 1,70 & 1,36 & 1,49 \\
\hline & Dez & 1,20 & 1,18 & 1,40 & 1,50 & 1,60 & 1,20 & 1,35 \\
\hline
\end{tabular}

Fonte: SEMAF, SEPROR, 2003. 
Tabela 12: Valores originais do Pepino praticada nas feiras livre na região de Manaus. (AM), durante o período de 1980-2003.

\begin{tabular}{|c|c|c|c|c|c|c|c|c|}
\hline & & Feiras & livres & na reg & Lão de 1 & Manaus & & \\
\hline Ano & Mês & $\begin{array}{c}\text { Mns. } \\
\text { Moderna }\end{array}$ & $\begin{array}{c}\text { Alvor } \\
1\end{array}$ & $\begin{array}{l}\text { Zona } \\
\text { Leste }\end{array}$ & Panair & $\begin{array}{l}\text { ADolfo } \\
\text { Lisboa }\end{array}$ & $\begin{array}{c}\text { Comp. } \\
2\end{array}$ & $\begin{array}{l}\text { Média } \\
\text { (R\$) }\end{array}$ \\
\hline \multirow[t]{12}{*}{1998} & Jan & 0,75 & 0,95 & 1,00 & 0,80 & 1,20 & 1,12 & 0,97 \\
\hline & Fev & 0,70 & 0,90 & 0,90 & 0,75 & 1,15 & 1,00 & 0,90 \\
\hline & Mar & 0,65 & 0,80 & 0,85 & 0,75 & 1,10 & 0,95 & 0,85 \\
\hline & Abr & 0,60 & 0,75 & 0,75 & 0,68 & 1,00 & 0,90 & 0,78 \\
\hline & Mai & 0,50 & 0,70 & 0,60 & 0,70 & 1,00 & 1,00 & 0,75 \\
\hline & Jun & 0,65 & 1,00 & 1,13 & 0,94 & 1,35 & 1,50 & 1,10 \\
\hline & Jul & 0,80 & 1,00 & 1,20 & 1,00 & 1,50 & 1,75 & 1,21 \\
\hline & Ago & 1,00 & 1,25 & 1,25 & 1,12 & 1,70 & 1,83 & 1,36 \\
\hline & Set & 1,10 & 1,35 & 1,28 & 1,20 & 1,90 & 2,00 & 1,47 \\
\hline & Out & 1,10 & 1,50 & 1,50 & 1,48 & 2,00 & 2,10 & 1,61 \\
\hline & Nov & 1,00 & 1,30 & 1,30 & 1,20 & 1,60 & 2,10 & 1,42 \\
\hline & Dez & 0,90 & 1,00 & 1,20 & 1,00 & 1,30 & 2,00 & 1,23 \\
\hline \multirow[t]{12}{*}{1999} & Jan & 0,77 & 0,93 & 0,85 & 0,81 & 1,19 & 1,08 & 0,94 \\
\hline & Fev & 0,71 & 0,90 & 0,80 & 0,75 & 1,16 & 1,00 & 0,89 \\
\hline & Mar & 0,65 & 0,80 & 0,75 & 0,73 & 1,10 & 1,00 & 0,84 \\
\hline & Abr & 0,62 & 0,77 & 0,71 & 0,66 & 1,03 & 0,90 & 0,78 \\
\hline & Mai & 0,60 & 0,70 & 0,60 & 0,61 & 1,00 & 0,87 & 0,73 \\
\hline & Jun & 0,65 & 0,90 & 1,00 & 0,92 & 1,40 & 1,45 & 1,05 \\
\hline & Jul & 0,88 & 1,00 & 1,11 & 0,99 & 1,52 & 1,68 & 1,20 \\
\hline & Ago & 0,89 & 1,12 & 1,25 & 1,00 & 1,68 & 1,73 & 1,28 \\
\hline & Set & 0,90 & 1,22 & 1,28 & 1,15 & 1,90 & 1,89 & 1,39 \\
\hline & Out & 1,00 & 1,00 & 1,30 & 1,20 & 1,97 & 1,94 & 1,40 \\
\hline & Nov & 0,87 & 0,92 & 1,15 & 1,20 & 1,56 & 1,80 & 1,25 \\
\hline & Dez & 0,69 & 0,90 & 1,10 & 0,95 & 1,30 & 1,50 & 1,07 \\
\hline \multirow[t]{12}{*}{2000} & Jan & 0,70 & 0,90 & 1,00 & 0,90 & 1,20 & 1,30 & 1,00 \\
\hline & Fev & 0,69 & 0,89 & 0,92 & 0,86 & 1,18 & 1,25 & 0,97 \\
\hline & Mar & 0,65 & 0,85 & 0,83 & 0,80 & 1,00 & 1,00 & 0,86 \\
\hline & Abr & 0,62 & 0,80 & 0,80 & 0,80 & 1,00 & 0,95 & 0,83 \\
\hline & Mai & 0,60 & 0,75 & 0,76 & 0,75 & 0,95 & 0,87 & 0,78 \\
\hline & Jun & 0,75 & 0,89 & 0,87 & 0,86 & 1,36 & 1,45 & 1,03 \\
\hline & Jul & 0,83 & 0,91 & 1,16 & 0,99 & 1,54 & 1,50 & 1,16 \\
\hline & Ago & 0,89 & 1,16 & 1,25 & 1,00 & 1,60 & 1,69 & 1,27 \\
\hline & Set & 0,90 & 1,25 & 1,30 & 1,18 & 1,84 & 1,80 & 1,38 \\
\hline & Out & 1,12 & 1,00 & 1,30 & 1,20 & 1,97 & 1,87 & 1,41 \\
\hline & Nov & 0,96 & 1,00 & 1,20 & 1,21 & 1,60 & 1,80 & 1,30 \\
\hline & Dez & 0,90 & 0,89 & 1,00 & 1,00 & 1,29 & 1,67 & 1,13 \\
\hline \multirow[t]{6}{*}{2001} & Jan & 0,88 & 0,82 & 0,93 & 0,91 & 1,20 & 1,35 & 1,02 \\
\hline & Fev & 0,75 & 0,80 & 0,85 & 0,80 & 1,19 & 1,20 & 0,93 \\
\hline & Mar & 0,70 & 0,80 & 0,80 & 0,73 & 1,10 & 1,00 & 0,86 \\
\hline & Abr & 0,70 & 0,76 & 0,75 & 0,71 & 1,03 & 1,00 & 0,83 \\
\hline & Mai & 0,73 & 0,70 & 0,70 & 0,70 & 1,00 & 0,95 & 0,80 \\
\hline & Jun & 0,65 & 0,94 & 0,99 & 0,95 & 1,35 & 1,36 & 1,04 \\
\hline
\end{tabular}




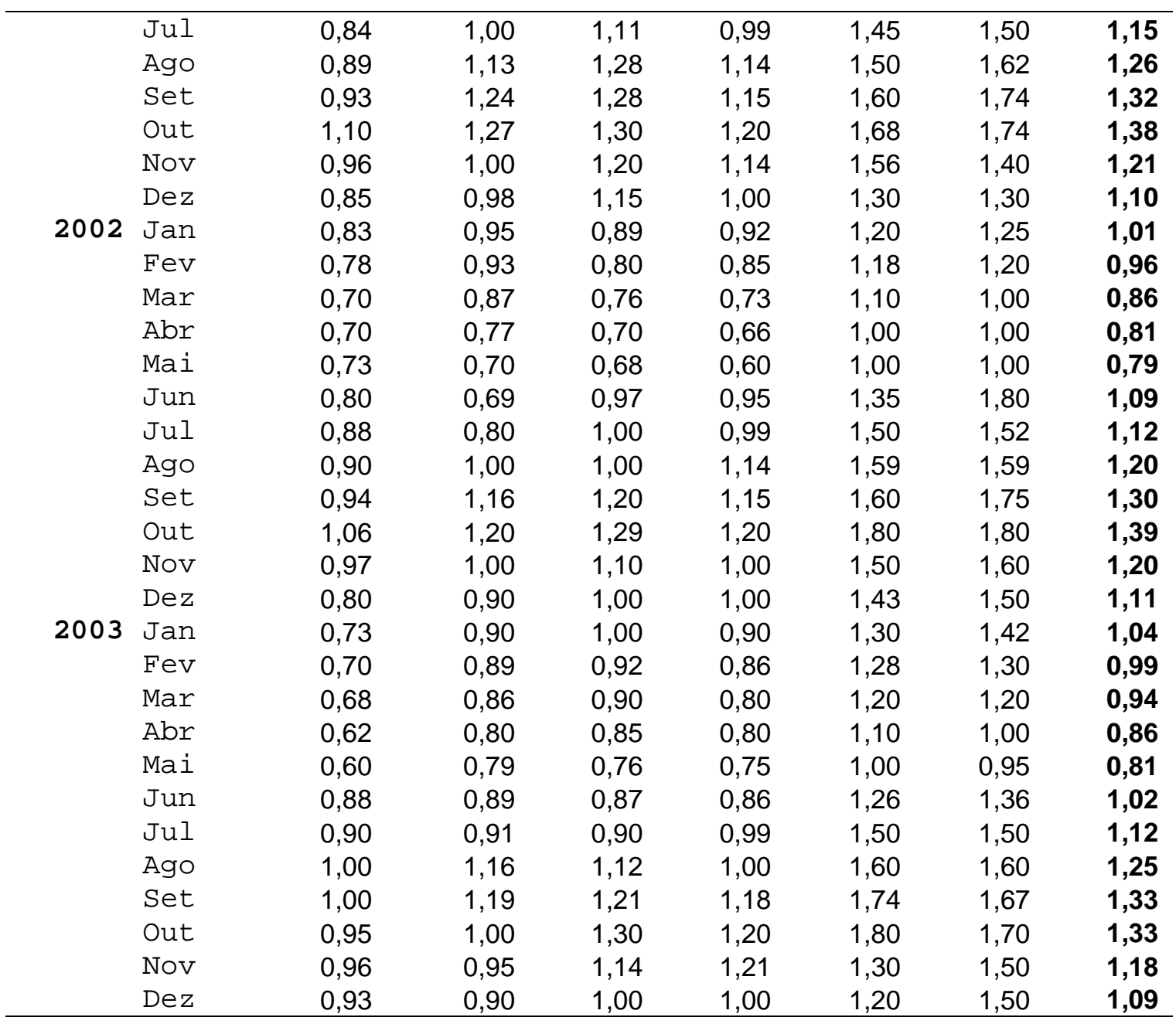

Fonte: SEMAF, SEPROR, 2003. 
Tabela 13: Valores originais do Maxixe praticada nas feiras livre na região de Manaus.(AM), durante o período de $1980-2003$.

\begin{tabular}{|c|c|c|c|c|c|c|c|c|}
\hline & & Feiras & livres & na re & ião de & Manaus & & \\
\hline Ano & Mês & $\begin{array}{c}\text { Mns. } \\
\text { Moderna }\end{array}$ & $\begin{array}{c}\text { Alvor } \\
1\end{array}$ & $\begin{array}{l}\text { Zona } \\
\text { Leste }\end{array}$ & Panair & $\begin{array}{l}\text { ADolfo } \\
\text { Lisboa }\end{array}$ & $\begin{array}{l}\text { Comp. } \\
2\end{array}$ & $\begin{array}{l}\text { Média } \\
\text { (R\$) }\end{array}$ \\
\hline \multirow[t]{12}{*}{1998} & Jan & 0,75 & 1,95 & 0,90 & 1,30 & 2,00 & 0,90 & 1,30 \\
\hline & Fev & 0,75 & 2,00 & 1,00 & 1,25 & 2,00 & 0,83 & 1,31 \\
\hline & Mar & 1,00 & 2,10 & 1,23 & 1,85 & 2,10 & 1,00 & 1,55 \\
\hline & Abr & 1,50 & 2,10 & 1,20 & 2,10 & 2,54 & 1,50 & 1,82 \\
\hline & Mai & 1,50 & 2,30 & 1,50 & 2,30 & 2,75 & 2,00 & 2,06 \\
\hline & Jun & 2,00 & 2,41 & 1,50 & 2,50 & 2,84 & 2,00 & 2,21 \\
\hline & Jul & 2,10 & 2,50 & 1,80 & 2,50 & 3,00 & 2,10 & 2,33 \\
\hline & Ago & 2,10 & 2,32 & 1,83 & 2,55 & 2,95 & 1,30 & 2,18 \\
\hline & Set & 1,00 & 2,23 & 1,72 & 2,50 & 2,80 & 1,10 & 1,89 \\
\hline & Out & 0,89 & 2,00 & 1,61 & 2,30 & 2,70 & 1,00 & 1,75 \\
\hline & Nov & 0,80 & 1,80 & 1,50 & 2,00 & 2,65 & 0,98 & 1,62 \\
\hline & Dez & 0,80 & 1,90 & 0,98 & 1,50 & 2,00 & 0,93 & 1,35 \\
\hline \multirow[t]{12}{*}{1999} & Jan & 0,79 & 1,89 & 0,90 & 1,45 & 1,98 & 0,92 & 1,32 \\
\hline & Fev & 0,76 & 2,00 & 0,97 & 1,38 & 2,00 & 0,90 & 1,34 \\
\hline & Mar & 1,00 & 2,05 & 1,00 & 1,74 & 2,00 & 1,00 & 1,47 \\
\hline & Abr & 1,45 & 2,10 & 1,10 & 2,00 & 2,10 & 1,58 & 1,72 \\
\hline & Mai & 1,50 & 2,25 & 1,46 & 2,12 & 2,84 & 1,90 & 2,01 \\
\hline & Jun & 2,00 & 2,35 & 1,50 & 2,51 & 2,94 & 2,00 & 2,22 \\
\hline & Jul & 2,08 & 2,34 & 1,75 & 2,52 & 2,96 & 2,10 & 2,29 \\
\hline & Ago & 2,10 & 2,32 & 1,80 & 2,55 & 2,95 & 1,30 & 2,17 \\
\hline & Set & 1,00 & 2,20 & 1,75 & 2,48 & 2,94 & 1,25 & 1,94 \\
\hline & Out & 0,98 & 2,00 & 1,70 & 2,30 & 2,80 & 1,00 & 1,80 \\
\hline & Nov & 0,80 & 1,90 & 1,65 & 2,00 & 2,50 & 1,00 & 1,64 \\
\hline & Dez & 0,79 & 1,85 & 1,35 & 1,50 & 2,00 & 0,93 & 1,40 \\
\hline \multirow[t]{12}{*}{2000} & Jan & 0,70 & 1,82 & 0,90 & 1,48 & 2,00 & 0,92 & 1,30 \\
\hline & Fev & 0,70 & 1,90 & 0,98 & 1,40 & 1,90 & 0,90 & 1,30 \\
\hline & Mar & 0,85 & 2,00 & 0,99 & 1,50 & 2,00 & 0,90 & 1,37 \\
\hline & Abr & 1,10 & 2,05 & 1,00 & 1,89 & 2,08 & 1,00 & 1,52 \\
\hline & Mai & 1,35 & 2,15 & 1,10 & 2,00 & 2,10 & 1,40 & 1,68 \\
\hline & Jun & 1,80 & 2,20 & 1,48 & 2,10 & 2,50 & 1,48 & 1,93 \\
\hline & Jul & 1,90 & 2,30 & 1,65 & 2,50 & 2,84 & 1,90 & 2,18 \\
\hline & Ago & 2,10 & 2,32 & 1,80 & 2,55 & 3,00 & 1,85 & 2,27 \\
\hline & set & 2,00 & 2,35 & 1,79 & 2,62 & 2,94 & 1,50 & 2,20 \\
\hline & Out & 1,50 & 2,00 & 1,70 & 2,50 & 2,86 & 1,30 & 1,98 \\
\hline & Nov & 1,00 & 1,90 & 1,60 & 2,10 & 2,70 & 1,00 & 1,72 \\
\hline & Dez & 0,85 & 1,87 & 1,20 & 1,50 & 2,63 & 0,93 & 1,50 \\
\hline \multirow[t]{4}{*}{2001} & Jan & 0,80 & 1,80 & 1,10 & 1,36 & 2,50 & 0,90 & 1,41 \\
\hline & Fev & 0,75 & 1,95 & 1,00 & 1,30 & 2,30 & 0,83 & 1,36 \\
\hline & Mar & 0,98 & 2,00 & 1,50 & 1,50 & 2,25 & 1,10 & 1,56 \\
\hline & Abr & 1,00 & 2,10 & 1,56 & 1,80 & 2,50 & 1,30 & 1,71 \\
\hline
\end{tabular}




\begin{tabular}{|c|c|c|c|c|c|c|c|c|}
\hline \multicolumn{2}{|c|}{ Mai } & 1,50 & 2,28 & 1,50 & 2,00 & 2,80 & 1,50 & 1,93 \\
\hline & Jun & 2,00 & 2,34 & 1,50 & 2,10 & 2,84 & 1,89 & 2,11 \\
\hline & Jul & 2,10 & 2,34 & 1,70 & 2,40 & 2,90 & 1,88 & 2,22 \\
\hline & Ago & 2,10 & 2,32 & 1,85 & 2,53 & 3,00 & 1,50 & 2,22 \\
\hline & Set & 1,90 & 2,23 & 1,75 & 2,48 & 3,00 & 1,35 & 2,12 \\
\hline & Out & 1,50 & 2,00 & 1,70 & 2,38 & 2,80 & 1,00 & 1,90 \\
\hline & Nov & 0,98 & 1,90 & 1,60 & 2,00 & 2,74 & 1,00 & 1,70 \\
\hline & Dez & 0,90 & 1,87 & 1,50 & 1,50 & 2,60 & 1,00 & 1,56 \\
\hline \multirow[t]{12}{*}{2002} & Jan & 0,85 & 1,85 & 1,20 & 1,46 & 1,98 & 0,92 & 1,38 \\
\hline & Fev & 0,78 & 1,95 & 1,15 & 1,40 & 1,95 & 0,90 & 1,36 \\
\hline & Mar & 0,98 & 2,00 & 1,15 & 1,65 & 1,95 & 0,99 & 1,45 \\
\hline & Abr & 1,20 & 2,00 & 1,20 & 1,90 & 2,00 & 1,00 & 1,55 \\
\hline & Mai & 1,35 & 2,10 & 1,30 & 2,00 & 2,10 & 1,23 & 1,68 \\
\hline & Jun & 1,50 & 2,20 & 1,50 & 2,10 & 2,50 & 1,25 & 1,84 \\
\hline & Jul & 1,80 & 2,25 & 1,55 & 2,25 & 2,52 & 1,60 & 2,00 \\
\hline & Ago & 2,00 & 2,30 & 1,70 & 2,35 & 2,70 & 1,50 & 2,09 \\
\hline & Set & 2,05 & 2,23 & 1,75 & 2,49 & 2,93 & 1,20 & 2,11 \\
\hline & Out & 1,80 & 2,10 & 1,79 & 2,40 & 2,80 & 1,00 & 1,98 \\
\hline & Nov & 1,50 & 2,00 & 1,60 & 1,90 & 2,65 & 0,95 & 1,77 \\
\hline & Dez & 1,00 & 1,87 & 1,50 & 1,50 & 2,35 & 0,98 & 1,53 \\
\hline \multirow[t]{12}{*}{2003} & Jan & 0,85 & 1,82 & 1,10 & 1,48 & 1,90 & 0,92 & 1,35 \\
\hline & Fev & 0,70 & 1,75 & 1,00 & 1,38 & 1,90 & 0,90 & 1,27 \\
\hline & Mar & 0,90 & 1,80 & 0,99 & 1,40 & 1,85 & 0,90 & 1,31 \\
\hline & $A b r$ & 1,00 & 2,00 & 1,00 & 1,50 & 2,00 & 1,00 & 1,42 \\
\hline & Mai & 1,50 & 2,15 & 1,13 & 2,00 & 2,10 & 1,35 & 1,71 \\
\hline & Jun & 1,68 & 2,19 & 1,25 & 2,08 & 2,35 & 1,48 & 1,84 \\
\hline & Jul & 1,83 & 2,20 & 1,60 & 2,10 & 2,84 & 1,50 & 2,01 \\
\hline & Ago & 2,00 & 2,32 & 1,80 & 2,55 & 2,97 & 1,50 & 2,19 \\
\hline & Set & 2,00 & 2,34 & 1,50 & 2,58 & 2,94 & 1,50 & 2,14 \\
\hline & Out & 1,85 & 1,98 & 1,65 & 2,50 & 2,86 & 1,30 & 2,02 \\
\hline & Nov & 1,50 & 1,90 & 1,60 & 2,00 & 2,83 & 1,20 & 1,84 \\
\hline & Dez & 1,00 & 1,87 & 1,20 & 1,89 & 2,60 & 1,00 & 1,59 \\
\hline
\end{tabular}

Fonte: SEMAF, SEPROR, 2003. 
Apêndice 3

Informações detalhadas das análises econômicas nas propriedades de terra firme e várzea. 
Tabela 14. Valor Presente Líquido (VPL); Relação Beneficio/Custo (B/C) Valor Esperado da Terra (VET) e Taxa Interna de Retorno (TIR), Propriedade TF-49.

\begin{tabular}{cccccc}
\hline $\begin{array}{r}\text { Indicadores de análise econômica com } \\
\text { horizonte temporal de } 30 \\
\text { anos }\end{array}$ & $\begin{array}{c}\text { Uso da terra } \\
\text { (ha) }\end{array}$ \\
\hline Indicadores & $5 \%$ & $10 \%$ & $12 \%$ & Total & SAF \\
\hline VPL & $-427,00$ & $-394,00$ & $-381,00$ & 5,25 & 0,12 \\
B/C & 0,74 & 0,69 & 0,68 & & \\
VET & $-665,00$ & $-446,00$ & $-420,00$ & & \\
TIR (0\%) & - & - & - & $100 \%$ & $2,0 \%$ \\
\hline
\end{tabular}

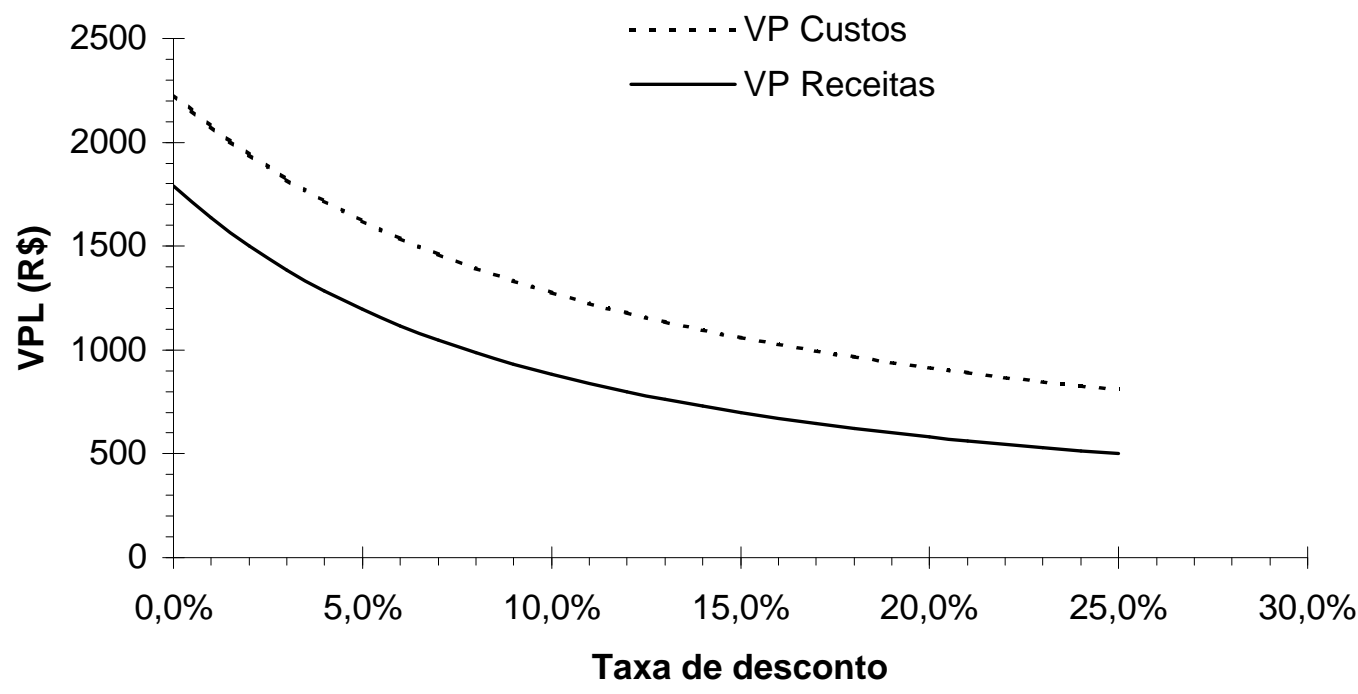

Figura 17- Apresenta as curvas de custo e receita, nota-se que a curva de custo está sempre superior a curva da receita em todas as taxas de desconto utilizadas confirmando o insucesso do projeto devido as suas limitações. 
Tabela 15. Valor Presente Líquido (VPL), Relação Beneficio/Custo (B/C); Valor Esperado da Terra (VET) e Taxa Interna de Retorno (TIR), propriedade TF-38.

\begin{tabular}{|c|c|c|c|c|c|c|}
\hline \multicolumn{5}{|c|}{$\begin{array}{c}\text { Indicadores de análise econômica com } \\
\text { horizonte temporal de } 30 \text { anos }\end{array}$} & \multicolumn{2}{|c|}{$\begin{array}{c}\text { Uso da terra } \\
\text { (ha) }\end{array}$} \\
\hline Ind & Ladores & $5 \%$ & $10 \%$ & $12 \%$ & Total & SAF \\
\hline & VPI & 772,00 & $-579,00$ & $-171,00$ & 12,0 & 0,23 \\
\hline & $B / C$ & 1,19 & 1,00 & 0,93 & & \\
\hline & VET & 940,00 & $-6,14$ & $-176,00$ & & \\
\hline TIR & $(9,60 \%)$ & - & & & $100 \%$ & $1,0 \%$ \\
\hline
\end{tabular}

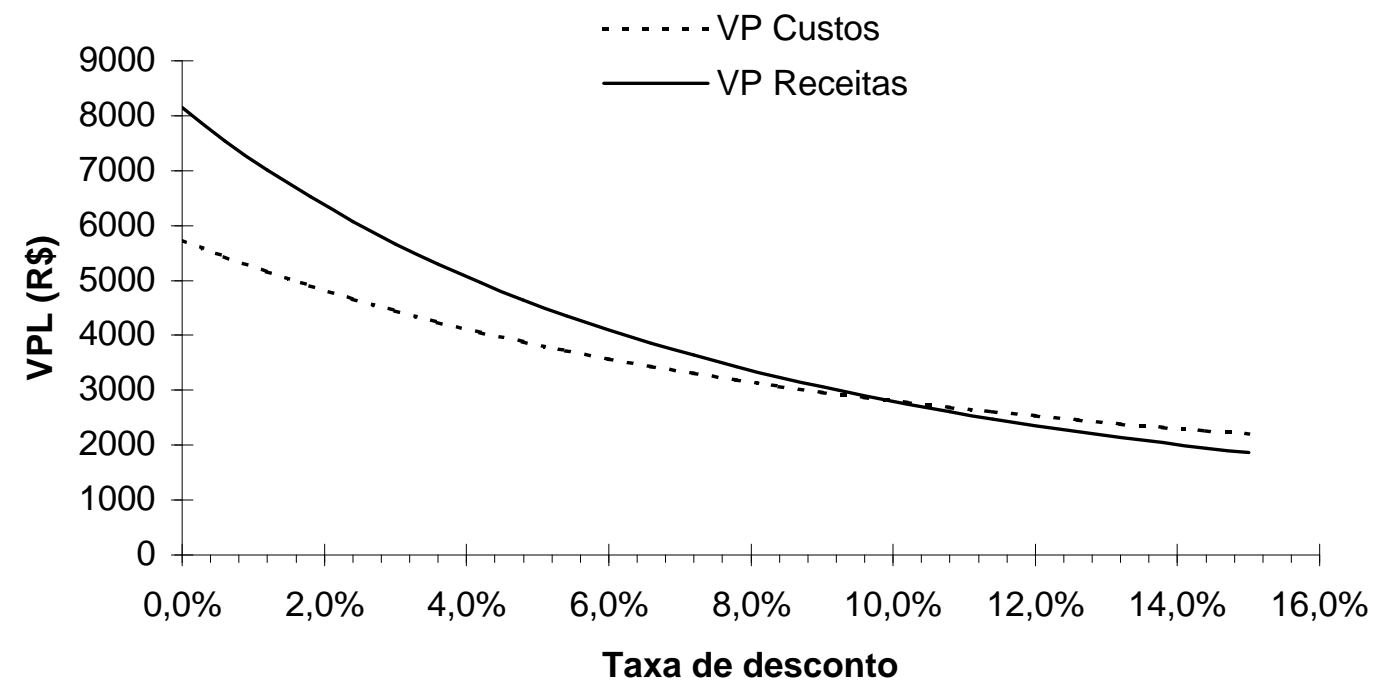

Figura 18 - apresenta as taxas de descontos utilizadas, percebe-se que a curva de receita iguala a curva de custo à $(9,6 \%)$, significando que a esta taxa a TIR torna o VPL igual a zero. 
Tabela 16. Valor Presente Líquido (VPL), Relação Beneficio/Custo (B/C); Valor Esperado da Terra (VET) e Taxa Interna de Retorno (TIR), propriedade TF-31.

\begin{tabular}{cccccr}
\hline \multicolumn{2}{r}{$\begin{array}{l}\text { Indicadores de análise econômica com } \\
\text { horizonte temporal de } 30 \\
\text { anos }\end{array}$} & $\begin{array}{c}\text { Uso da terra } \\
\text { (ha) }\end{array}$ \\
\hline Indicadores & $5 \%$ & $10 \%$ & $12 \%$ & Total & SAF \\
\hline VPL & 280,00 & $-334,00$ & $-470,00$ & 12,5 & 0,66 \\
B/C & 1,10 & 0,85 & 0,77 & & \\
VET & 364,00 & $-354,00$ & $-486,00$ & & \\
TIR (6, $\mathbf{4 0})$ & & & & $100 \%$ & $5,5 \%$ \\
\hline
\end{tabular}

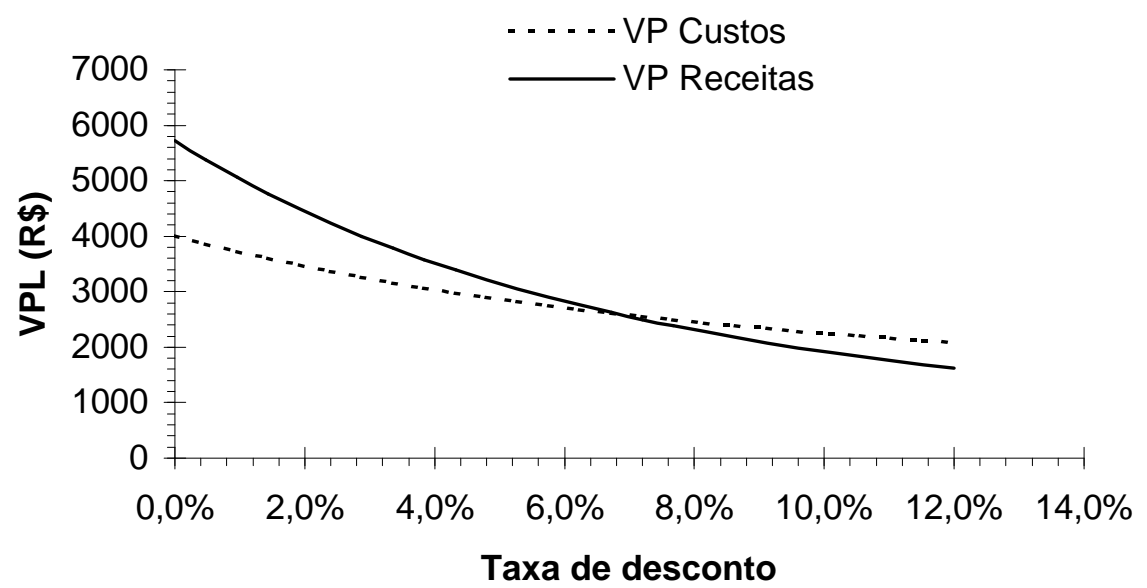

Figura 19. apresenta as taxas de descontos utilizadas, percebe-se que a curva de receita iguala a curva de custo à $(6,40 \%)$, significando que a esta taxa a TIR torna o VPL igual a zero. 
Tabela 17. Valor Presente Líquido (VPL), Relação Beneficio/Custo (B/C); Valor Esperado da Terra (VET) e Taxa Interna de Retorno (TIR), propriedade TF-46.

\begin{tabular}{crrrrr}
\hline \multicolumn{2}{r}{$\begin{array}{l}\text { Indicadores de análise econômica com } \\
\text { horizonte temporal de } 30 \\
\text { anos }\end{array}$} & $\begin{array}{c}\text { Uso da terra } \\
\text { (ha) }\end{array}$ \\
\hline Indicadores & $5 \%$ & $10 \%$ & $12 \%$ & Total & SAF \\
\hline VPL & 969,00 & 474,00 & 354,00 & 7,5 & 0,32 \\
B/C & 1,34 & 1,22 & 1,18 & & \\
VET & 1,260 & 502,00 & 366,00 & & \\
TIR (24\%) & - & - & - & $100 \%$ & $4,3 \%$ \\
\hline
\end{tabular}

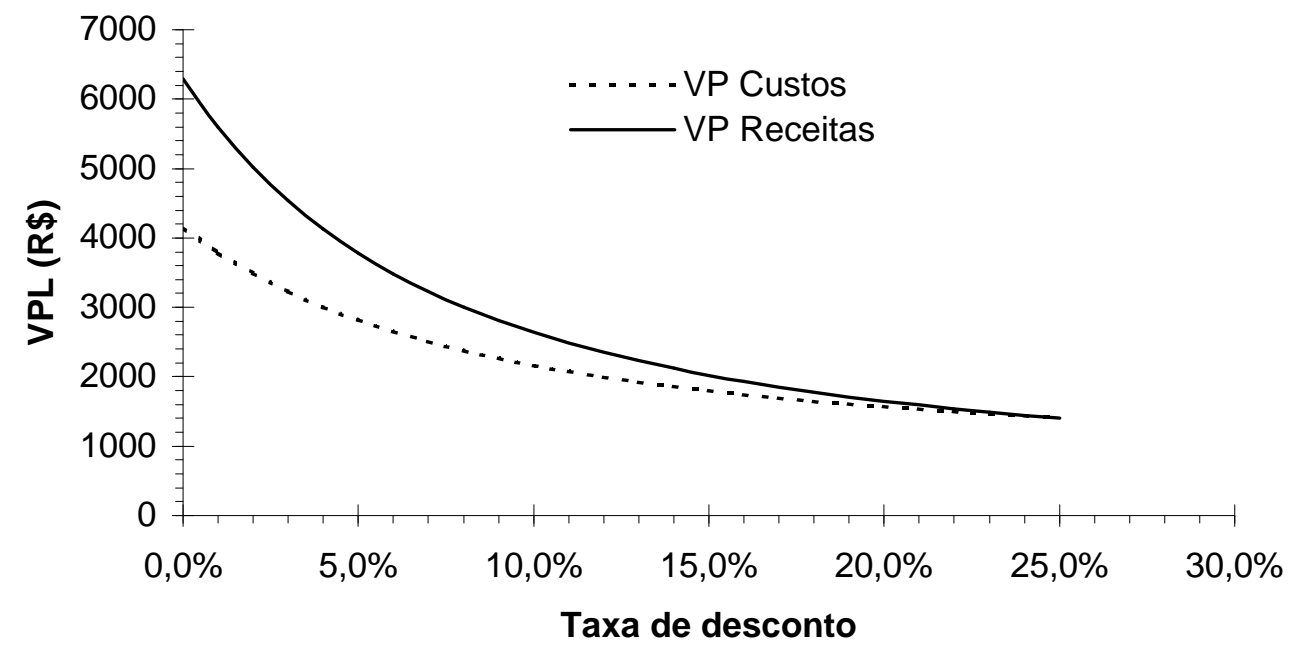

Figura 20. apresenta as taxas de descontos utilizadas, percebe-se que a curva de receita iguala a curva de custo à $(24,0 \%)$, significando que a esta taxa a TIR torna O VPL igual a zero. 
Tabela 18. Valor Presente Líquido (VPL), Relação Beneficio/Custo (B/C); Valor Esperado da Terra (VET) e Taxa Interna de Retorno (TIR), propriedade 50.

\begin{tabular}{|c|c|c|c|c|c|c|}
\hline \multicolumn{5}{|c|}{$\begin{array}{c}\text { Indicadores de análise econômica com } \\
\text { horizonte temporal de } 30 \text { anos }\end{array}$} & \multicolumn{2}{|c|}{$\begin{array}{c}\text { Uso da terra } \\
\text { (ha) }\end{array}$} \\
\hline Ind & Ladores & $5 \%$ & $10 \%$ & $12 \%$ & Total & $\mathrm{SAF}$ \\
\hline & VPI & 909,00 & 363,00 & 239,00 & 7,5 & 0,56 \\
\hline & $B / C$ & 1,23 & 1,14 & 1,10 & & \\
\hline & VET & 1183,00 & 384, & 247,00 & & \\
\hline TIR & $(18,0 \%)$ & - & - & & $100 \%$ & $7,5 \%$ \\
\hline
\end{tabular}

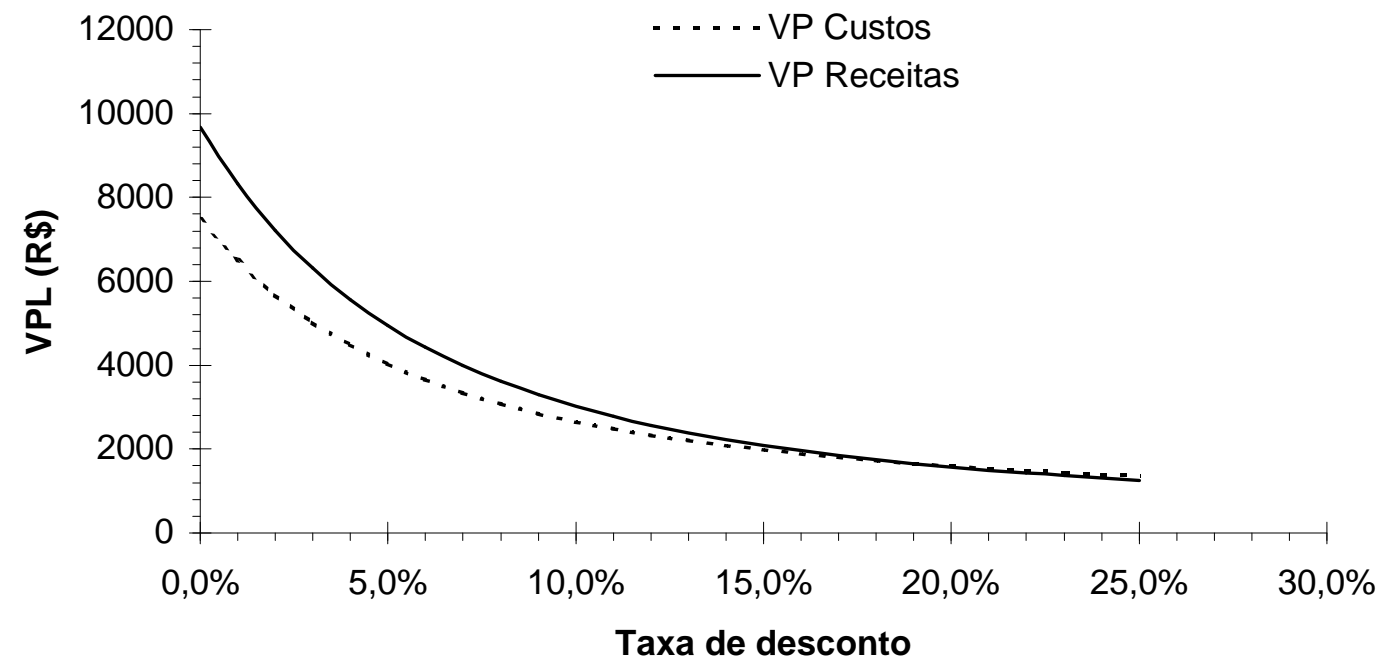

Figura 21. apresenta as taxas de descontos utilizadas, percebe-se que a curva de receita iguala a curva de custo à $(18,0 \%)$, significando que a esta taxa a TIR torna $O$ VPL igual a zero. 
Tabela 19. Valor Presente Líquido (VPL), Relação Beneficio/Custo (B/C); Valor Esperado da Terra (VET) e Taxa Interna de Retorno (TIR), propriedade TF-32.

\begin{tabular}{crrrrr}
\hline \multicolumn{2}{c}{$\begin{array}{c}\text { Indicadores de análise econômica com } \\
\text { horizonte temporal de } 30 \text { anos }\end{array}$} & $\begin{array}{c}\text { Uso da terra } \\
\text { (ha) }\end{array}$ \\
\hline Indicadores & $5 \%$ & $10 \%$ & $12 \%$ & Total & SAF \\
\hline VPL & 3256,00 & 1161,00 & 793,00 & 4,5 & 1,26 \\
B/C & 1,83 & 1,38 & 1,29 & & \\
VET & 4237,00 & 1231,00 & 98,54 & & \\
TIR (15\%) & - & - & - & $100 \%$ & $2,8 \%$ \\
\hline
\end{tabular}

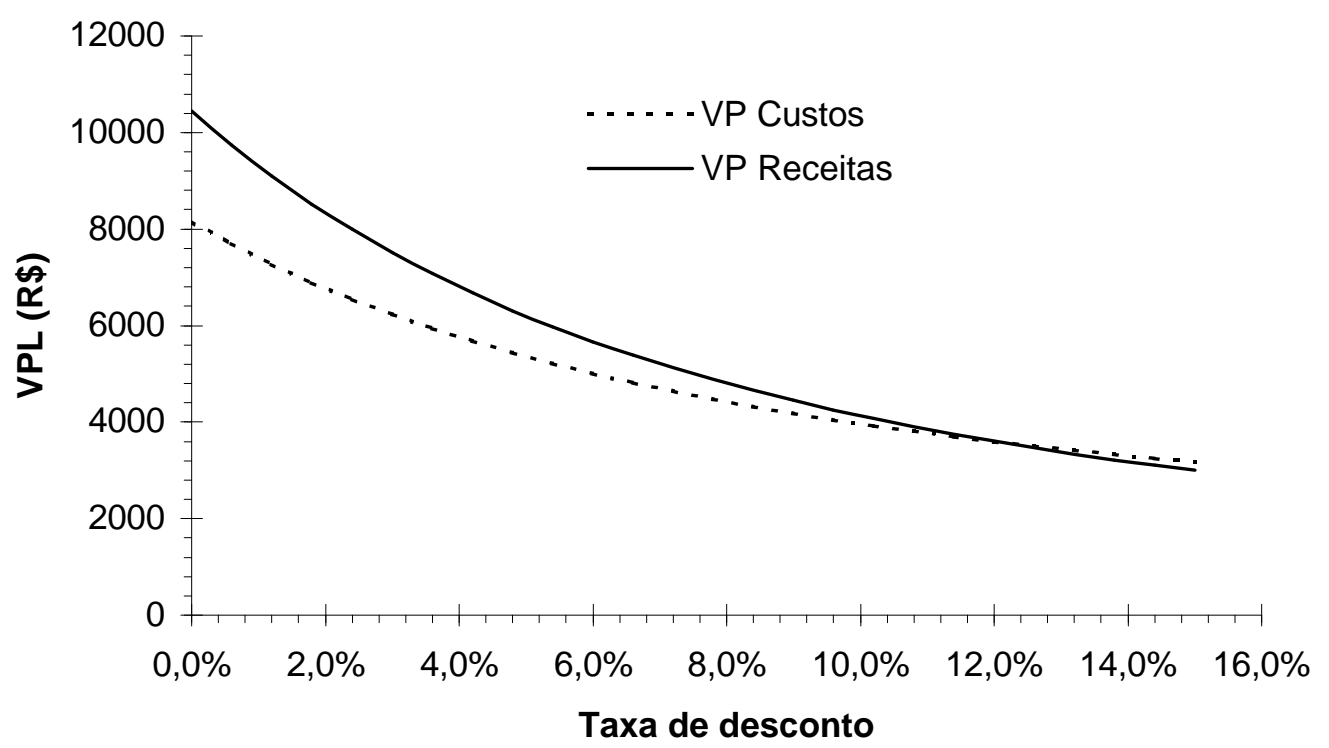

Figura 22. apresenta as taxas de descontos utilizadas, percebe-se que a curva de receita iguala a curva de custo à $(15,0 \%)$, significando que a esta taxa a TIR torna O VPL igual a zero. 
Tabela 20. Valor Presente Líquido (VPL), Relação Beneficio/Custo (B/C); Valor Esperado da Terra (VET) e Taxa Interna de Retorno (TIR), propriedade TF-47.

\begin{tabular}{ccrrrr}
\hline \multicolumn{2}{r}{$\begin{array}{c}\text { Indicadores de análise econômica com } \\
\text { horizonte temporal de } 30 \\
\text { anos }\end{array}$} & $\begin{array}{c}\text { Uso da terra } \\
\text { (ha) }\end{array}$ \\
\hline Indicadores & $5 \%$ & $10 \%$ & $12 \%$ & Total & SAF \\
\hline VPL & 1866,00 & 824,00 & 574,00 & 14,0 & 0,50 \\
B/C & 2,57 & 1,84 & 1,63 & & \\
VET & 2428,00 & 847,00 & 593,00 & & \\
TIR (23\%) & - & - & - & $100 \%$ & $3,6 \%$ \\
\hline
\end{tabular}

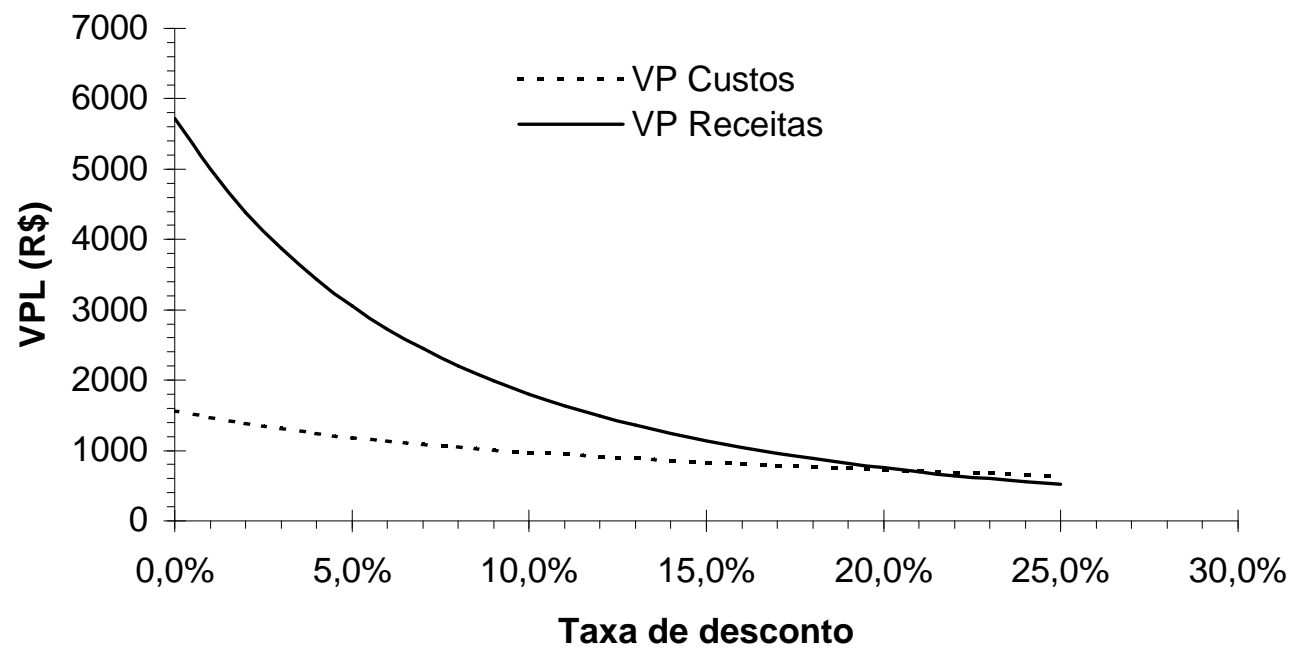

Figura 23. apresenta as taxas de descontos utilizadas, percebe-se que a curva de receita iguala a curva de custo à $(23,0 \%)$, significando que a esta taxa a TIR torna O VPL igual a zero. 
Tabela 34. Valor Presente Líquido (VPL), Relação Beneficio/Custo (B/C); Valor Esperado da Terra (VET) e Taxa Interna de Retorno (TIR), propriedade TF-34.

\begin{tabular}{cccccc}
\hline \multicolumn{2}{r}{$\begin{array}{r}\text { Indicadores de análise econômica com } \\
\text { horizonte temporal de } 30 \text { anos }\end{array}$} & $\begin{array}{c}\text { Uso da terra } \\
\text { (ha) }\end{array}$ \\
\hline Indicadores & $5 \%$ & $10 \%$ & $12 \%$ & Total & SAF \\
\hline VPL & 15.663 & 8.785 & 7.072 & 14,0 & 0,50 \\
B/C & 2,12 & 2,00 & 1,94 & & \\
VET & 24.434 & 10.158 & 7.798 & & \\
TIR (19\%) & - & - & - & $100 \%$ & $3,6 \%$ \\
\hline
\end{tabular}

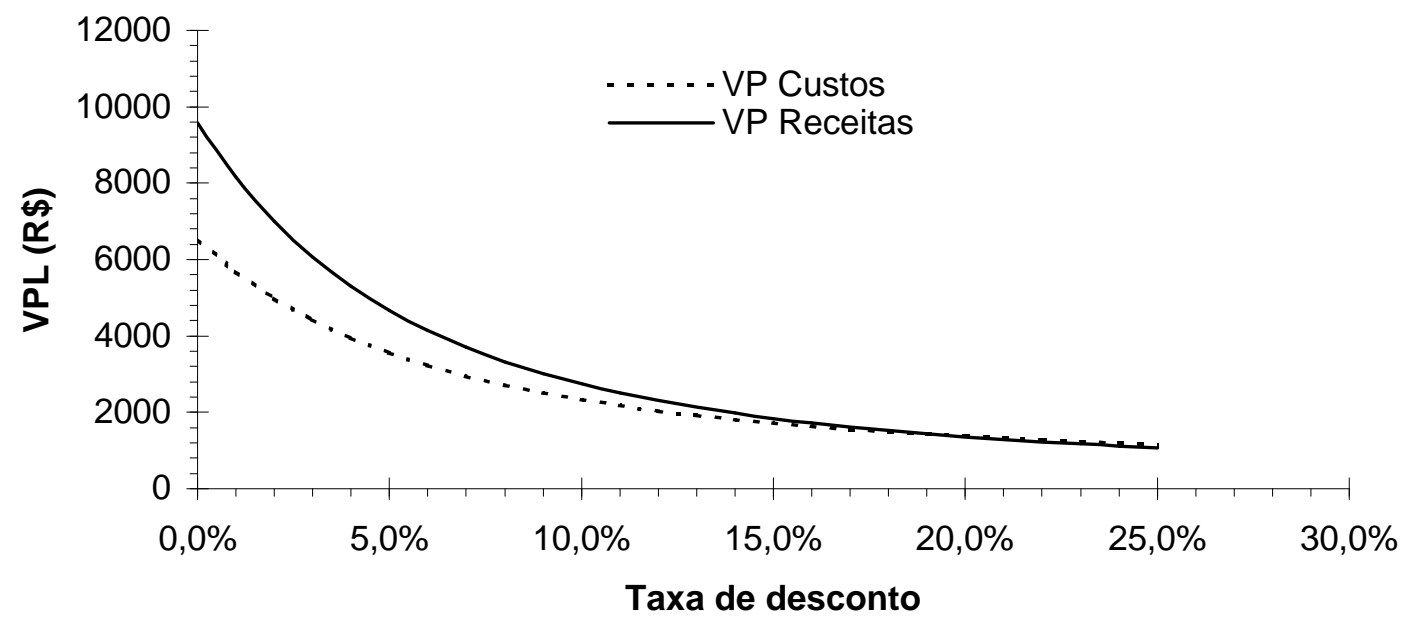

Figura 24. apresenta as taxas de descontos utilizadas, percebe-se que a curva de receita iguala a curva de custo à $(19,0 \%)$, significando que a esta taxa a TIR torna o VPL igual a zero. 
Tabela 22. Valor Presente Líquido (VPL), Relação Beneficio/Custo (B/C); Valor Esperado da Terra (VET) e Taxa Interna de Retorno (TIR), propriedade TF-16.

\begin{tabular}{crrrrr}
\hline $\begin{array}{r}\text { Indicadores de análise econômica com } \\
\text { horizonte temporal de } 30 \\
\text { anos }\end{array}$ & $\begin{array}{c}\text { Uso da terra } \\
\text { (ha) }\end{array}$ \\
\hline Indicadores & $5 \%$ & $10 \%$ & $12 \%$ & Total & SAF \\
\hline VPL & 44,60 & $-48,00$ & $-107,00$ & 9,0 & 0,30 \\
B/C & 1,01 & 0,98 & 0,94 & & \\
VET & 58,00 & $-51,00$ & $-112,00$ & & \\
TIR (8\%) & - & - & - & $100 \%$ & $3,6 \%$ \\
\hline
\end{tabular}

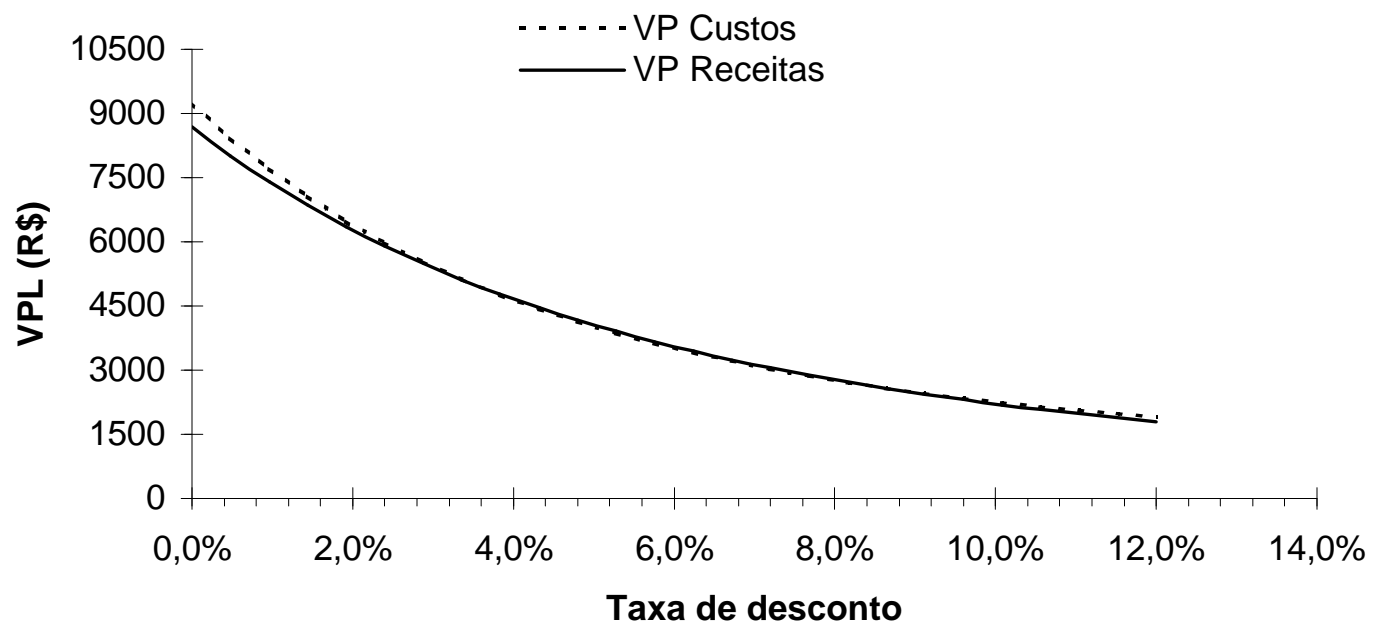

Figura 25. apresenta as taxas de descontos utilizadas, percebe-se que a curva de receita iguala a curva de custo à $(8,0 \%)$, significando que a esta taxa a TIR torna O VPL igual a zero. 
Tabela 23. Valor Presente Líquido (VPL), Relação Beneficio/Custo (B/C); Valor Esperado da Terra (VET) e Taxa Interna de Retorno (TIR), propriedade TF-18.

\begin{tabular}{cccrrr}
\hline $\begin{array}{r}\text { Indicadores de análise econômica com } \\
\text { horizonte temporal de } 30 \\
\text { anos }\end{array}$ & $\begin{array}{c}\text { Uso da terra } \\
\text { (ha) }\end{array}$ \\
\hline Indicadores & $5 \%$ & $10 \%$ & $12 \%$ & Total & SAF \\
\hline VPL & 388,00 & 84,00 & 18,041 & 15,00 & 0,30 \\
B/C & 1,09 & 1,03 & 1,01 & & \\
VET & 505,00 & 89,00 & 19,00 & & \\
TIR (12,0\%) & - & - & - & $100 \%$ & 2,00 \\
\hline
\end{tabular}

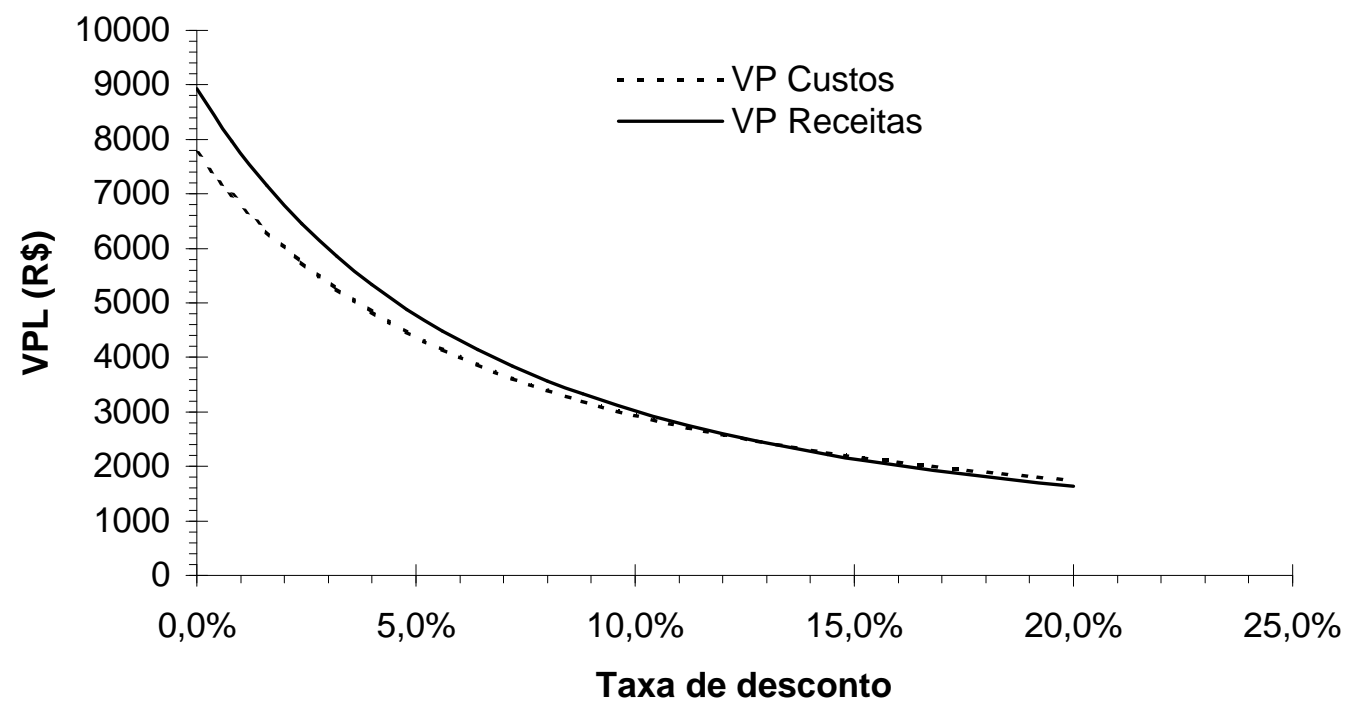

Figura 26. apresenta as taxas de descontos utilizadas, percebe-se que a curva de receita iguala a curva de custo à $(12,0 \%)$, significando que a esta taxa a TIR torna O VPL igual a zero. 
Tabela 24. Valor Presente Líquido (VPL), Relação Beneficio/Custo (B/C); Valor Esperado da Terra (VET) e Taxa Interna de Retorno (TIR) propriedade TF-07.

\begin{tabular}{crrrrr}
\hline $\begin{array}{r}\text { Indicadores de análise econômica com } \\
\text { horizonte temporal de } 30 \\
\text { anos }\end{array}$ & $\begin{array}{c}\text { Uso da terra } \\
\text { (ha) }\end{array}$ \\
\hline Indicadores & $5 \%$ & $10 \%$ & $12 \%$ & Total & SAF \\
\hline VPL & 443,00 & 171,00 & 101,00 & 15,00 & 0,30 \\
B/C & 1,3 & 1,06 & 1,04 & & \\
VET & 181,00 & 181,00 & 104,00 & & \\
TIR (16\%) & - & - & - & $100 \%$ & 2,00 \\
\hline
\end{tabular}

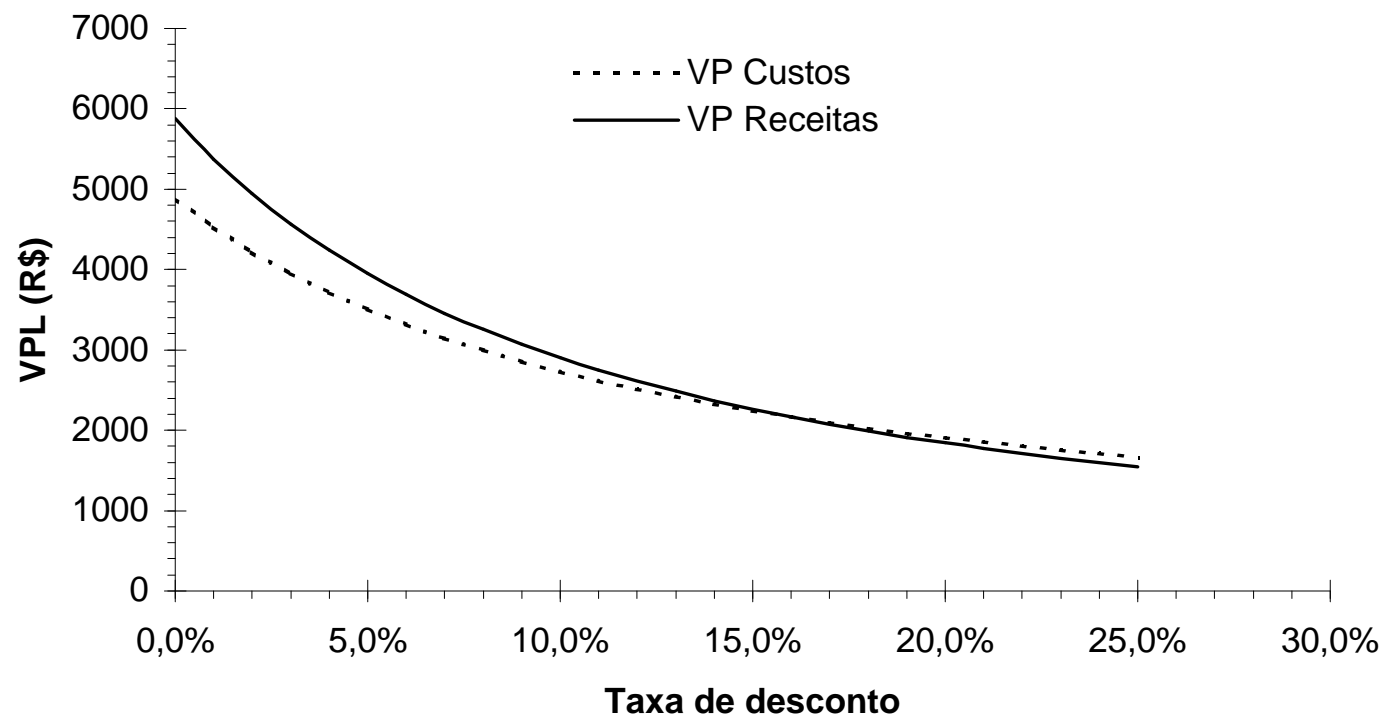

Figura 27. apresenta as taxas de descontos utilizadas, percebe-se que a curva de receita iguala a curva de custo à $(16,0 \%)$, significando que a esta taxa a TIR torna o VPL igual a zero. 
Tabela 25. Valor Presente Líquido (VPL), Relação Beneficio/Custo (B/C); Valor Esperado da Terra (VET) e Taxa Interna de Retorno (TIR), propriedade TF-06.

\begin{tabular}{crrrrr}
\hline $\begin{array}{r}\text { Indicadores de análise econômica com } \\
\text { horizonte temporal de } 30 \\
\text { anos }\end{array}$ & $\begin{array}{c}\text { Uso da terra } \\
\text { (ha) }\end{array}$ \\
\hline Indicadores & $5 \%$ & $10 \%$ & $12 \%$ & Total & SAF \\
\hline VPL & 726,56 & 228,00 & 117,00 & 10,00 & 0,40 \\
B/C & 1,15 & 1,07 & 1,04 & & \\
VET & 945,00 & 242,00 & 121,00 & & \\
TIR (15\%) & - & - & - & $100 \%$ & 4,00 \\
\hline
\end{tabular}

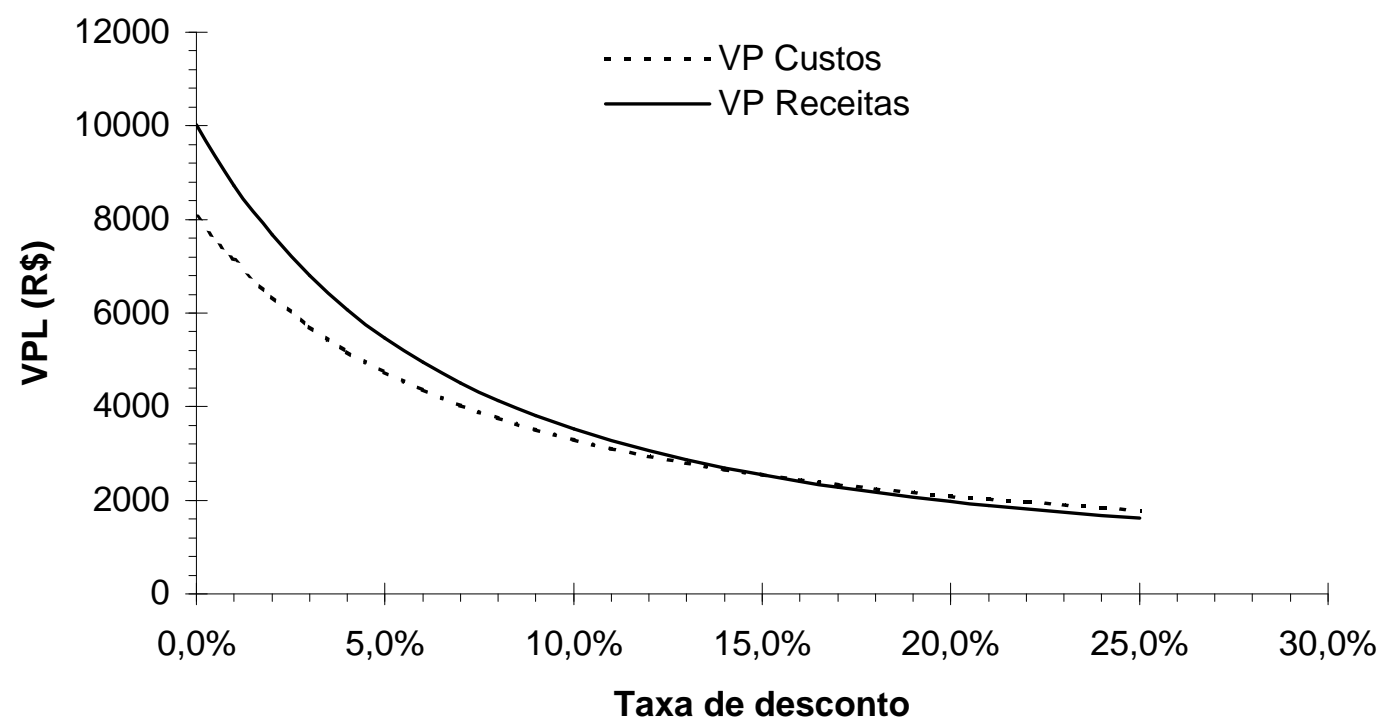

Figura 28. apresenta as taxas de descontos utilizadas, percebe-se que a curva de receita iguala a curva de custo à $(15,0 \%)$, significando que a esta taxa a TIR torna o VPL igual a zero. 
Tabela 26. Valor Presente Líquido (VPL), Relação Beneficio/Custo (B/C); Valor Esperado da Terra (VET) e Taxa Interna de Retorno (TIR), propriedade TF-10.

\begin{tabular}{cccccc}
\hline $\begin{array}{l}\text { Indicadores de análise econômica com } \\
\text { horizonte temporal de } 30 \\
\text { anos }\end{array}$ & $\begin{array}{c}\text { Uso da terra } \\
\text { (ha) }\end{array}$ \\
\hline Indicadores & $5 \%$ & $10 \%$ & $12 \%$ & Total & SAF \\
\hline VPL & 1322,00 & 33,00 & $-1106,00$ & 8,00 & 0,40 \\
B/C & 1,14 & 1,0 & $-0,96$, & & \\
VET & 800,00 & 6,00 & $-15,00$ & & \\
TIR (15\%) & - & - & - & $100 \%$ & 5,00 \\
\hline
\end{tabular}

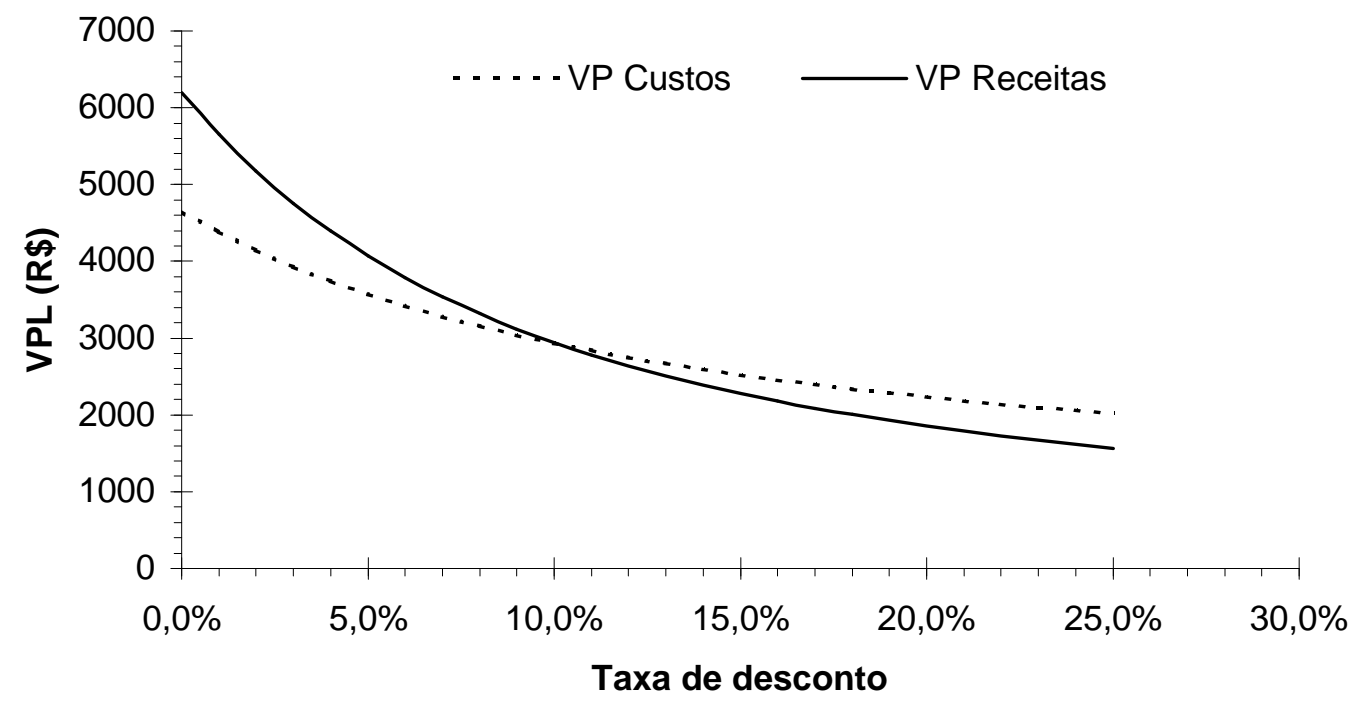

Figura 29. apresenta as taxas de descontos utilizadas, percebe-se que a curva de receita iguala a curva de custo à $(15,0 \%)$, significando que a esta taxa a TIR torna O VPL igual a zero. 
Tabela 27. Valor Presente Líquido (VPL), Relação Beneficio/Custo (B/C); Valor Esperado da Terra (VET) e Taxa Interna de Retorno (TIR), propriedade vz-8.

\begin{tabular}{cccccc}
\hline $\begin{array}{r}\text { Indicadores de análise econômica com } \\
\text { horizonte temporal de } 30 \\
\text { anos }\end{array}$ & $\begin{array}{c}\text { Uso da terra } \\
\text { (ha) }\end{array}$ \\
\hline Indicadores & $5 \%$ & $10 \%$ & $12 \%$ & Total & SAF \\
\hline VPL & 792,00 & 398,00 & 299,00 & 21,00 & 0,50 \\
B/C & 1,12 & 1,08 & 1,07 & & \\
VET & 1031,00 & 422,00 & 309,00 & & \\
TIR (23\%) & - & - & - & $100 \%$ & 2,00 \\
\hline
\end{tabular}

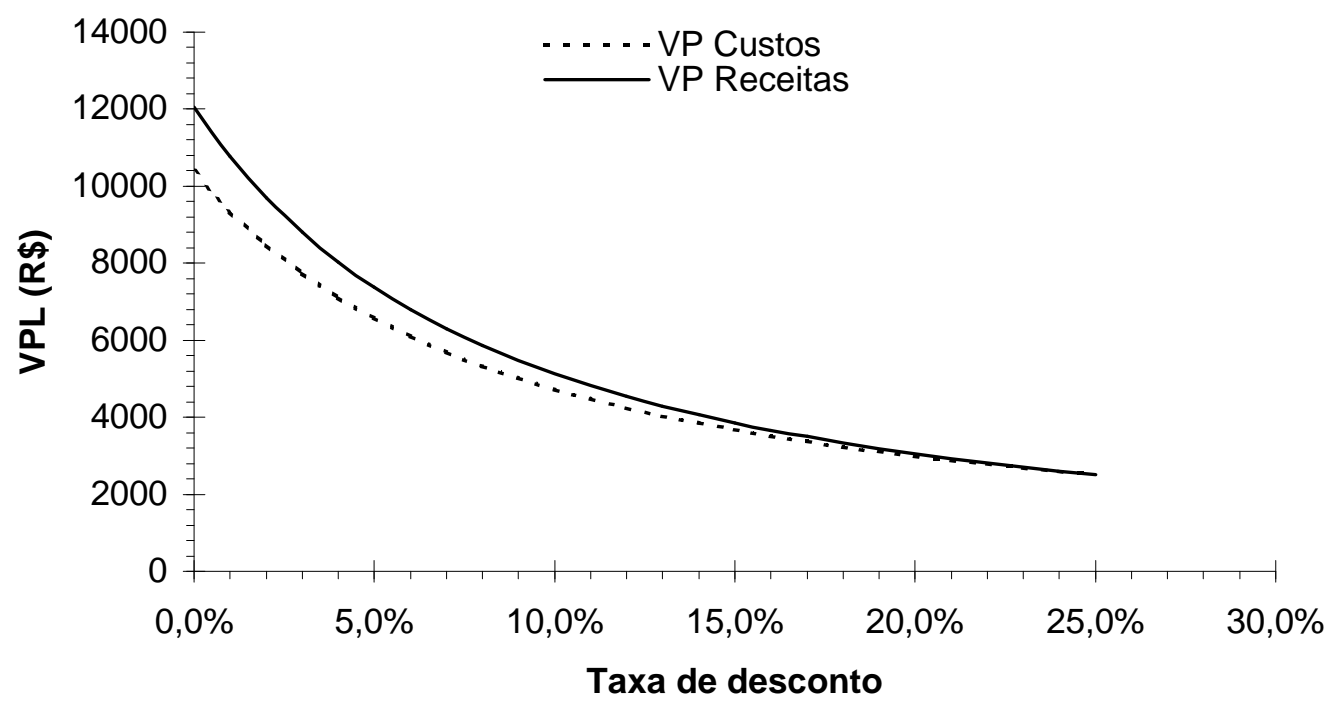

Figura 30. apresenta as taxas de descontos utilizadas, percebe-se que a curva de receita iguala a curva de custo à $(23,0 \%)$, significando que a esta taxa a TIR torna O VPL igual a zero. 
Tabela 28. Valor Presente Líquido (VPL), Relação Beneficio/Custo (B/C); Valor Esperado da Terra (VET) e Taxa Interna de Retorno (TIR), propriedade vz-07.

\begin{tabular}{|c|c|c|c|c|c|}
\hline \multicolumn{4}{|c|}{$\begin{array}{l}\text { Indicadores de análise econômica com } \\
\text { horizonte temporal de } 30 \text { anos }\end{array}$} & \multicolumn{2}{|c|}{$\begin{array}{l}\text { Uso da terra } \\
\text { (ha) }\end{array}$} \\
\hline Indicadores & $5 \%$ & $10 \%$ & $12 \%$ & Total & SAF \\
\hline VPL & 781,00 & 326,00 & 20,900 & 21,00 & 0,50 \\
\hline$B / C$ & 1,08 & 1,05 & 1,03 & & \\
\hline VET & 1016,00 & 346,00 & 216,00 & & \\
\hline TIR (17\%) & & & & $100 \%$ & 2,00 \\
\hline
\end{tabular}

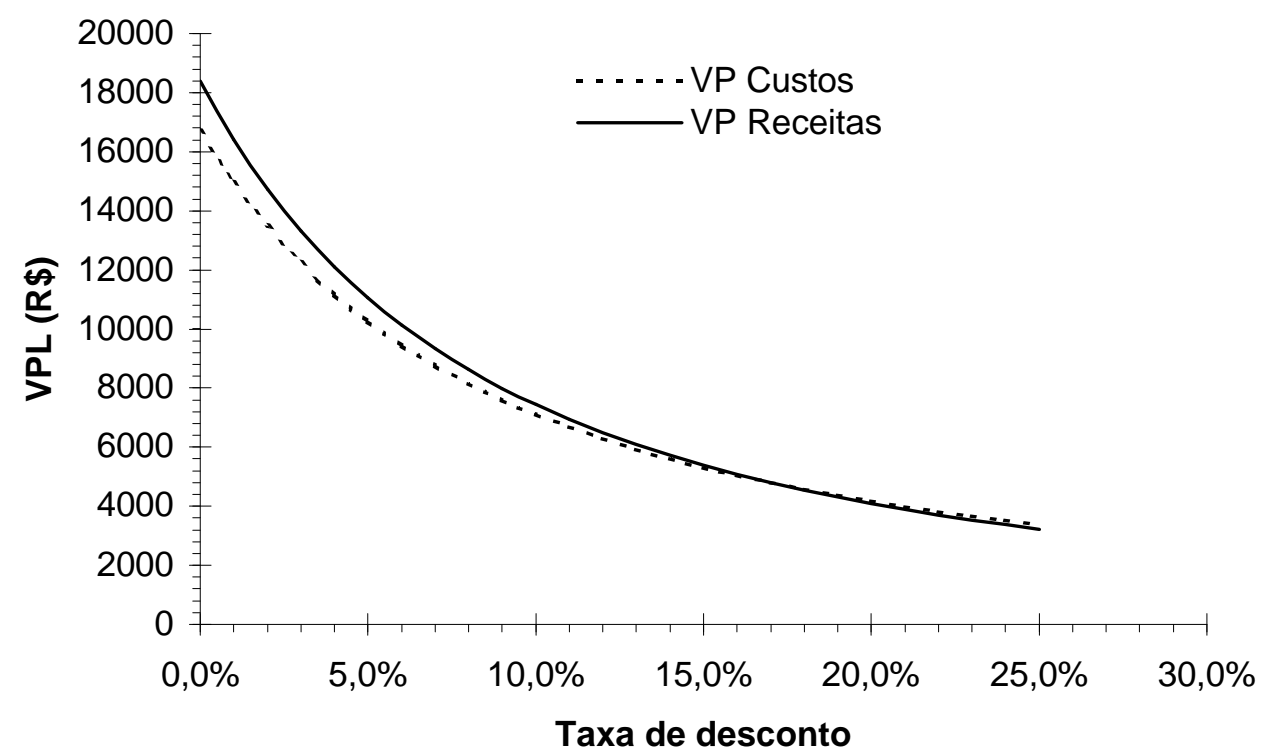

Figura 31. apresenta as taxas de descontos utilizadas, percebe-se que a curva de receita iguala a curva de custo à $(17,0 \%)$, significando que a esta taxa a TIR torna o VPL igual a zero. 
Tabela 29. Valor Presente Líquido (VPL), Relação Beneficio/Custo (B/C); Valor Esperado da Terra (VET) e Taxa Interna de Retorno (TIR), propriedade Vz-06.

\begin{tabular}{|c|c|c|c|c|c|}
\hline \multicolumn{4}{|c|}{$\begin{array}{l}\text { Indicadores de análise econômica } \\
\text { horizonte temporal de } 30 \text { anos }\end{array}$} & (ha) & $\begin{array}{l}\text { terra } \\
\text { ) }\end{array}$ \\
\hline Indicadores & $5 \%$ & $10 \%$ & $12 \%$ & Total & $\mathrm{SAF}$ \\
\hline VPL & 471,00 & 145,00 & 86,00 & 21,00 & 0,50 \\
\hline$B / C$ & 1,08 & 1,04 & 1,03 & & \\
\hline VET & 543,00 & 154,00 & 89,00 & & \\
\hline TIR (16\%) & & & & $100 \%$ & 2,00 \\
\hline
\end{tabular}

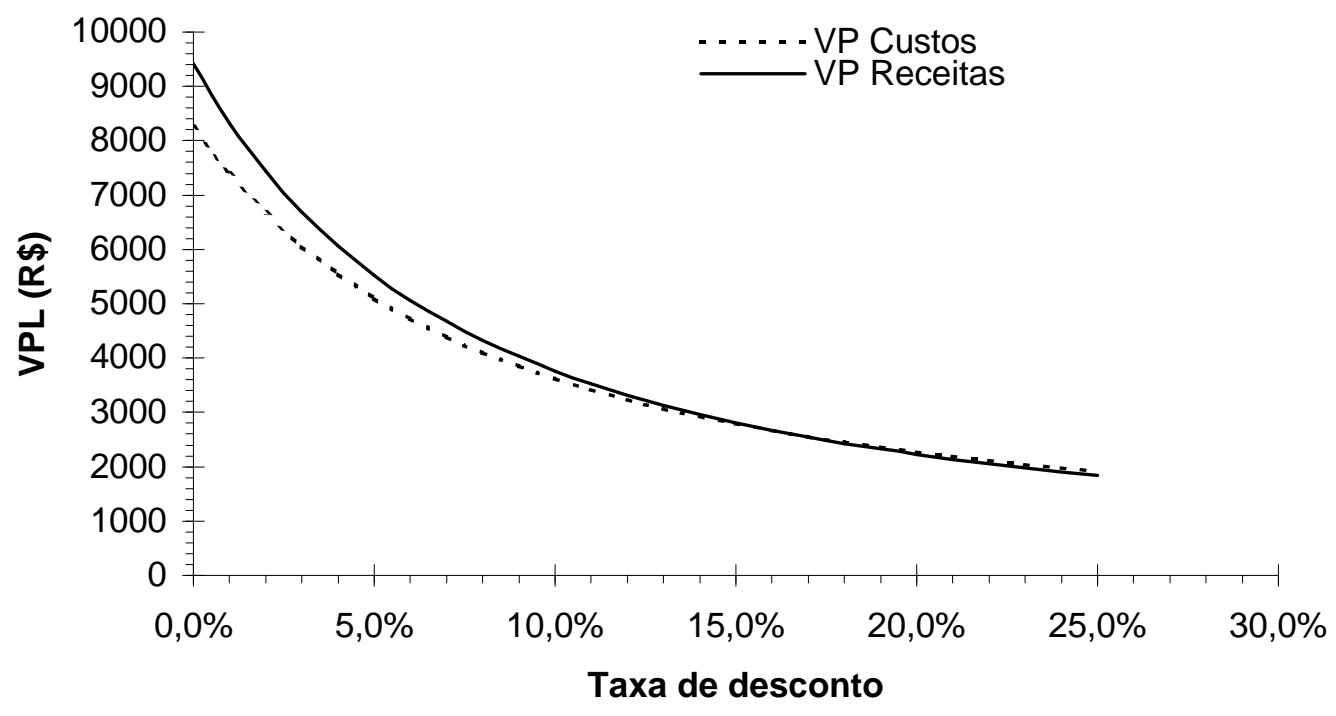

Figura 32. apresenta as taxas de descontos utilizadas, percebe-se que a curva de receita iguala a curva de custo à $(16,0 \%)$, significando que a esta taxa a TIR torna O VPL igual a zero. 
Tabela 30. Valor Presente Líquido (VPL), Relação Beneficio/Custo (B/C); Valor Esperado da Terra (VET) e Taxa Interna de Retorno (TIR), propriedade Vz-01.

\begin{tabular}{|c|c|c|c|c|c|}
\hline \multicolumn{4}{|c|}{$\begin{array}{c}\text { Indicadores de análise econômica com } \\
\text { horizonte temporal de } 30 \text { anos }\end{array}$} & \multicolumn{2}{|c|}{$\begin{array}{l}\text { Uso da terra } \\
\text { (ha) }\end{array}$} \\
\hline Indicadores & $5 \%$ & $10 \%$ & $12 \%$ & Total & $\mathrm{SAF}$ \\
\hline VPL & 1347,00 & 289,00 & 129,00 & 26,00 & 0,70 \\
\hline$B / C$ & 1,11 & 1,04 & 1,02 & & \\
\hline VET & 1752,00 & 307,00 & 133,00 & & \\
\hline TIR (14\%) & & & & $100 \%$ & 2,70 \\
\hline
\end{tabular}

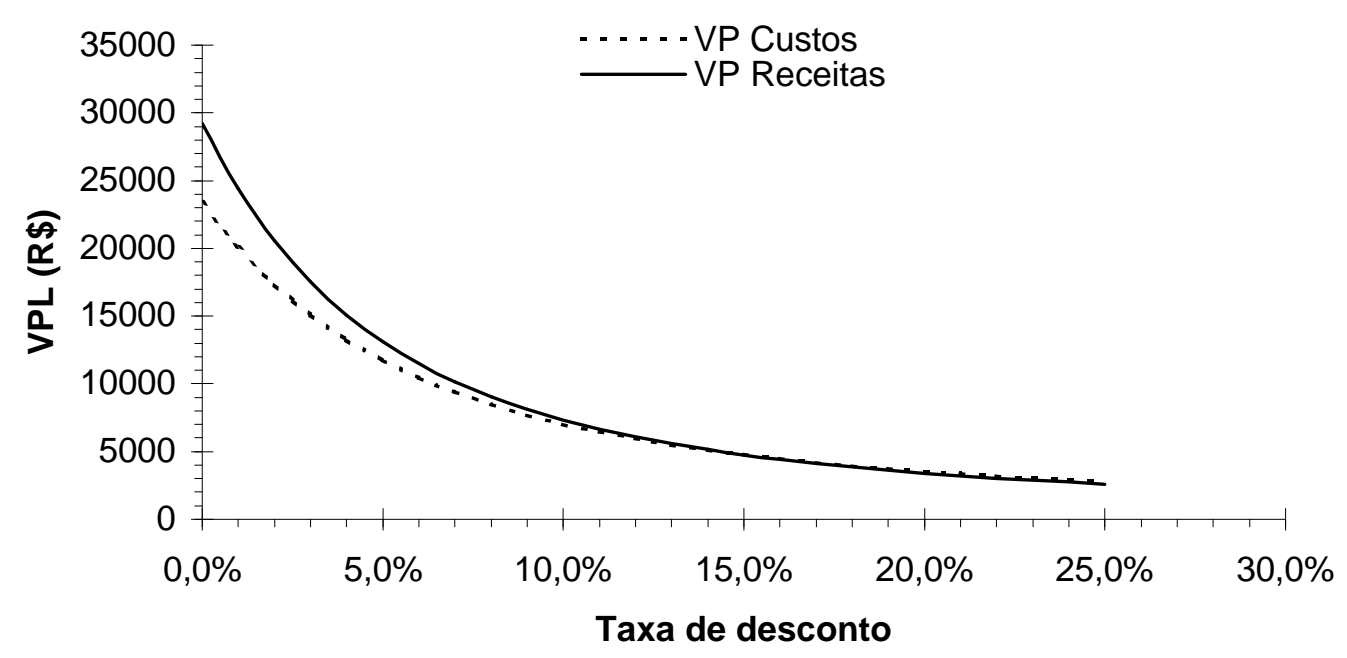

Figura 33. apresenta as taxas de descontos utilizadas, percebe-se que a curva de receita iguala a curva de custo à $(14,0 \%)$, significando que a esta taxa a TIR torna O VPL igual a zero. 
Tabela 31. Valor Presente Líquido (VPL), Relação Beneficio/Custo (B/C); Valor Esperado da Terra (VET) e Taxa Interna de Retorno (TIR), propriedade vz-05.

\begin{tabular}{|c|c|c|c|c|c|}
\hline \multicolumn{4}{|c|}{$\begin{array}{c}\text { Indicadores de análise econômica com } \\
\text { horizonte temporal de } 30 \text { anos }\end{array}$} & \multicolumn{2}{|c|}{$\begin{array}{l}\text { Uso da terra } \\
\text { (ha) }\end{array}$} \\
\hline Indicadores & $5 \%$ & $10 \%$ & $12 \%$ & Total & $\mathrm{SAF}$ \\
\hline VPI & 178,00 & 3,31 & $-43,00$ & 26,00 & 0,70 \\
\hline$B / C$ & 1,05 & 1,00 & 0,98 & & \\
\hline VET & 232,00 & 3,51 & $-44,00$ & & \\
\hline $\operatorname{TIR}(10 \%)$ & & & & $100 \%$ & 2,70 \\
\hline
\end{tabular}

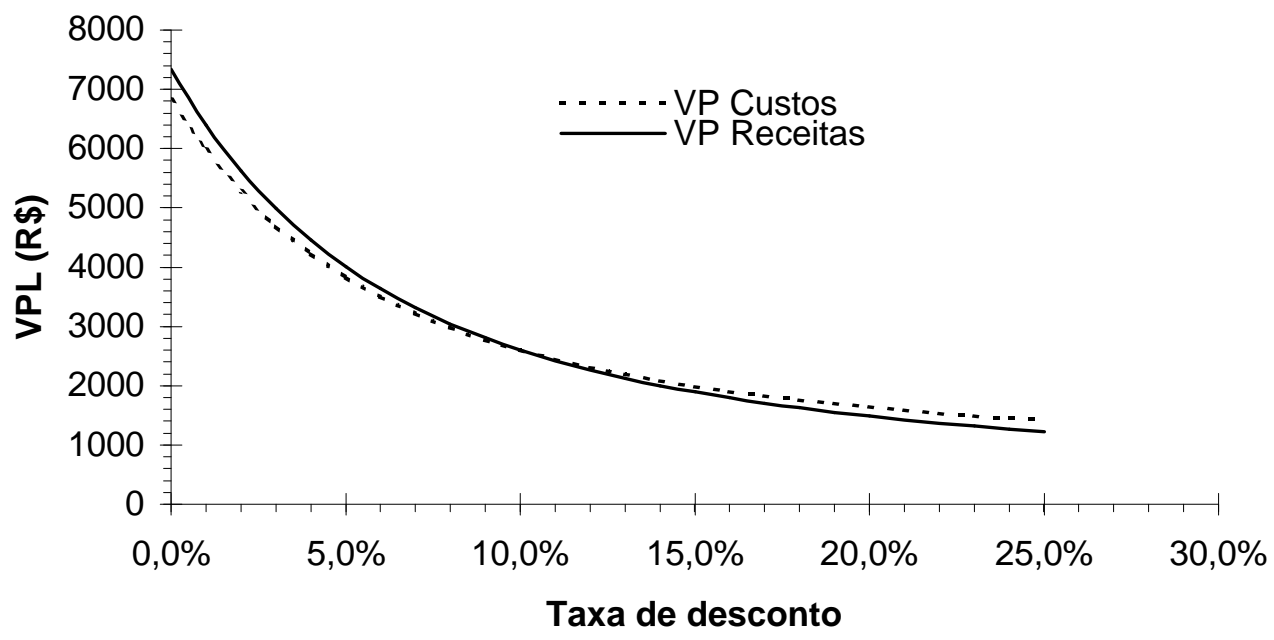

Figura 34. apresenta as taxas de descontos utilizadas, percebe-se que a curva de receita iguala a curva de custo à $(10,0 \%)$, significando que a esta taxa a TIR torna O VPL igual a zero. 
Tabela 32. Valor Presente Líquido (VPL), Relação Beneficio/Custo (B/C); Valor Esperado da Terra (VET) e Taxa Interna de Retorno (TIR), propriedade VZ-02.

\begin{tabular}{|c|c|c|c|c|c|}
\hline \multicolumn{4}{|c|}{$\begin{array}{l}\text { Indicadores de análise econômica com } \\
\text { horizonte temporal de } 30 \text { anos }\end{array}$} & \multicolumn{2}{|c|}{$\begin{array}{l}\text { Uso da terra } \\
\text { (ha) }\end{array}$} \\
\hline Indicadores & $5 \%$ & $10 \%$ & $12 \%$ & Total & SAF \\
\hline VPL & 48,00 & 345,00 & $-9,00$ & 28,00 & 0,80 \\
\hline$B / C$ & 1,03 & 1,00 & 0,99 & & \\
\hline VET & 124,00 & 6,00 & $-14,46$ & & \\
\hline TIR (10\%) & & & & $100 \%$ & 2,80 \\
\hline
\end{tabular}

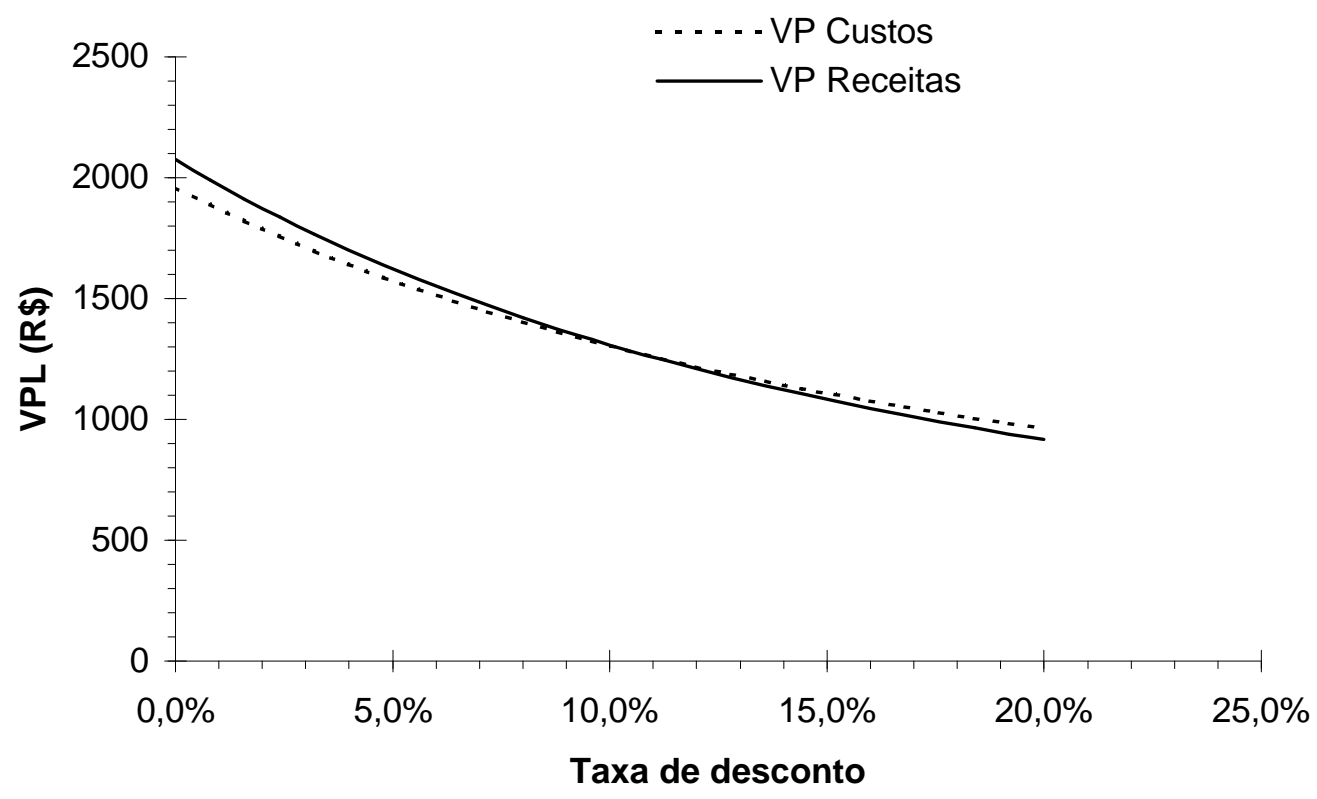

Figura 35. apresenta as taxas de descontos utilizadas, percebe-se que a curva de receita iguala a curva de custo à $(10,0 \%)$, significando que a esta taxa a TIR torna O VPL igual a zero. 
Tabela 33. Valor Presente Líquido (VPL), Relação Beneficio/Custo (B/C); Valor Esperado da Terra (VET) e Taxa Interna de Retorno (TIR), propriedade vz-04.

\begin{tabular}{cccccc}
\hline $\begin{array}{r}\text { Indicadores de análise econômica com } \\
\text { horizonte temporal de } 30\end{array}$ & $\begin{array}{c}\text { Uso da terra } \\
\text { (ha) }\end{array}$ \\
\hline $\begin{array}{c}\text { Indicadores } \\
\text { VPL }\end{array}$ & $5 \%$ & $10 \%$ & $12 \%$ & Total & SAF \\
B/C & 180,00 & 104,00 & 81,00 & 8,70 & 0,50 \\
VET & 466,00 & 170,00 & 120,00 & & \\
TIR (23\%) & & & 1,06 & 1,05 & 5,70 \\
\hline
\end{tabular}

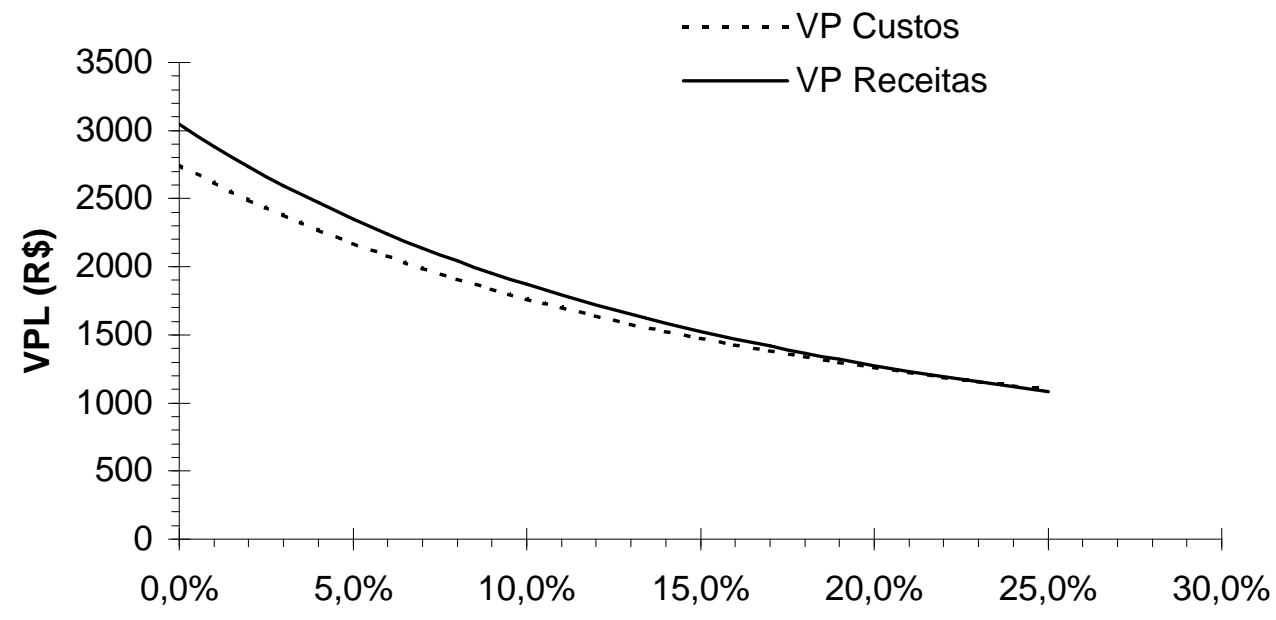

Taxa de desconto

Figura 36. apresenta as taxas de descontos utilizadas, percebe-se que a curva de receita iguala a curva de custo à $(23,0 \%)$, significando que a esta taxa a TIR torna O VPL igual a zero. 
Tabela 34. Valor Presente Líquido (VPL), Relação Beneficio/Custo (B/C); Valor Esperado da Terra (VET) e Taxa Interna de Retorno (TIR), propriedade vz-03.

\begin{tabular}{|c|c|c|c|c|c|}
\hline \multicolumn{4}{|c|}{$\begin{array}{c}\text { Indicadores de análise econômica com } \\
\text { horizonte temporal de } 30 \text { anos }\end{array}$} & \multicolumn{2}{|c|}{$\begin{array}{c}\text { Uso da terra } \\
\text { (ha) }\end{array}$} \\
\hline Indicadores & $5 \%$ & $10 \%$ & $12 \%$ & Total & $\mathrm{SAF}$ \\
\hline VPI & 67,00 & 1,18 & $-18,00$ & 12,30 & 0,60 \\
\hline$B / C$ & 1,04 & 1,0 & 0,99 & & \\
\hline VET & 175,00 & 2,0 & $-27,00$ & & \\
\hline TIR (10\%) & & & & $100 \%$ & 4,80 \\
\hline
\end{tabular}

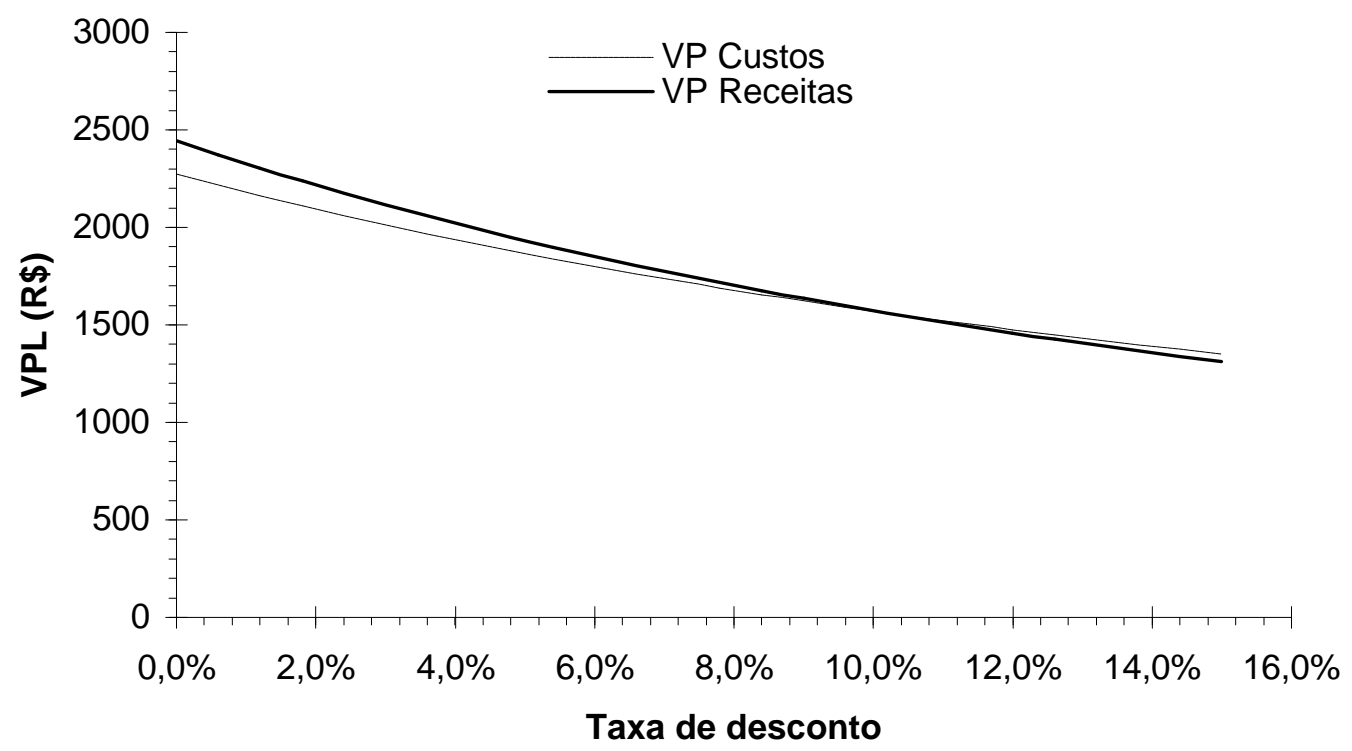

Figura 37. apresenta as taxas de descontos utilizadas, percebe-se que a curva de receita iguala a curva de custo à $(23,0 \%)$, significando que a esta taxa a TIR torna O VPL igual a zero. 